\title{
Analysis of the potential of renewable energy development in Saudi Arabia
}

\author{
Fahad Alqahtani
}

Follow this and additional works at: https://researchrepository.wvu.edu/etd

\section{Recommended Citation}

Alqahtani, Fahad, "Analysis of the potential of renewable energy development in Saudi Arabia" (2016). Graduate Theses, Dissertations, and Problem Reports. 5084.

https://researchrepository.wvu.edu/etd/5084

This Thesis is protected by copyright and/or related rights. It has been brought to you by the The Research Repository @ WVU with permission from the rights-holder(s). You are free to use this Thesis in any way that is permitted by the copyright and related rights legislation that applies to your use. For other uses you must obtain permission from the rights-holder(s) directly, unless additional rights are indicated by a Creative Commons license in the record and/ or on the work itself. This Thesis has been accepted for inclusion in WVU Graduate Theses, Dissertations, and Problem Reports collection by an authorized administrator of The Research Repository @ WVU. For more information, please contact researchrepository@mail.wvu.edu. 


\title{
SAUDI ARABIA
}

\author{
Fahad Alqahtani \\ Thesis Submitted to the \\ Statler College of Engineering and Mineral Resources \\ at West Virginia University
}

in partial fulfillment of the requirements for the degree of

\author{
Master of Science in \\ Industrial Engineering
}

Majid Jaridi, Ph.D., Chair

Kenneth Currie, Ph.D.

Feng Yang, Ph.D.
Department of Industrial and Management Systems Engineering Morgantown, West Virginia
2016

Keywords: Renewable Energy, Non-Renewable Energy, Forecasting Regressions Model, Power Generation.

Copyright 2016 Fahad Alqahtani 


\begin{abstract}
ANALYSIS OF THE POTENTIAL OF RENEWABLE ENERGY DEVELOPMENT IN

SAUDI ARABIA
\end{abstract}

Fahad Alqahtani

Saudi Arabia is one nation that has been exploring the potential of renewable energy for many years. Saudi authorities, scientists, and researchers view renewable energy as a preferable longterm energy strategy. Despite this, because Saudi Arabia is one of the leading oil producing nations and relies heavily on it as a form of energy, solar energy has not been given much serious consideration. Solar and wind energy are the best sources of renewable energy in Saudi Arabia; however, because of the large amount of oil in the country, most do not want to explore the option of renewable energy. Hence, it is essential to explore the alternative sources to insure reliable supply for potential future need. This will be investigated through this research, in which three different forecasting methods were generated for 32 cities: the decomposition method, multiple linear regressions (linear trend model), and multiple linear models (seasonal model). These three methods have developed a preferred model that can forecast renewable energy in the future. The main objectives of this research are i) to establish the potential of solar and wind energy generation as a suitable, cost-effective alternative to petroleum products and ii) to establish the potential for maximizing renewable power generation to support the grid supply to Saudi cities. The software developed for this thesis (Visual Basic) is aimed at enabling a user to use advanced data analysis techniques to handle a given research issue. Moreover, the results of this research demonstrated that the total of the output of solar and wind power in 32 locations in Saudi Arabia are $162.032 \mathrm{GW}$, and $1.298 \mathrm{GW}$, respectively. Thus, in order to reduce the cost of energy, installing renewable farms is recommended. 


\section{ACKNOWLEDGEMENTS}

I wish to give special thanks to my advisor, Dr. Majid Jaridi, for his continuous support, encouragement and guidance, and for having confidence in me. I was lucky to work with him and learn from his experience and skills in my field of research.

I wish to extend my thanks to my committee members, Dr. Kenneth Currie and Dr. Feng Yang, for their time and efforts to review this research, and their precious suggestions and comments.

Finally, my thanks and appreciations go to my parents, my wife, and my friends for their support, help, and encouragement. At last, this research is dedicated to my brothers, Hamad, Saad, and Abdullah Alqahtani. They are my indispensable impetus to move forward. 


\section{Table of Contents}

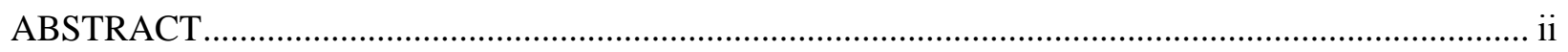

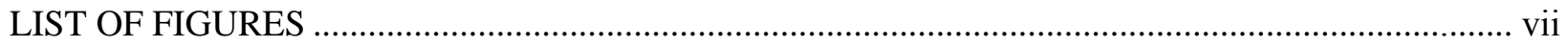

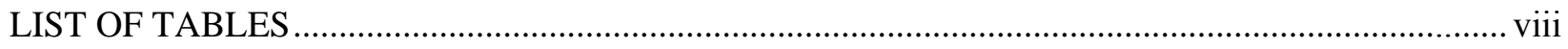

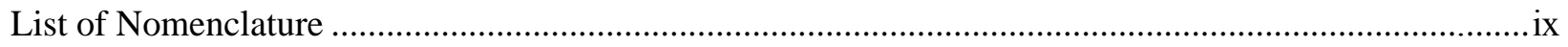

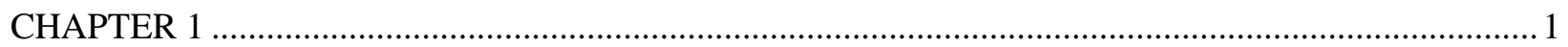

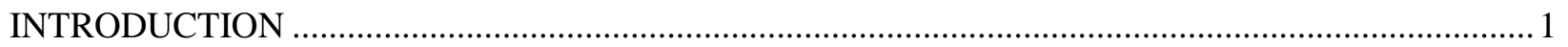

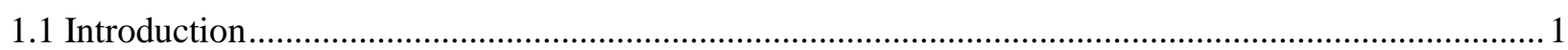

1.2 Status of Non-Renewable Energy in Saudi Arabia ......................................................................... 1

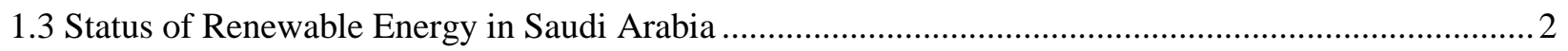

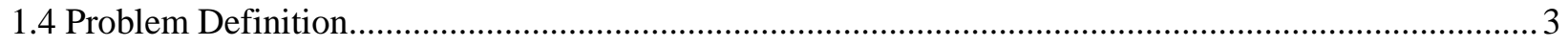

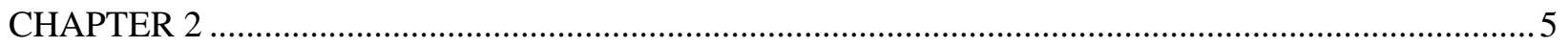

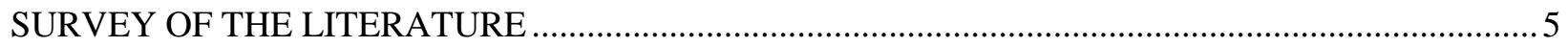

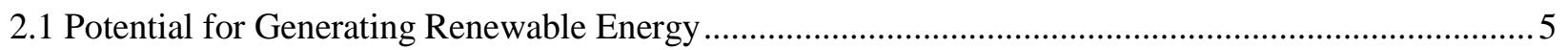

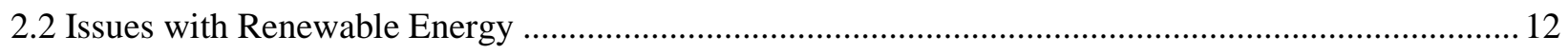

2.3 Potential for Selling or Distributing Electricity from Renewable Energy and Associated Benefits..... 18

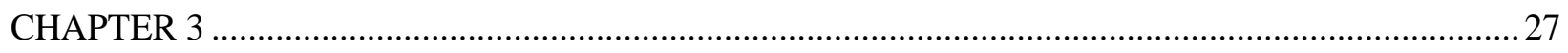

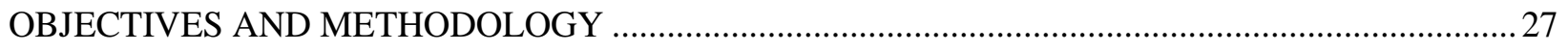

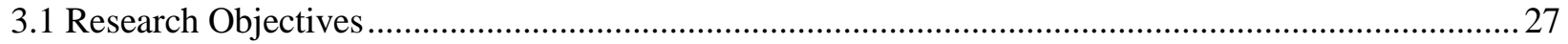

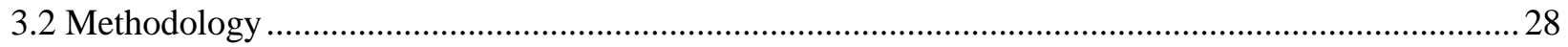

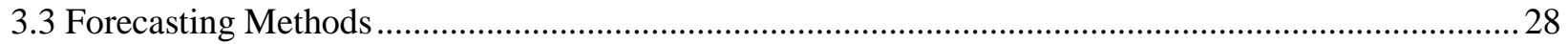

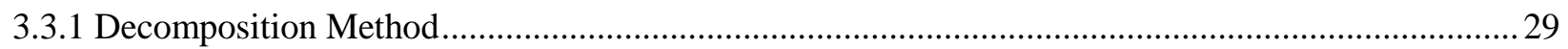

3.2 Multiple Linear Regression: Linear Trend Model ....................................................................... 33

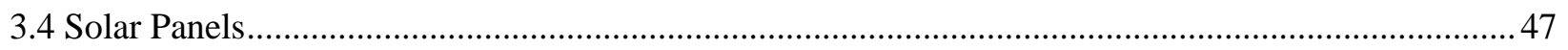

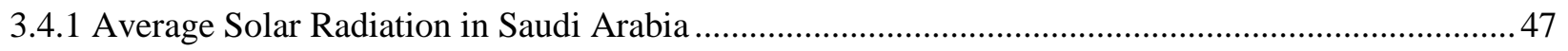

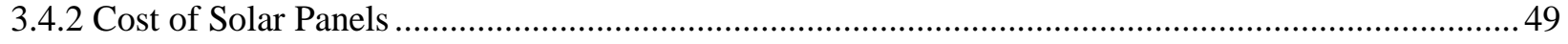

3.4.3 Number of Solar Panels for a Solar Panel Farm ..........................................................................52

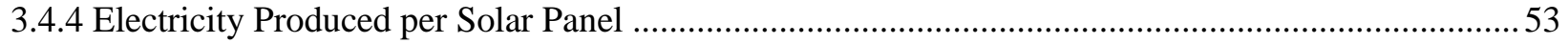

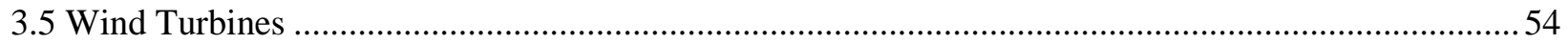

3.5.1 Average Speed and Strength of Wind in Saudi Arabia...............................................................5

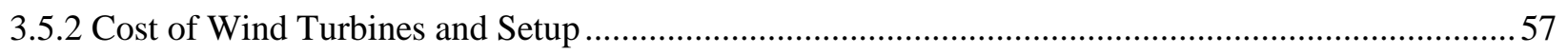

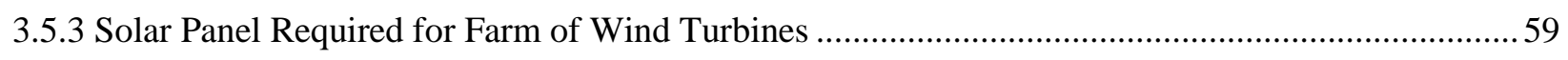

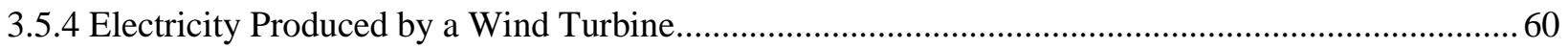




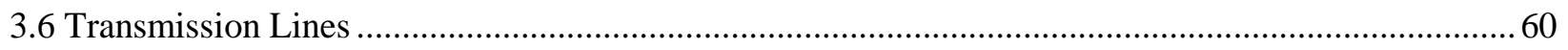

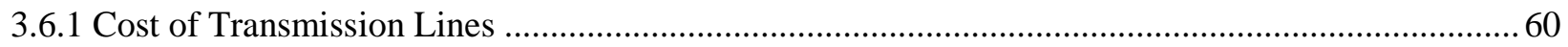

3.6.2 Transfer of Electricity through Transmission Lines to Consumers ................................................65

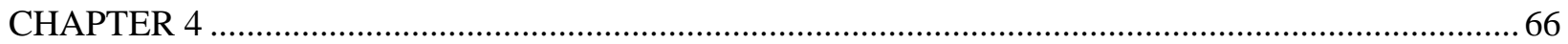

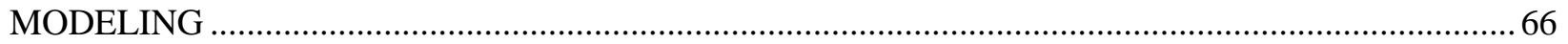

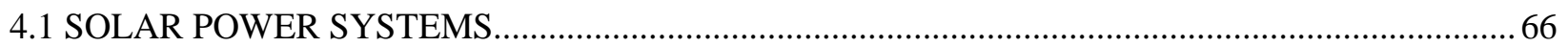

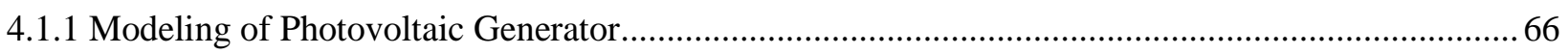

4.1.2 Estimation of the Number of Panels Needed in a Solar Power System .........................................6 68

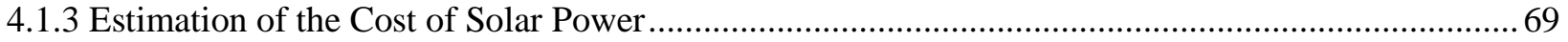

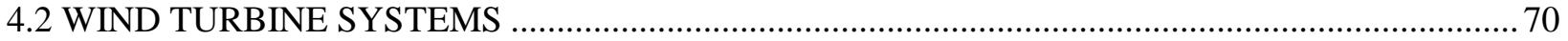

4.2.1 Modeling the Output Characteristics of Wind Turbine Systems .................................................... 72

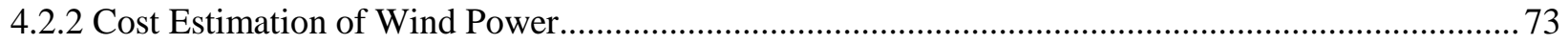

4.2.3 The Cost Model and Equations for Solar and Wind Turbine Systems ........................................... 76

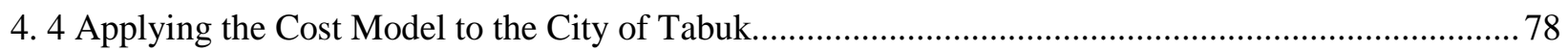

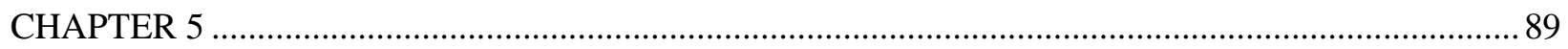

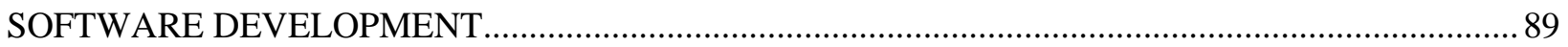

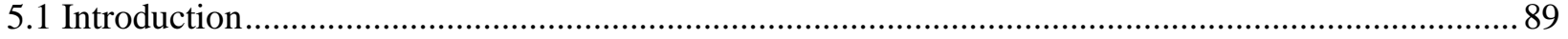

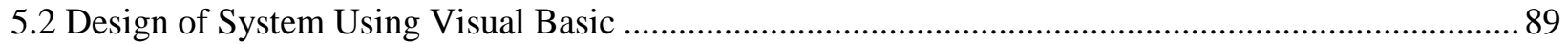

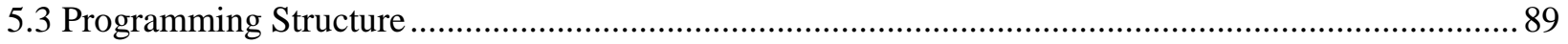

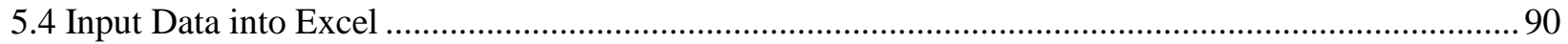

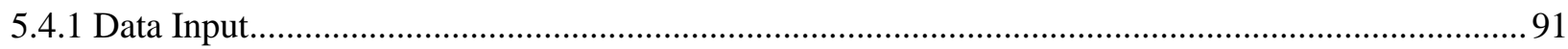

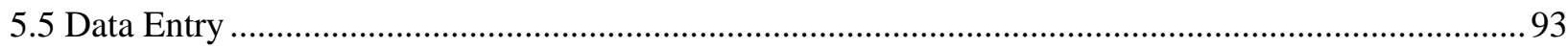

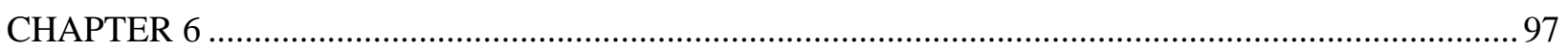

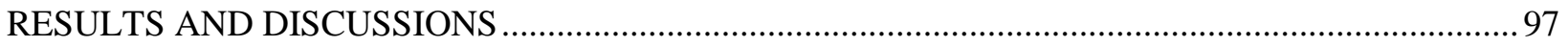

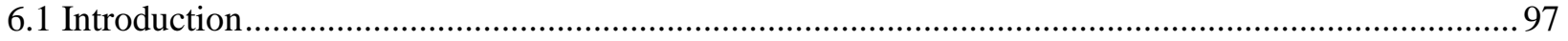

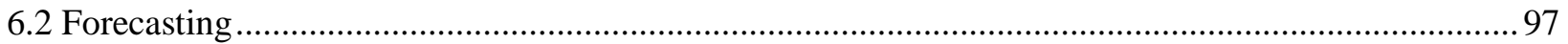

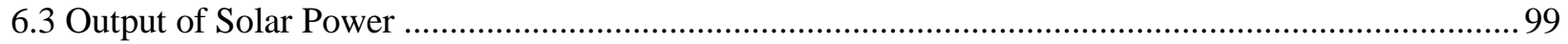

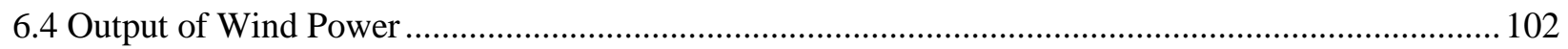

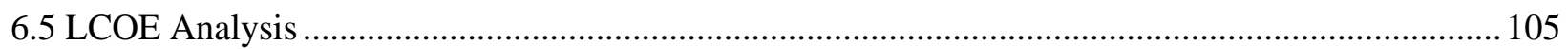

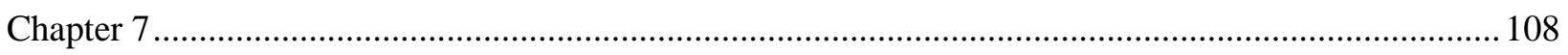

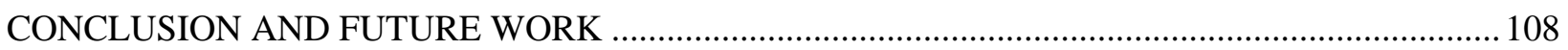

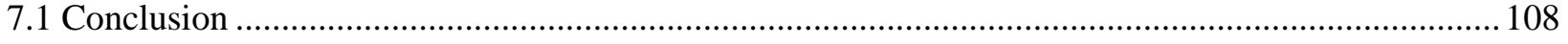

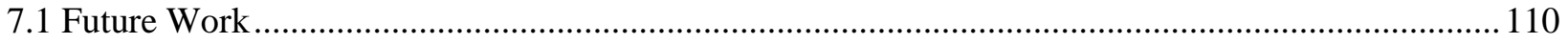




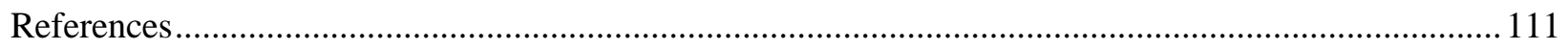




\section{LIST OF FIGURES}

Figure 3.1 Global Horizontal Solar Irradiation.............................................................. 30

Figure 3.2 Direct Normal Irradiance for Some Cities.......................................................... 32

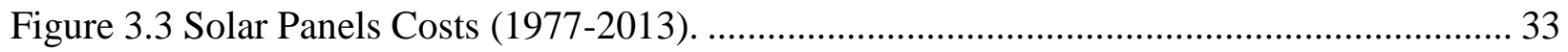

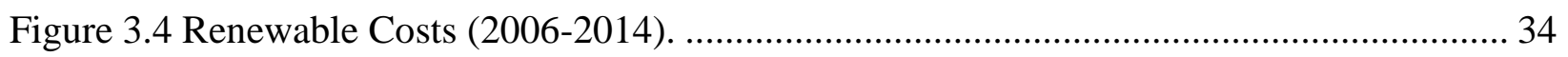

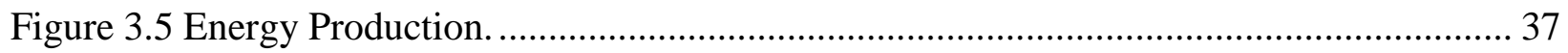

Figure 3.6 Average Speed and Strength of Wind (Dahran, Riyadh, and Jeddah). .................... 38

Figure 3.7 Average Wind Speed ( Some Part of KSA). .................................................... 40

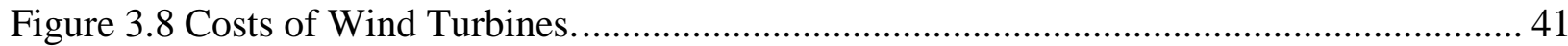

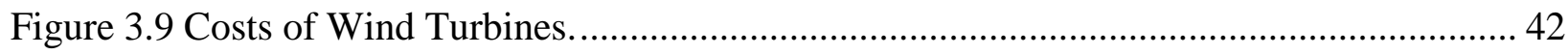

Figure 3.10 Costs of Transmission Lines Component............................................................. 45

Figure 3.11 Price for the Power Models ............................................................................ 46

Figure 3.12 Cost per Kilometer and Total costs. ............................................................ 47 


\section{LIST OF TABLES}

Table 3.1 Direct Normal Irradiance for Selected Cities .............................................................. 31

Table 3.2 Number of Solar Panels for Solar Panel Farm............................................................. 35

Table 3.3 Average Wind Speed (Some Parts of KSA) ……………….................................... 39

Table 3.4 Cost Transmission Lines per Mile ............................................................................ 44 


\section{List of Nomenclature}

$\mathrm{P}_{\mathrm{PV}}=$ Power output, KW.

$\eta_{\mathrm{g}}=$ Instantaneous PV generator efficiency.

$\mathrm{A}_{\mathrm{m}}=$ Area of a single module used in a system, $\mathrm{m} 2$.

$\mathrm{G}_{\mathrm{t}}=$ Global irradiance incident on the titled plane, $\mathrm{W} / \mathrm{m}^{2}$

$\mathrm{N}=$ Number of modules.

$\eta_{\mathrm{r}}=$ Reference efficiency of the PV generator.

$\eta_{\mathrm{pt}}=$ Efficiency of power tracking equipment.

$\mathrm{T}_{\mathrm{c}}=$ Temperature of $\mathrm{PV}$ cell, ${ }^{\circ} \mathrm{C}$.

$\mathrm{T}_{\mathrm{r}}=\mathrm{PV}$ cell reference temperature, ${ }^{\circ} \mathrm{C}$.

$\beta_{\mathrm{t}}=$ Temperature coefficient of efficiency

$T_{a}=$ Ambient temperature, ${ }^{\circ} \mathrm{C}$.

$U_{L}=$ Overall heat loss coefficient, $\mathrm{W} / \mathrm{m} 2$ per ${ }^{\circ} \mathrm{C}$.

NOCT $=$ Nominal operating cell temperature.

$\mathrm{P}_{\mathrm{WG}}(\mathrm{V})=$ Output power of wind generator at wind speed, $\mathrm{KW}$.

$\mathrm{P}_{\mathrm{r}}=$ Rated power, $\mathrm{KW}$.

$\mathrm{V}_{\mathrm{ci}}=$ Cut-in wind speeds, $\mathrm{m} / \mathrm{s}$

$\mathrm{V}_{\mathrm{r}}=$ Rated wind speeds, $\mathrm{m} / \mathrm{s}$.

$\mathrm{V}_{\text {co }}=$ Cut-out wind speeds, $\mathrm{m} / \mathrm{s}$

LCE $=$ Levelised cost of energy.

$\mathrm{E}_{\text {load }}=$ Yearly output, $\mathrm{kWh}$.

$\mathrm{TPV}=$ Total actual cost of all system components, $\$$. 
$\mathrm{CRF}=$ Total cost of capital recovery factor, $\$$.

$\mathrm{C}_{\mathrm{pv}}=$ Capital and maintenance costs of the PV generator in system life, $\$$.

$\mathrm{C}_{\text {wind }}=$ Capital and maintenance costs of the wind turbines in system life, $\$$.

LCOE $=$ The average lifetime Levelised cost of electricity generation, $\$ / \mathrm{kWh}$.

It $=$ Investment expenditures in the year $\mathrm{t}, \$$.

$\mathrm{Mt}=$ Operations and maintenance expenditures in the year $\mathrm{t}, \$$.

$\mathrm{Et}=$ Electricity generation in the year $\mathrm{t}, \mathrm{KW}$.

$\mathrm{r}=$ Discount rate

$\mathrm{n}=$ Economic life of the system, year. 


\section{CHAPTER 1}

\section{INTRODUCTION}

\subsection{Introduction}

Saudi Arabia lies along coordinates $24.0000^{\circ} \mathrm{N}$ and $45.0000^{\circ} \mathrm{E}$ in the Asian continent, putting it in a desert environment where temperatures can reach 70 degrees Celsius. For this reason, Saudi Arabia has been exploring the potential of using solar energy for many years. Solar energy has been viewed by Saudi authorities, scientists, and researchers as a preferred alternative source of energy. Despite this, the fact that Saudi Arabia is also one of the leading oil-producing nations and relies heavily on it as a form of energy, solar energy has not been given serious consideration in the past. This research intends to re-examine the situation and help bring about a renewed interest in solar energy in Saudi Arabia.

\subsection{Status of Non-Renewable Energy in Saudi Arabia}

Saudi Arabia's oil reserve is one of the largest in the world, which has led to significant development in this segment. This heavy focus has partly been motivated by the fact that oil sales are high, and form a major component of the country's foreign earnings. In fact, the oil industry has invited numerous foreign direct investment opportunities, mostly from Britain and the United States. This focus has made oil important as a non-renewable energy resource. Statistics from 2010 indicate that the economic impact of Saudi Arabia's oil sector cannot be understated. The oil income makes up about $90 \%$ of the country's total revenue. Clearly oil is an important commodity, hence the significant involvement of the state-owned firm Saudi Aramco in the industry. 
Ghawar oil field is the largest in the world, and has a remaining reserve potential estimated at 70 billion barrels. This is a relatively large amount compared to other oil-producing nations, and is part of the challenge involved with focusing on renewable energy sources. In fact, Saudi Arabia is the largest producer and exporter of petroleum products in the world. This puts its oil industry ahead of other related industries. Another major commodity is natural gas, of which Saudi Arabia was estimated to be the $4^{\text {th }}$ largest producer after Iran, Russia, and Qatar. Clearly Saudi Arabia has significant potential in the non-renewable energy sector, something that has kept it away from meaningful exploration of renewable energy.

Saudi Arabia remains the largest exporter of petroleum-related products in the Middle East. Despite the focus on renewable energy by consumers, research has shown that there is little motivation by many residents to explore alternative energy sources. For example, at the household level there has been a low rate in adopting solar energy as a viable alternative. The availability of non-renewable energy at a lower price places a barrier in the way of promoting renewable energy as a viable energy source. This high reliance on non-renewable energy sources among consumers coupled with the production advantage means that the domestic prices for petroleum products, such as gasoline and natural gas, are about $40 \%$ less than international prices.

\subsection{Status of Renewable Energy in Saudi Arabia}

The largest potential source of renewable energy in Saudi Arabia is solar. Despite the convergence of several factors that would seem to make solar power a viable source of energy, it remains largely unutilized, or underutilized. The issue is not just the use of solar energy by consumer, but also a significant lack of production. Research shows that there is little investment 
in solar energy, especially by the state, which is contrary to its heavy involvement and investment in petroleum products. This means that there is little motivation among state stakeholders, energy sector engineers, and other professionals in the sector to develop an effective policy that can be relied upon to push forward the widespread adoption of solar energy in Saudi Arabia.

The renewable energy issue in Saudi is further complicated by the high reliance among consumers on petroleum products. This is because of the current low cost of petroleum-based energy, as well as the high initial investment required to setup solar energy production centers. It is worth noting that the average investment required for non-renewable energy surpasses that of renewable energy, which means that high consumption plays a role in driving the growth of nonrenewable energy at the expense of solar energy. In fact, the majority of existing solar power generating ventures is funded from the private sector where the costs end up being high and unsustainable in the long run.

\subsection{Problem Definition}

This research intends to evaluate the renewable energy potential of Saudi Arabia, taking into account the fact that it is one of the world's leading producers of non-renewable energy in the form of petroleum. Because of this, Saudi Arabia has been characterized as one of the developed nations that is most reliant on petroleum, despite the abundant solar energy in the region. Data will be collected and analyzed to establish the extent to which solar energy can be utilized in Saudi Arabia.

The objectives of this research are to develop forecasting model for the amount of irradiation and wind energy that can be produced in 32 major cities of Saudi Arabia. So, that can be input to 
the economic analysis model. Also, this research will develop an economic analysis model to investigate the potential of solar and wind energy as a cost-effective, suitable alternative to petroleum products. To establish this, information will be collected about the current cost of petroleum production and compared to the cost of solar and wind energy production. To do this, it will be necessary to collect information about the unit production of solar and wind energy and determine the other costs accrued during the production process, such as marketing. It is also necessary to collect information about the region in Saudi Arabia that has the most exposure to solar irradiation and singling it out as a suitable solar energy production zone.

Additionally, this research will also develop user-friendly software to perform economic and sensitivity analyses, to determine the plausibility of solar and wind energy as a suitable alternative to petroleum products with regard to cost. 


\section{CHAPTER 2}

\section{SURVEY OF THE LITERATURE}

\subsection{Potential for Generating Renewable Energy}

According to Alrashed and Asif (2015), a large portion of Saudi Arabia's electricity consumption falls on the housing sector. This sector alone accounts for $52 \%$ of the country's total electricity consumption, and there is a significant need for the government to develop a strategy for using alternative energy in this sector. Alrashed and Asif (2015) propose Zero Energy Homes (ZEHs) as one of the ways in which the Saudi government can enhance sustainable housing practices in the country. The concept of ZEHs has been implemented in other parts of the world, though it is new to Saudi Arabia (Alrashed and Asif, 2015). This paper is an investigative study on how local weather causes uncertainty in the implementation of the concept in Saudi Arabia. According to the study, the main aspects of weather that affect the ZEH concept in Saudi Arabia include air temperature, wind speed, global solar radiation, and relative humidity. The investigation reviews the effect of Saudi weather conditions on ZEHs in comparison with other homes built under the same weather conditions in other parts of the world. In the study, five homes in Borrego Springs, Lake Bennett, Cupertino, and Tucson, AZ acted as samples for comparison since they stood in weather conditions similar to the ones in Saudi Arabia (Alrashed and Asif, 2015). The study concluded that ZEHs do have the ability to withstand certain weather conditions, as well as the capability to produce energy that sustains and exceeds their consumption. According to the study, wind speed and solar radiation do not have any significant impact on ZEHs. Air temperature and relative humidity have minimal effects on ZEHs, but typical weather conditions in Saudi Arabia will not affect the homes in the region. Therefore, 
Saudi weather conditions do not pose an obstacle to the construction of ZEHs (Alrashed and Asif, 2015).

According to Alawaji, (2001a), Saudi Arabia has significantly increased its investments in solar -energy research and development since the mid-seventies. The country decided to implement the results of this research after twenty years in order to evaluate the economic viability of solar energy. The article analyzes various projects that the country initiated, and discusses the lessons learned from their operation and maintenance. Saudi Arabia prides itself on possessing one-fourth of the world's proven oil reserves (Alawaji, 2001). The country also produces 204.5 trillion cubic feet of natural gas per year. The country continues to put pressure on its two main energy resources, since its energy demands grows at 5\% annually. The evergrowing demand for energy compels the government to invest heavily in energy sources, subsidize the energy sector, as well as revise the electricity tariff rates. Alawaji, (2001a) notes that Saudi Arabia has an immense wealth of solar exposure, having 2200 thermal kilowatt hours per square meter. Research for solar energy in Saudi Arabia spans back to 1960, and the country has experienced significant population growth over the years. The major solar research and development projects that Saudi Arabia has embarked on include the Solar Village project, solar power water desalination projects, the Solar Thermal Dish project, and the Photovoltaic Research project (Alawaji, 2001a). These projects focus on various aspects of solar energy, including the remoteness of certain villages, industrial energy uses, and directional variation effects, among other considerations. There were several lessons learned from these projects that are useful not only to Saudi Arabia, but also to other countries that have similar climates. For instance, it is clear that developing countries should apply systems that work in developed countries rather than initiating their own research. In addition, researchers must take seriously their obligation to 
make use of scientific knowledge and interact with other stakeholders in implementing solar energy concepts (Alawaji, 2001a).

Alnatheer, (2005) explains that, although Saudi Arabia is rich in oil and natural gas deposits, other energy sources including solar are also viable for the country's energy production. The paper notes that the world has gained considerable operational experience while implementing renewable energy systems in the last several years, and expounds upon the experience gained while applying quantitative assessment to the environmental benefits, cost, and savings benefits that Saudi Arabia may receive from implementing large-scale solar energy. The assessment falls in the Integrated Resource Planning (IRP) project that is concerned with electric utility in Saudi Arabia. The project has a mandate to evaluate potential energy sources and the demand-side resources in order to develop a plan that gives rise to low-societal-cost energy sources. There are several facts that validate the use of renewable energy sources in Saudi Arabia. First, renewable sources exist in abundance, which means that they have the potential to generate energy that surpasses the national demand requirements. Renewable sources also have the potential to provide a continuum of energy services. In addition, the use of renewable energy comes with several public benefits, such as energy security, economic development, and reduction of environmental pollution. According to Alnatheer, (2005), there are barriers that Saudi Arabia needs to overcome in order to fully exploit solar energy. The barriers include a lack of participation from the World Bank and Inter-American Development Bank, a lack of information on the part of vendors and customers, and higher financing costs than traditional energy projects. After also including non-market benefits, the paper concludes that solar energy stands as a potential source of low-societal-cost energy. Use of solar power is indeed a viable alternative to fossil-fuel generated energy in Saudi Arabia (Alnatheer, 2005). 
In their article, Almasoud and Gandayh, (2014) hold the view that the increase in energy demand in Saudi Arabia necessitates an expansion of power generation capabilities in the country. They also point out that conventional generation of energy leads to pollution of the environment and emits greenhouse gases which negatively impact human health. The article asserts that there is a need for supporting the conventional generation of power during peak season with generation methods that do not affect human health. The alternative energy source should also operate in a way that conserves the environment. Almasoud and Gandayh, (2014), note that Saudi Arabia sits on a geographical location that supports solar energy generating. Being on a location that is described as a sun-belt, the country could become one of the largest producers of solar energy. Solar energy could prove to be a significant competitor of fossil fuels that saves on the indirect cost of conventional energy generation. According to the article, photovoltaic cells can be used to generate clean solar energy. Low-quality fuels and poor generation methods currently used in Saudi Arabia emit pollutants that affect human health. Use of high-sulfur crude oil and the existence of power plants that do not control their emissions contribute to both pollution of the environment, and poor human health (Almasoud and Gandayh, 2014). On the economics of solar energy, there is a notable decrease in solar energy production making it to be economically viable compared to conventional fossil fuel. The offload in conventional sources of energy comes in handy on Saudi Arabia's sunny days, due to the need for air conditioning. The sunny period coincides with the largest production of solar radiation (Almasoud and Gandayh, 2014). This means that the high demand for energy in Saudi Arabia can be met through use of solar energy.

In efforts to provide a lesson to Saudi Arabia regarding its Renewable Energy Feed-In Tariff (REFIT), Ramli and Twaha, (2015) wrote an analysis paper that compares selected regions 
in the world. According to the duo, renewable energy technologies will play an integral part in the energy supply mix aimed at achieving energy sustainability. Fossil fuels are at the verge of exhaustion, and the world continues to feel the devastating effects of their usage (Ramli and Twaha, 2015).The continuing research and technological progress aims at bringing down the cost of renewable energy. Many regions in the world have already incorporated the advancements in their energy systems with support from various schemes. Feed-in tariffs (FITs) are a constituent of a smart grid that uses solar energy as a contributor to the energy supply in countries that use renewable sources of energy (Ramli and Twaha, 2015). In addition to smart meter deployment, other regulatory interventions such as variation in tariffs, and renewable heat incentives also act as technological advancements that need to be deployed. The authors call for research on the FIT design model that befits the subject country. There are two FIT designs, namely market dependent FITs and non-market dependent FITs (Ramli and Twaha, 2015). Either inflation and fixed pay-off or the market price for electricity determines the rates to be paid, so the primary difference between the two FIT designs is whether the payment depends on the electricity price. In their summary, Ramli and Twaha, (2015) hold that it is crucial to have a sound policy in renewable energy (RE) source development and utilization. The FIT scheme stands as one of the most widely used support strategies because it promotes renewable energy through the provision of significant benefits to taxpayers as well as RE project developers. In conclusion, Saudi Arabia stands to benefit from use of FIT policy as a constituent of RE development strategies.

Hepbasli and Alsuhaibani, (2011) hold the broader view that renewable energy is not only beneficial to Saudi Arabia, but to the entire world. Saudi Arabia has realized the benefits that come with use of solar power giving rise to power plants, such as the solar hydrogen production plant in the solar village, Riyadh. The plant, deemed the world's first solar hydrogen 
production plant, has a production capability of $350 \mathrm{~kW}$ (Hepbasli and Alsuhaibani, 2011). Despite the immense potential to produce large amounts of solar power, the country has not realized the full potential due to several obstacles. This paper addresses current applications in addition to considering the important aspects of future solar energy projects. The paper also analyzes various studies and makes an assessment of the studies on the basis of available energy technologies that prove sustainable in a bid to establish sound energy policies (Hepbasli and Alsuhaibani, 2011). The paper expounds on various topics that relate to solar energy, including the types of solar radiation correlations, solar stills, solar collectors, solar hydrogen, and solar education. Notably, Saudi Arabia follows the Science and Technology National Policy future general directions guideline in laying down an integrated guidance framework to meet its science and technology objectives (Hepbasli and Alsuhaibani, 2011). The development of renewable energy sources such as solar energy is in line with this set framework. Currently, there are several renewable projects in Saudi Arabia, and corresponding lessons that the country can learn from them. Among other conclusions that the authors make, they state that Saudi Arabia holds a huge potential to generate solar energy (Hepbasli and Alsuhaibani, 2011). In addition, renewable energy has played a pivotal role in water desalination in the country, allowing Saudi Arabia to achieve one of its high-priority goals. However, desalination uses a lot of energy that contributes to the negative environmental impact, and declining human health due to pollution. In order to optimally supply desalination with clean power, Saudi Arabia should deploy renewable energy as well as hybrid systems via various support schemes.

Dincer, (2011) affirms that energy is one of main agendas that countries are meeting to discuss. As one of crucial aspects of living, the meetings between countries on energy seek to create a balance between consumer demand and the supply of energy. There is research that aims 
to find more efficient ways of using energy, and also improve upon the efficient use of renewable energy. This research runs alongside the global energy demand and supply meetings. One of the most dominant sources of renewable energy is photovoltaic energy (Dincer, 2011). Due to its efficiency, the solar energy stands as one of the energy systems that the world will use in future. Dincer expounds on the position of using photovoltaic power in the United States, China, and Japan. The study also seeks to discuss the subject countries' current and future policies regarding use of such energy. The use of renewable energy saves fossil fuels and promotes a human-friendly environment free of pollution. Global warming and other issues related to pollution have recently attracted much of the world's attention, prompting the need to address environmental conservation. Compared to other methods of harnessing solar energy, the photovoltaic (PV) method is preferred since it is noiseless, has a flexible scale, and does not produce carbon dioxide emissions, among other advantages (Dincer, 2011). Germany and Spain lead the world in the use of PV, having installed $65 \%$ of all European installations. In a bid to promote use of PV, European countries have introduced incentives for using PV panels. Germany and Spain lead in the use of PV as a percentage of their total energy production, while America holds the third position (Dincer, 2011). Notably, only the U.S. has managed to create a sustainable PV system, creating a long-term market for installers, financiers, and developers, among other stakeholders. Japan has made significant strides in the use of PV by making use of roof-top PV technologies and incentives to promote the use of PV. In conclusion, retail financing terms have to be made flexible in order to achieve an optimal market growth of PV power (Dincer, 2011).

Razykov, et al. (2011), review the technical progress of PV and discuss the various technologies that PV has employed over the years of its development. PV employs two 
technologies, namely mono- and polycrystalline thin films that use various bases such as Si or other semiconductors, nano-PV, and others. Their study asserts that PV electricity stands as one of the best options that the world has for meeting its future energy requirements. PV electricity has achieved a tremendous growth pattern, marking an annual rise of $35-40 \%$ from the 1960 s to 2011 (Razykov, et al, 2011). In 2009, worldwide PV production stood at 10.66 GW. PV technologies that are close to theoretical predicted maximum efficiency values are SI and GaAs. Wafer Si solar cells dominate the other kinds of PV cells in the mono- and polycrystalline PV technologies (Razykov, et al, 2011). The cost of solar cells came down after the introduction of thin-film PV. Stabilizing atmospheric $\mathrm{CO}_{2}$ in the future entails the use of PV and other renewable energy sources, such as the use of hydrogen for transport.

Becquerel discovered the PV effect in the year 1839 during a study on the effect of light on electrolytic cells. The 1950s saw a significant development of PV, while the 1970s energy crisis accelerated the research and development of PV (Razykov, et al, 2011). The energy conversion in a cell depends on its thermodynamic efficiency. In bid to increase power conversion efficiency in solar cells, various methods have been used over time including hotelectron extraction, of tandem cells, and intermediate-band devices, among others In terms of economics, the rapid PV market growth spans back to the 1980s. At the moment, the PV market growth runs concurrently with that of computers and telecommunications, with $\mathrm{Si}$ and $\mathrm{pc}-\mathrm{Si}$ wafer technologies accounting for more than $80 \%$ of the PV market (Razykov, et al, 2011).

\subsection{Issues with Renewable Energy}

In their article, Al-Ajlan, et al. (2006) address the development of sustainable policies for conserving electrical energy in Saudi Arabia. The end of the year 1998 witnessed the 
commencement of a restructuring program in Saudi Arabia that was aimed at achieving a performance that was sustainable. Even though progress was evident in the country, there were a number of challenges that it encountered, including low capacity generation margins that were low in generation, high growth in demand, inefficient use of energy, and the need for large capital investments in order to cover the current and future growth. Rapid economic development coupled with a lack of energy conservation measures contributed to the rise in energy consumption in Saudi Arabia over the last two decades. The energy requirements in the country have increased progressively, in 2001 reaching 25 times their size in 1975 (Al-Ajlan, et al, 2006). A demand of $60 \mathrm{GW}$ is expected by the year 2023, a level that cannot be met based on the current trend in energy production. The year 2001 witnessed collaboration between the electricity company of Saudi Arabia and the Ministry of Water and Electricity as one of the current sustainable policies that improved peak load savings (Al-Ajlan, et al, 2006). However, long-term sustainability requires more than this one isolated policy. It calls for national level policies that entail public awareness, legislation, and energy regulation, among other elements. The deployment of energy conservation is the best solution to reducing the forecasted demand. $1 \%$ of all utility sales revenue is invested in energy efficiency (Al-Ajlan, et al, 2006). Savings on air conditioning in Saudi Arabia can produce a return on investment that can amount to US\$250 million per annum. In their conclusion, Al-Ajlan, et al. (2006) hold that energy demand issues do not receive the attention they need from the government.

Huraib, et al. (1996) shed light on the lessons drawn from Saudi Arabian solar projects. The authors concentrate on two institutions, namely the Energy Research Institute (ERI) together with the King Abdulaziz Science and Technology City (KACST). The activities that the paper incorporates are from some of the major ongoing R\&D activities, since they have more details 
than emerging projects. The projects under review in the paper include PV, solar water heating, desalination, and solar hydrogen production, among others that were evaluated for solar energy applications. The paper also offers recommendations for solar energy research, development, and demonstration, in addition to future dissemination within Saudi Arabia. In their paper, Huraib, et al. (1996) assert that, though Saudi Arabia has a wealth of oil and natural gas, these resources are bound to be depleted eventually, but the country has an inexhaustible source of energy in the sun. Most of the country's population is located in urban areas, and it is difficult to include the population in more rural areas in the electric grid. In addition, the country is characterized by mountainous regions that are difficult and expensive to connect to the grid. It is against this backdrop that solar energy proves the most viable energy source in the country. Due to its importance, KACST in collaboration with other entities carried out research on Saudi Arabia's solar energy (Huraib, et al., 1996). The main challenges in the deployment of solar energy include high cost as well as the lower conversion efficiency. Overcoming those barriers would open the door to efficient deployment of solar energy. Over time, KACST has gained significant experience in research on solar energy. For instance there is a clear advantage in having a shared funding instead of a single source of funding (Huraib, et al., 1996). The other lesson concerns the achievement of generation results in the absence of official involvement. More solar energy projects are being initiated in Saudi the incorporate the lessons learned from existing projects (Huraib, et al, 1996).

Alawaji (2001b) explores life after oil in Saudi Arabia, with a special emphasis on the evolution of solar energy. Saudi Arabia initiated seven projects that were funded in conjunction with the US, and Germany. The main aim of the projects was to develop renewable energy technology and demonstrate its application. The demonstration entailed designing and installing 
seven projects. It took more than twenty years before the evaluation in order to ascertain the social, scientific, and country-level benefits. To begin with, Alawaji's (2001b) evaluation is on the solar village project that had the initial objective of supplying the remote population with solar power. The solar-powered water desalination projects comes in second, having an objective of supplying solar energy to industries that are in need of thermal or electric energy. Water is a precious commodity in Saudi Arabia, and remote places use diesel pumps to pump water to the surface (Alawaji, 2001b). The activity is quite costly, making solar power one of the less expensive methods. Both pumping and desalination require a lot of energy that the PV installations provide. The other projects include Solar Radiation Resources projects, Wind Energy Assessment Projects, the Solar Thermal Dish Project, the Solar-Powered Hydrogen Utilization Project, the Photovoltaic Research Project, Solar Driers, the Solar-Powered Highway Devices Project, and the 350KW Solar Hydrogen Production Project, among others. According to Alawaji (2001b), the barriers to full exploitation of solar energy in Saudi Arabia include the widespread availability of low-cost oil, the dust effect that hinders the PV arrays by reducing available thermal radiation, and a lack of solar energy subsidies. From the study, the lessons learned include how to create public awareness on the use of solar energy outside of academia (Alawaji, 2001b). The study also cites some action plans, including promoting interaction between research centres and industries that are found locally.

According to Timilsina, et al. (2011), technological advancement in the recent years has accelerated the use of solar energy. In addition, government subsidies and reduced costs have also contributed to the rising use of such energy. The study analyzes the technical, economic, and policy aspects involved in the deployment and development of solar energy. Despite its reduction in price over the years, solar energy's cost remains above that of conventional energy 
technologies (Timilsina, et al, 2011). Being expensive limits the use of solar energy. The paper explains that, due to its renewable nature, solar energy attracts incentives such as fiscal and regulatory incentives, feed-in tariffs, and renewable portfolio standards, among other accruing benefits. The other benefit from the use of solar energy entails the carbon credit markets, though there is a limitation in the incentives offered by the existing carbon market instruments (Timilsina, et al, 2011). Technical, financial as well as regulatory barriers hamper the widespread deployment of solar energy despite its huge technical potential. These barriers confine solar energy to small-scale production in most cases, since it is challenging to produce large-scale solar energy, especially in developing countries. In the future, both developed and developing countries will need policy supports over time in order to realize the full potential of solar energy. Without such support, no significant strides can be achieved in solar energy deployment due to the aforementioned barriers (Timilsina, et al., 2011). According to the article, solar energy is divided into three categories: passive and active, photovoltaic and thermal, and concentrating and non-concentrating. In conclusion, the paper asserts that solar energy exists in abundance in several parts of the world, and the market has seen an upward trend in solar energy harnessing technology deployment (Timilsina, et al, 2011). Policy supports plays a vital role in the growth and expansion of solar energy application.

In their paper, Solangi, et al., (2011) review global solar energy policy. The group holds that the rise in energy demands have made the world look for other alternative energy sources. Solar energy has the benefit of being readily-available, cheap energy alternative with little to no negative environmental impacts. Globally, different countries have come up with different policies that are geared to increase solar usage and reduce the usage of fossil fuels. This paper reviews the different kinds of policies that different countries apply in their solar energy 
management, paying special attention to several countries where the employment of such policies has been successful in solar energy management. Past literature illustrates that FITs, incentives, and RPSs are some of the successful policies that countries apply in their solar energy management. The policies are credited for their motivation, as well as interest in the use and development of renewable energy technologies. Particularly, Solangi, et al., (2011) analyze the Malaysian solar energy policies and compares it with the policies of other countries. The paper defines a solar energy policy as a government strategy that addresses energy development and sustainable energy industry development. While addressing global energy consumption, the paper recognizes oil as one of the significant components of the energy mix that will remain in place in the long run, though its consumption will gradually decrease (Solangi, et al, 2011). In the future PV solar technology is bound to produce large-scale energy that will be domestically secure and environmentally friendlier. In the US several solar energy policies are in place, including the renewable portfolio standard. Germany relies on a FIT, whereas Spain has both FITs and a target for nationwide renewable energy (Solangi, et al., 2011). The paper also analyzes solar energy policies of France, China, Pakistan, and Australia, among other nations.

According to Al-filali, et al., (2012), nations have over time sought to overcome the resource curse, in addition to other economic growth barriers through several strategies. These strategies include import substitution, and current strategies that employ micro-finance and capabilities of a human nature approaches. The international community is still in pursuit of an optimal development strategy. Al-filali, et al., (2012), asserts that nations have invested great attention and effort in their quest to achieve a knowledge economy, with a special emphasis on Saudi Arabia as one such nation. The authors expound on the strategy's anatomy and identify the preconditions and barriers that impede the strategy's success. Using Saudi Arabia as an example 
of the nations that pursue a knowledge economy sets an example to other nations in search of effective plans that support economic transition and development. Saudi Arabia prides itself on being one of the richest G20 nations, but it has continued to fight the long-established link that binds it as an economy, with global oil market conditions for more than ten years (Al-filali, et al, 2012). Apart from finding the oil revenues quite attractive, Saudi Arabia has embarked on economic diversification. Whereas other countries are struggling with the negative impact of oil production, Saudi Arabia has gone beyond the oil revenue to ensure that its economy remains vibrant and stable. In their conclusion, Al-filali, et al, (2012) hold that Saudi Arabia has a strong commitment to move away from an economy that is oil-dependent. The kingdom has shown strong signs of joining the ranks of nations that uphold a knowledge economy (Al-filali, et al., 2012).

\subsection{Potential for Selling or Distributing Electricity from Renewable Energy and Associated}

\section{Benefits}

Lund's 2007 paper discusses how renewable energy can be applied in setting strategies for sustainable development. The paper identifies three technological changes that constitute said strategies. The changes include savings on the energy demand side, improvements in energy

production efficiency, and having renewable energy replace fossil fuels. Large-scale deployment plans for renewable energy call for the integration of renewable sources into a coherent energy system that measures factors related to energy savings and efficiency influence. The paper focuses on Denmark while exploring the problems and perspectives that exist in its conversion to $100 \%$ renewable energy systems (Lund, 2007). The paper concludes that there is a possibility for such a conversion to take place. The presence of the necessary renewable energy sources, coupled with further energy system technological advancements, makes it possible to create such 
a renewable energy system. According to Lund (2007), there are challenges in the renewable energy expansion in the supply system. Hydro-power and wood energy surpasses that of wind and solar in many countries, but the latter's potential is substantial (Lund, 2007). Renewable energy strategies concerned with sustainable development face two major challenges: energy system integration of highly intermittent resources and inclusion of the transportation sector in the strategies. Since 1973, Denmark has been incorporating savings and efficiency developments in its energy policy after its oil crisis in that period (Lund, 2007). The country has managed to maintain steady primary fuel consumption for over 30 years while still increasing its GDP by $70 \%$. Denmark has also managed to achieve $14 \%$ replacement of fossil fuels with renewable energy (Lund, 2007). In addition, transportation and electricity consumption, especially on the heated areas, have increased significantly. Denmark acts as a perfect example of how to combine renewables, savings, and efficiency improvements in order to come up with sustainable development strategies. Replacement of oil-based transportation with other sources, inclusion of small CHP plants in regulation, and adding electrolysers into the system, are some of the ways in which to convert an energy system into a 100\% renewable system (Lund, 2007).

Omer (2008) asserts that buildings consume over $40 \%$ of the total world's yearly energy consumption. Some of the energy uses in a building include heating, air conditioning, and lighting. With increased concerns about the effects of $\mathrm{CO}_{2}$ and other greenhouse gas emissions, there has been a renewed interest in installing environmentally-friendly technologies for heating and cooling. A 1997 Montreal protocol sought to replace refrigerant chemicals that destroyed the stratospheric ozone. There was also a need to conserve energy in order to minimize the depletion of world energy reserves, in addition to reducing pollution. Omer (2008) is of the view that one way that energy consumption in buildings could be reduced would be to alter building design to 
require less energy for cooling, heating, hot water supply, and ventilation. In order to reduce energy consumption on ventilation, passive measures can be employed in place of using air conditioners. In addition, the use of renewable energy in buildings has a significant impact on reducing the use of fossil fuels. It is through a promotion of innovative renewable energy sources that the ecosystem can be preserved through greenhouse gas emission reduction both locally and globally. According to Omer (2008), several benefits arise from the use of renewable energy in buildings. The benefits include amelioration of the conditions in the environment, provision of a quality indoor environment, and more comfort in the building, among others. Air speed, temperature, lighting, noise, and relative humidity are some of the determinants of the comfort of a building's occupants. These determinants also constitute the building performance (BP) (Omer, 2008). Industrial use of fossil fuels significantly contributes to climate change. Industrialized nations bear the biggest burden of responsibility for high emissions, though developing nations are also advised to exercise caution (Omer, 2008). The paper concludes with a call to embrace the use of green or sustainable approaches in order to uphold environment conservation (Omer, 2008).

According to Borenstein (2012), the main argument on public policy regarding the use of renewable energy is its mitigation of negative aspects of fossil fuel use. It is difficult to ascertain whether the use of renewable energy offers other benefits including price stability, job creation, and energy security. It also difficult to compare the cost of the renewable used to produce energy against the positive environmental impact that arises from their use. Borenstein (2012) holds that the determinants of the real cost of electricity are timing, location, and other characteristics. A controversy exists in the quantification of the non-market value of the reduced emissions, since it is difficult to quantify; that is, the benefits that accrue from reduced emissions, e.g. a reduction in 
green gas emissions, cannot have a market value placed on them easily. The paper points out that economists over time have used pricing externalities to relate to efficiency. The costs saved are some of the pricing externalities to which economists peg efficiency (Borenstein, 2012). Taxes on emissions, as well as a tradable permit system, represent some of the proposed market-based policies, but countries such as the US have given limited political support to such policies. The paper seeks to address market and non-market valuation of renewable energy electricity, in addition to the subsidies and the costs that are in already known. This means of valuation aims to incorporate the additional benefit and costs of renewables rather than stopping at the high direct cost of renewables. In his conclusion, Borenstein (2012) says that appropriate pricing of environmental externalities mitigates the failure in energy markets. Policymakers often overlook the pricing of externalities as an impossible-to-quantify element, yet it is one of the single most efficient policies (Borenstein, 2012). Governments should embrace evaluating the costs and benefits of technologies with respect to modern electricity systems.

According to Metcalf (2010), American federal tax policy introduces a wide variety of energy investment incentives. The paper makes a review of the participating policies and creates estimates of marginal effective tax rates for various energy capital investments that were in place as of the year 2007. The paper also considers investment in wind generation capital in addition to user regression investment against measure of cost of capital alongside other controls. Metcalf (2010) also demonstrates the significant role of the federal production tax credit in fueling wind investments over the last eighteen years. The US is an example of how countries are making investments in new energy capital infrastructure. The nation is currently actively engaged in funding clean energy projects, and making legislation that aims to reduce greenhouse gas emissions. The systems that the US is putting in place are $80 \%$ focused on energy production and 
consumption, while the remaining $20 \%$ focuses on developing renewable energy sources by 2020. New capital investments play a significant role in meeting the administration's goals, which include reducing the reliance on petroleum goods and reducing greenhouse emissions. Energy is both a contributor of taxes and a recipient of tax incentives (Metcalf, 2010). Energy production and distribution undergoes a tax evaluation under the corporate income tax, which falls under the federal tax provision code. On depreciation, electric generating capital has a varied depreciation type depending on the production plant. For example, the recovery period for renewable sources ranges from 5 years, and that of coal ranges from 20 years. In the paper, Metcalf (2010) continues to analyze taxation from the energy perspective. In conclusion, the paper asserts that the federal tax code has been instrumental in shaping US energy policy. Future research has been given the task to evaluate whether current tax-based subsidies will equate to capping carbon pricing and carbon fees, or a trade bill.

Solar energy in India is the topic that Sharma, et al. (2012) explore with interest in the strategies, policies, perspectives, and future potential. In their article, they hold that renewable energy is the solution to the energy problems that developing countries such as India are facing. Besides adding new capacity, the use of renewable energy in India helps in securing energy, addressing concerns about the environmental impact of energy generation, and creating a massive renewable energy market. India has capitalized on solar thermal electricity (STE), which can be developed into a future energy production option. The paper seeks to expound on the availability, current status, promotion policies, and major achievements that influence renewable energy in India. In 1988, India established an energy regulatory commission to promote competition, efficiency, and economy of the electricity industry, and applied restructuring to several countries including Orissa State's board of electricity. Despite the deficit in energy 
supply, India is the sixth largest producer of electricity in the world. In India, the production of electricity from renewable sources continues to gain momentum due to the positive environmental impact that the system records. India employs renewable energy largely in the form of PV installations and solar thermal power plants. According to Sharma, et al. (2012), India has a rich solar energy resource. The country experiences 250 to 300 sunny days per year, meaning it receives a significant amount of solar radiation. India's government has enacted several electricity policies that are aimed at promoting renewable energy. For example, the Electricity Act 2003 seeks to promote the use of renewable energy in rural areas. Despite the existing shortage of energy in India, use of PV installations has proved itself to be a viable renewable energy source in the country's future.

Banos, et al. (2012) review the optimization methods that are applied to renewable and sustainable energy. In their view, energy acts as a vital input for both social and economic developments. The demand for energy has risen sharply due to domestic, industrial, and agricultural activities, with a specific emphasis on emerging countries. The rise in demand has resulted in fuel price increments, and also increased pollution necessitating the need to put renewable energy sources in place. Various barriers hamper the efficient deployment of renewable energy sources. Discontinuity of generation is one of the significant drawbacks in the use of renewable energy sources, and calls for complex processes for optimization methods. However, the complexity is easily broken down through the use of advanced computer software and hardware that have sufficient computational resources. In their paper, Banos, et al. (2012) expound on the optimization methods that stand as the current state-of-the-art computational methods that are applicable in the renewable and sustainable energy fields. Use of renewable energy technologies paves the way for the achievement of sustainable development, in addition 
to providing a solution to the existing environmental problems related to energy generation. The complexity of the energy problems prompts the use of optimization algorithms in finding a viable solution. In mathematics, optimization is defined as the replacement of inputs of a function until a reduced result is arrived at. When computerized, optimization becomes the process of designing, implementing, and testing an algorithm when solving varied optimization problems. Various forms of renewable energy sources apply different optimization methods. The credibility of Banos, et al.'s (2012) review comes from the group's consideration of over 200 papers drawn from major referenced journals. These materials offers quality information on how the optimization of renewable sources can be arrived at in order to create sustainable development using renewable energy systems.

With respect to the role of renewable sources in the protection of the environment, Panwar, et al. (2011) reviews the use of renewable technologies. The authors assert that an optimal use of the technologies helps in minimizing environmental impacts, reduces the production of secondary waste, and ensures sustainability based on current and future societal energy needs. The sun emits energy in the form of light and heat, which the environment absorbs, using several means. Biomass and wind energy are some of the renewable energy flows that result from environmental transformations caused by sunlight. Panwar, et al. (2011) hold the view that renewable energy mitigates both the effects of pollution and the effects of global warming. The paper explores the reduction of carbon dioxide through the use of solar cookers, improved cooking stoves, water heaters, and dryers (Panwar, et al., 2011). Renewable energy sources that are used domestically have the potential to provide energy that is free from air pollutants and greenhouse gases. Rural areas benefit the most from the use of renewable energy due to job creation. Decentralizing the collection of renewable energy in rural areas makes it 
possible to have a cheap, reliable, and environmentally-friendly means of using energy. In order to generate the solar power, PV systems and solar thermal power are employed (Panwar, et al., 2011). Wind energy and bio-energy also have their share in the energy mix that helps in environmental protection. Of course, different equipment is need to harvest energy from these sources, however. In conclusion, the paper affirms the great role that renewable energy plays in conservation of the environment (Panwar, et al., 2011). It is through maximization of renewable energy that optimal conservation of the environment can be achieved.

Marques and Fuinhas (2011) study the commitment that various countries have made to renewable energy sources. The duo comes up with a paper that gives focus to 24 European countries, while applying panel dynamic estimators. In their study Europe proved to be on the frontline in fighting against climate change after an estimator was applied, resulting in a persistent effect on renewables. Previous level of renewables usage positively affects the current usage in a significant way. One challenge that remains for the consistent use of renewables is the continued use of conventional energy sources. Some of the methods that are used to bring a switch from traditional energy to renewable energy do not work, including social awareness of sustainability and $\mathrm{CO}_{2}$ reduction targets (Marques and Fuinhas, 2011). From 1990-2006, prices of fuels that were not significant in promoting the use of renewable energy increased. The period was considered not to have a market that promoted renewables. The paper notes that there is a relation between the choice of the energy that a nation adopts and the maintenance of presentday living standards. The two options operate on a platform that determines the planet's survival and the sustainability of the economy (Marques and Fuinhas, 2011). Currently, global warming is evident to such a notable degree that significant numbers of glaciers are melting as a consequence of $\mathrm{CO}_{2}$ and other greenhouse gas emission. The paper employs dynamic panel data 
estimators to ascertain the level of commitment to carry out an energy production from renewable sources. The paper also seeks to find the determinants that promote or hamper the implementation of the commitment (Marques and Fuinhas, 2011). The study finds a positive relation between previous uses of renewable energy with the assessed period's usage, however it lacks evidence that awareness plays a significant part in the use of renewable sources (Marques and Fuinhas, 2011). In conclusion, it was not the market that hampered optimal use of renewable energy, but other sources since the fossil fuel prices were unstable. 


\section{CHAPTER 3}

\section{OBJECTIVES AND METHODOLOGY}

\subsection{Research Objectives}

The aim of the current research is to re-examine and re-evaluate the potential for solar energy in Saudi Arabia, and establish the existence of motivating factors that can be used to encourage and sustain future growth of the domestic solar energy sector. Also, generate three different forecasting methods for about 32 cities in Saudi Arabia to find which model is the best for each case of data. Considering the cost model is one of the important works in this research. This is due to issues regarding the nation's heavy reliance on petroleum products, the fact that Saudi Arabia is one of the largest producers of oil in the world, the low domestic cost of petroleum products, and the high reliance factor among Saudi consumers. In this regard, the research objectives are as follows:

i. Develop forecasting model for the amount of irradiation and wind energy that can be produced in 32 major cities of Saudi Arabia. So, that can be input to the economic analysis model.

ii. Develop an economic analysis model to investigate the potential of solar and wind energy as a cost-effective, suitable alternative to petroleum products.

iii. Develop user-friendly software to perform economic and sensitivity analyses. 


\subsection{Methodology}

The methodology to be followed is as following:

1. To begin with, the research will collect information on the average solar irradiation in Saudi Arabia. This study will consider the fact that the cost of an average domestic solar panel differs widely with that of the solar panels required for establishing solar farms.

2. To collect data about wind turbines as well. The data collected will include the average speed and strength of wind in different parts of Saudi Arabia. This information will be used to see how these compare with solar energy productive areas in Saudi Arabia and establish the potential for using a blended approach for renewable energy production.

3. Use that data to perform and analysis to come up with forecasting model. This research will apply three different methods to that data for 32 cities, using either decomposition method, or multiple linear regression (linear trend model), and multiple linear model (seasonal model).

4. Use the output of the forecasting model and economic analysis model to see what the cost of 32 cities would be to generate and deliver solar and wind energy.

5. Develop user-friendly software to perform economic and sensitivity analyses.

6. After, perform an economic analysis model of the data, then interpret the results and make recommendation.

\subsection{Forecasting Methods}

This research will use three different methods of forecasting, and compare between them which one is the best for each case to be used in the forecasting model. There is evidence that both the decomposition and multiple linear regressions are important concepts in the field of forecasting. While decomposition is the approach of separating historical data into various 
components, multiple linear regressions focus on the relationship that exists between two or more variables. In next section will apply three different methods to the data for the city of Tabuk.

\subsubsection{Decomposition Method}

- Definition

Decomposition is a technique used in forecasting and other sectors. For instance, in economics and statistics. The technique will decompose or separate historical data into many components for purposes of using them to improve the results. That is, the use of this approach results in more accurate results relative to the utilization of the simple trend line. While the use of simple trend line can be utilized in some simple calculations, it results in inaccuracies. The rationale used is that it's possible to separate various components and later combining them (Shekhar, 2004). Separately, the use of small components makes it possible to assess them independently, understand their importance; evaluate them to discount them based on the market and economic variations (Shekhar, 2004). These uses of separate a components help in the improvement of the accuracy of the results.

\section{- Forecasting}

After the calculation of the different components, the generation of the forecast is easy. Table 3.1 is presented 5 months moving average and the seasonal IRR

$$
T=a+b t
$$


Table 3.1 5-MV and seasonal IRR

\begin{tabular}{|c|c|c|c|c|c|}
\hline Months & & & Actual Data & 5-Month MA & Seasonal * IRR \\
\hline Jan-13 & 1 & 1 & 2.5 & & \\
\hline Feb-13 & 2 & 2 & 3.9 & & \\
\hline Mar-13 & 3 & 3 & 6.8 & 5.84 & 1.164 \\
\hline Apr-13 & 4 & 4 & 7.2 & 7.28 & 0.989 \\
\hline May-13 & 5 & 1 & 8.8 & 8.54 & 1.030 \\
\hline Jun-13 & 6 & 2 & 9.7 & 9.40 & 1.032 \\
\hline Jul-13 & 7 & 3 & 10.2 & 10.12 & 1.008 \\
\hline Agust-13 & 8 & 4 & 11.1 & 10.34 & 1.074 \\
\hline Sep-13 & 9 & 1 & 10.8 & 10.04 & 1.076 \\
\hline Oct-13 & 10 & 2 & 9.9 & 8.82 & 1.122 \\
\hline Nov-13 & 11 & 3 & 8.2 & 7.02 & 1.168 \\
\hline Dec-13 & 12 & 4 & 4.1 & 5.60 & 0.732 \\
\hline Jan-14 & 13 & 1 & 2.1 & 4.66 & 0.451 \\
\hline Feb-14 & 14 & 2 & 3.7 & 4.38 & 0.845 \\
\hline Mar-14 & 15 & 3 & 5.2 & 4.99 & 1.043 \\
\hline Apr-14 & 16 & 4 & 6.8 & 6.29 & 1.081 \\
\hline May-14 & 17 & 1 & 7.14 & 7.53 & 0.948 \\
\hline Jun-14 & 18 & 2 & 8.6 & 8.73 & 0.985 \\
\hline Jul-14 & 19 & 3 & 9.9 & 9.45 & 1.048 \\
\hline Agust-14 & 20 & 4 & 11.2 & 9.88 & 1.134 \\
\hline Sep-14 & 21 & 1 & 10.4 & 9.50 & 1.095 \\
\hline Oct-14 & 22 & 2 & 9.3 & 8.40 & 1.107 \\
\hline Nov-14 & 23 & 3 & 6.7 & 6.94 & 0.965 \\
\hline Dec-14 & 24 & 4 & 4.4 & 5.70 & 0.772 \\
\hline Jan-15 & 25 & 1 & 3.9 & 4.96 & 0.786 \\
\hline Feb-15 & 26 & 2 & 4.2 & 4.84 & 0.868 \\
\hline Mar-15 & 27 & 3 & 5.6 & 4.95 & 1.131 \\
\hline Apr-15 & 28 & 4 & 6.1 & 5.30 & 1.151 \\
\hline & & & & & \\
\hline & & & & \\
\hline
\end{tabular}

Table 3.2 Average Seasonal Factor and Seasonal Index of Tubuk City

\begin{tabular}{|c|c|c|c|}
\hline 5-Week & Avg. Seasonal Factor & Avg. $* \mathbf{1 0 0}$ & Seasonal Index = (Avg. $* \mathbf{1 0 0}) * \mathbf{4 0 0 / 3 8 9 . 8 5}$ \\
\hline 1 & 1.049 & 104.879 & 1.067 \\
\hline 2 & 0.985 & 98.539 & 1.002 \\
\hline 3 & 0.925 & 92.517 & 0.941 \\
\hline 4 & 0.935 & 93.505 & 0.951 \\
\hline 5 & 1.021 & 102.121 & 1.039 \\
\hline & & 491.561 & 5.000 \\
\hline
\end{tabular}


Table 3.3 is presented the mean square error (MSE), and The mean absolute percentage error (MAPE). Also, it shows the forecast data of solar irradiation of Tabuk City.

Table 3.3 Deseasonalized and forecast of solar irradiation data of Tubuk City

\begin{tabular}{|c|c|c|c|c|c|}
\hline Season (x) & Deseasonalized & Trend & Forecast & APE & SE \\
\hline 1 & 2.343 & 7.555 & 8.059 & 222.363 & 30.903 \\
\hline 2 & 3.891 & 7.584 & 7.602 & 94.911 & 13.701 \\
\hline 3 & 7.226 & 7.614 & 7.165 & 5.363 & 0.133 \\
\hline 4 & 7.570 & 7.643 & 7.269 & 0.963 & 0.005 \\
\hline 5 & 8.472 & 7.673 & 7.970 & 9.435 & 0.689 \\
\hline 6 & 9.093 & 7.702 & 8.216 & 15.295 & 2.201 \\
\hline 7 & 10.177 & 7.732 & 7.749 & 24.026 & 6.006 \\
\hline 8 & 11.795 & 7.761 & 7.303 & 34.203 & 14.413 \\
\hline 9 & 11.355 & 7.791 & 7.410 & 31.393 & 11.495 \\
\hline 10 & 9.531 & 7.820 & 8.123 & 17.950 & 3.158 \\
\hline 11 & 7.687 & 7.850 & 8.374 & 2.119 & 0.030 \\
\hline 12 & 4.091 & 7.879 & 7.897 & 92.614 & 14.419 \\
\hline 13 & 2.232 & 7.909 & 7.442 & 254.395 & 28.540 \\
\hline 14 & 3.890 & 7.938 & 7.550 & 104.051 & 14.822 \\
\hline 15 & 5.006 & 7.968 & 8.276 & 59.157 & 9.463 \\
\hline 16 & 6.374 & 7.997 & 8.531 & 25.458 & 2.997 \\
\hline 17 & 7.124 & 8.027 & 8.045 & 12.676 & 0.819 \\
\hline 18 & 9.139 & 8.056 & 7.581 & 11.848 & 1.038 \\
\hline 19 & 10.409 & 8.086 & 7.690 & 22.322 & 4.883 \\
\hline 20 & 10.782 & 8.115 & 8.429 & 24.738 & 7.676 \\
\hline 21 & 9.749 & 8.145 & 8.688 & 16.457 & 2.929 \\
\hline 22 & 9.279 & 8.174 & 8.193 & 11.905 & 1.226 \\
\hline 23 & 7.120 & 8.204 & 7.720 & 15.223 & 1.040 \\
\hline 24 & 4.626 & 8.233 & 7.830 & 77.965 & 11.768 \\
\hline 25 & 3.755 & 8.263 & 8.583 & 120.067 & 21.927 \\
\hline 26 & 3.937 & 8.292 & 8.846 & 110.615 & 21.584 \\
\hline 27 & 5.587 & 8.322 & 8.341 & 48.941 & 7.512 \\
\hline 28 & 6.482 & 8.351 & 7.859 & 28.831 & 3.093 \\
\hline
\end{tabular}




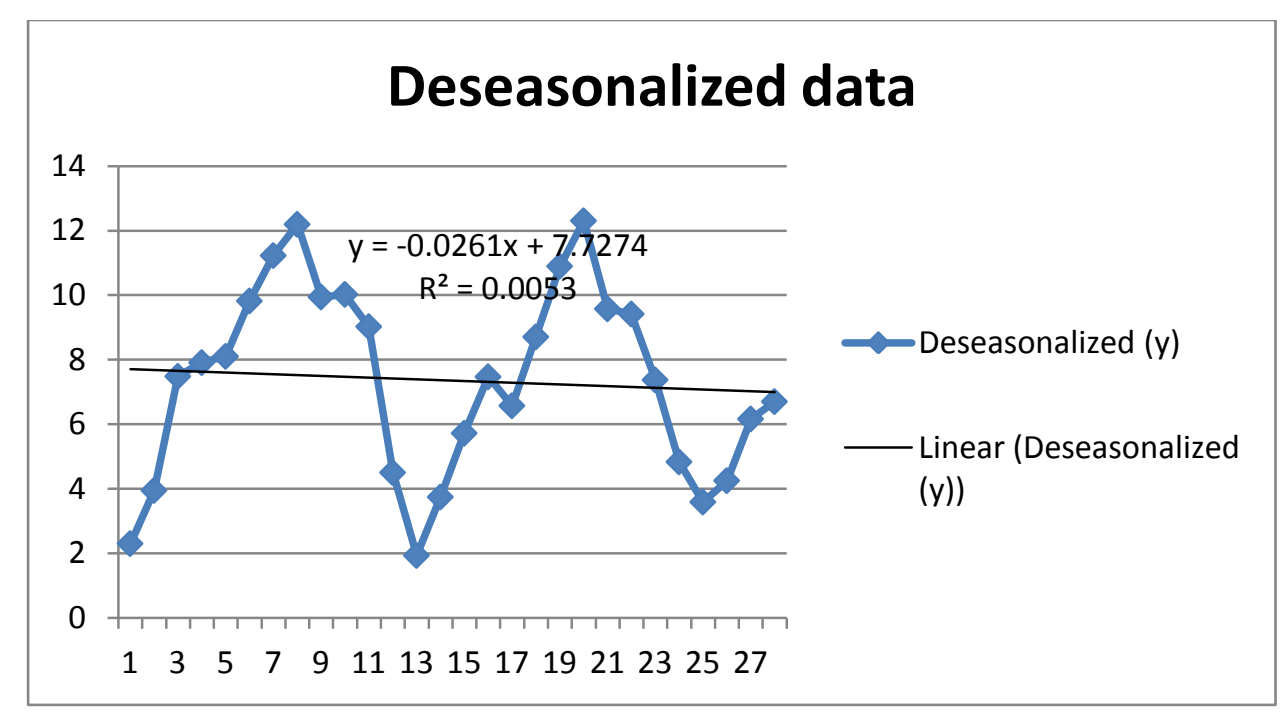

Figure 3.1 Deseasonalized data and R- Square

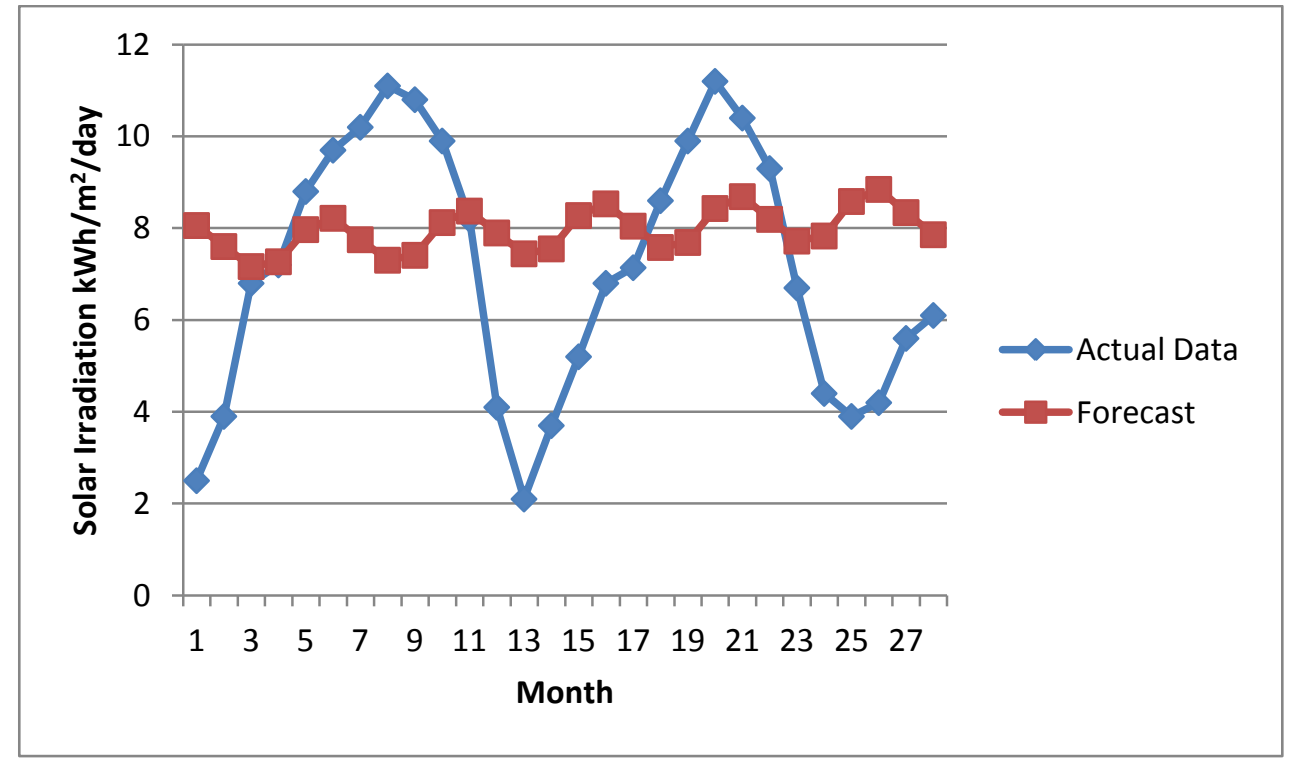

Figure 3.2 Actual and Forecast Data (Decomposition Method)

Figure 3.2 shows that the decomposition method does not result in a good fit, as the model does not effectively capture the seasonality in the data set.

The estimation of error variance is shown as the following (MSE):

$$
\widehat{\sigma_{\epsilon}^{2}}=\frac{\sum_{t=1}^{T}\left(x_{t}-\widehat{x_{t}}\right)^{2}}{T-2}
$$




$$
\widehat{\sigma_{\epsilon}^{2}}=\frac{238.470}{28-2}=9.172
$$

The mean absolute percentage error (MAPE):

$$
\begin{array}{r}
\text { MAPE }=\frac{1}{n} \sum_{t=1}^{n}\left|\frac{A_{t}-F_{t}}{A_{t}}\right| \\
\text { MAPE }=\frac{1}{28}(1495.281)=53.403
\end{array}
$$

Where, $A_{t}$ is actual data, and $F_{t}$ is forecast data

\subsection{Multiple Linear Regression: Linear Trend Model}

\section{- Definition}

Multiple linear regressions are an advancement of the simple linear regression. The inadequacies of the simple linear regression made it necessary for statisticians to use of a more advanced technique. This approach analyzes a relationship that exists between two components that are independent and one dependent (Yan, \& Su, 2009). It can also compare more variables and its flexibility also informs the use of the approach. The equation resembles

$$
Y=b+b_{1} x_{1}+b_{2} x_{2}+\ldots+b_{n} x_{n}
$$

Where the predicted value is represented by $Y$. Each of the regression coefficients is a representation of the variations in $\mathrm{Y}$ relative to a definite change in $x$ when all the other variables are constant.

This approach has found usage not only by forecasters but also in statistics and economics. Regression analysis, multi-regression analysis, in particular, has an extensive application. In fact, regression analysis developed from the simple application in biology to advanced usage in industries and other sectors. 


\section{- Tabuk City Model}

Here, used Tubuk City solar irradiation data to find what the best model to fit that data.

(1) Fit the straight line model $x_{t}=b_{1}+b_{2} t+\epsilon_{t} \quad$, we can get the following formula:

$$
\begin{aligned}
& \widehat{b_{1}}=\frac{2(2 T+1)}{T(T-1)} \sum_{t=1}^{T} x_{t}-\frac{6}{T(T-1)} \sum_{t=1}^{T} t x_{t} \\
& \widehat{b_{2}}=\frac{12}{T\left(T^{2}-1\right)} \sum_{t=1}^{T} t x_{t}-\frac{6}{T(T-1)} \sum_{t=1}^{T} x_{t}
\end{aligned}
$$

In this case, $\mathrm{T}=28$, we have: 
Table 3.4 Actual and Forecast Data of Solar Irradiation Data of Tubuk City

\begin{tabular}{|l|c|c|c|c|}
\hline Months & (t) & Actual Data $(\mathbf{X} \mathbf{t})$ & $\mathbf{t} * \mathbf{X t}$ & $\hat{\mathbf{Y}}$ \\
\hline Jan-13 & 1 & 2.5 & 2.5 & 7.4903 \\
\hline Feb-13 & 2 & 3.9 & 7.8 & 7.4606 \\
\hline Mar-13 & 3 & 6.8 & 20.4 & 7.4309 \\
\hline Apr-13 & 4 & 7.2 & 28.8 & 7.4012 \\
\hline May-13 & 5 & 8.8 & 44 & 7.3715 \\
\hline Jun-13 & 6 & 9.7 & 58.2 & 7.3418 \\
\hline Jul-13 & 7 & 10.2 & 71.4 & 7.3121 \\
\hline Agust-13 & 8 & 11.1 & 88.8 & 7.2824 \\
\hline Sep-13 & 9 & 10.8 & 97.2 & 7.2527 \\
\hline Oct-13 & 10 & 9.9 & 99 & 7.223 \\
\hline Nov-13 & 11 & 8.2 & 90.2 & 7.1933 \\
\hline Dec-13 & 12 & 4.1 & 49.2 & 7.1636 \\
\hline Jan-14 & 13 & 2.1 & 27.3 & 7.1339 \\
\hline Feb-14 & 14 & 3.7 & 51.8 & 7.1042 \\
\hline Mar-14 & 15 & 5.2 & 78 & 7.0745 \\
\hline Apr-14 & 16 & 6.8 & 108.8 & 7.0448 \\
\hline May-14 & 17 & 7.14 & 121.38 & 7.0151 \\
\hline Jun-14 & 18 & 8.6 & 154.8 & 6.9854 \\
\hline Jul-14 & 19 & 9.9 & 188.1 & 6.9557 \\
\hline Agust-14 & 20 & 11.2 & 224 & 6.926 \\
\hline Sep-14 & 21 & 10.4 & 218.4 & 6.8963 \\
\hline Oct-14 & 22 & 9.3 & 204.6 & 6.8666 \\
\hline Nov-14 & 23 & 6.7 & 154.1 & 6.8369 \\
\hline Dec-14 & 24 & 4.4 & 105.6 & 6.8072 \\
\hline Jan-15 & 25 & 3.9 & 97.5 & 6.7775 \\
\hline Feb-15 & 26 & 4.2 & 109.2 & 6.7478 \\
\hline Mar-15 & 27 & 5.6 & 151.2 & 6.7181 \\
\hline Apr-15 & 28 & 6.1 & 170.8 & 6.6884 \\
\hline Total & $\mathbf{4 0 6}$ & $\mathbf{1 9 8 . 4 4}$ & $\mathbf{2 8 2 3 . 0 8}$ & \\
\hline
\end{tabular}

Then, we can get $\widehat{b_{1}}=\frac{2(2 * 28+1)}{28 * 27} * 198.44-\frac{6}{28 * 27} * 2823.08=7.52$

$$
\widehat{b_{2}}=\frac{12}{28(784-1)} * 2823.08-\frac{6}{28 * 27} * 198.44=-0.0297
$$

The straight line model is:

$x_{t}=\widehat{b_{1}}+\widehat{b_{2}} t+\epsilon_{t}=7.52+(-0.0297 \mathrm{t})+\epsilon_{t}$

The forecast equation is: 


$$
\widehat{x_{t+\tau}}(T)=\widehat{b_{1}}(T)+\widehat{b_{2}}(T) *(T+\tau)
$$

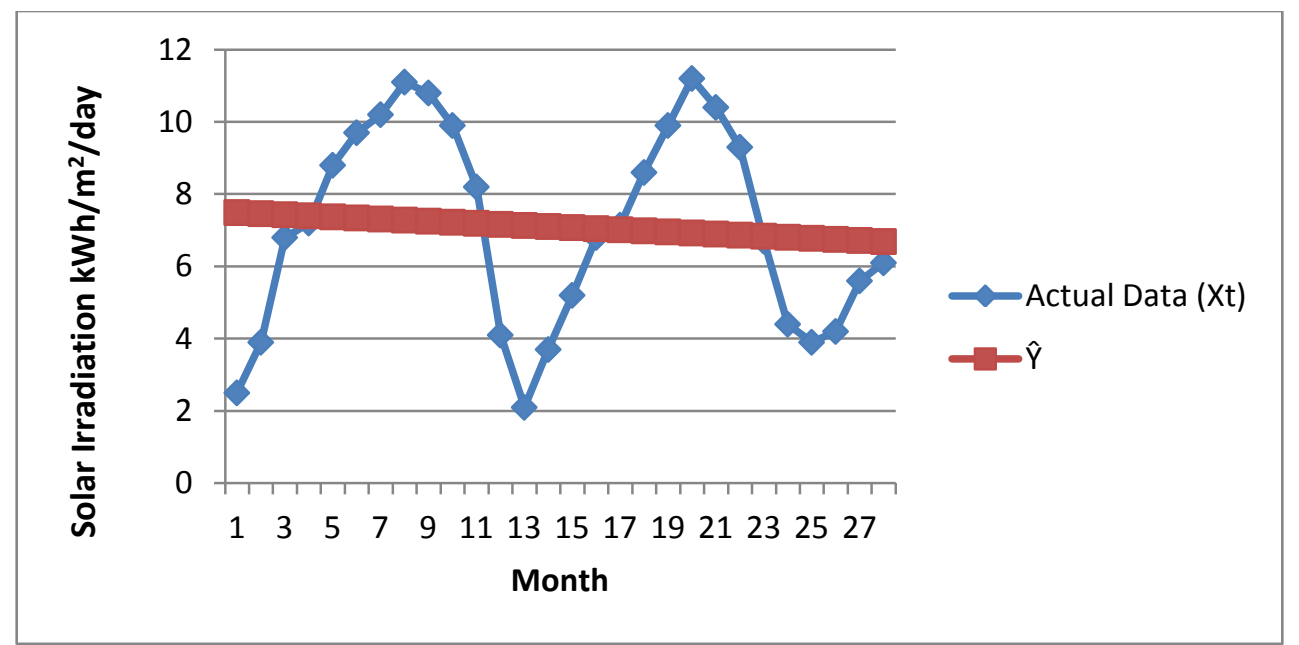

Figure 3.3 Actual and Forecast Data (Multiple Linear Method)

(2) Estimate the error variance:

The estimation of error variance is shown as the following:

$$
\widehat{\sigma_{\epsilon}^{2}}=\frac{\sum_{t=1}^{T}\left(x_{t}-\widehat{x_{t}}\right)^{2}}{T-2}
$$

Step 1: calculate all the estimated sale data in the past 28 periods using the fitted model we get $\operatorname{from}(1): \widehat{x_{t}}=\widehat{b_{1}}+\widehat{b_{2}} t, \mathfrak{t}=1,2, \ldots, 27,28$.

Table 3.5 is presented the mean square error (SE), and The mean absolute percentage error (APE). Also, it shows the forecast data of solar irradiation of Tabuk City. 
Table 3.5 Forecast, SE, and APE

\begin{tabular}{|c|c|c|c|c|}
\hline$(t)$ & $\operatorname{Actual}$ Data $\left(x_{t}\right)$ & $\widehat{x_{t}}$ & SE & APE \\
\hline 1 & 2.5 & 7.490 & 24.903 & 199.612 \\
\hline 2 & 3.9 & 7.461 & 12.678 & 91.297 \\
\hline 3 & 6.8 & 7.431 & 0.398 & 9.278 \\
\hline 4 & 7.2 & 7.401 & 0.040 & 2.794 \\
\hline 5 & 8.8 & 7.372 & 2.041 & 16.233 \\
\hline 6 & 9.7 & 7.342 & 5.561 & 24.311 \\
\hline 7 & 10.2 & 7.312 & 8.340 & 28.313 \\
\hline 8 & 11.1 & 7.282 & 14.574 & 34.393 \\
\hline 9 & 10.8 & 7.253 & 12.583 & 32.845 \\
\hline 10 & 9.9 & 7.223 & 7.166 & 27.040 \\
\hline 11 & 8.2 & 7.193 & 1.013 & 12.277 \\
\hline 12 & 4.1 & 7.164 & 9.386 & 74.722 \\
\hline 13 & 2.1 & 7.134 & 25.340 & 239.710 \\
\hline 14 & 3.7 & 7.104 & 11.589 & 92.005 \\
\hline 15 & 5.2 & 7.075 & 3.514 & 36.048 \\
\hline 16 & 6.8 & 7.045 & 0.060 & 3.600 \\
\hline 17 & 7.14 & 7.015 & 0.016 & 1.749 \\
\hline 18 & 8.6 & 6.985 & 2.607 & 18.774 \\
\hline 19 & 9.9 & 6.956 & 8.669 & 29.740 \\
\hline 20 & 11.2 & 6.926 & 18.267 & 38.161 \\
\hline 21 & 10.4 & 6.896 & 12.276 & 33.689 \\
\hline 22 & 9.3 & 6.867 & 5.921 & 26.166 \\
\hline 23 & 6.7 & 6.837 & 0.019 & 2.043 \\
\hline 24 & 4.4 & 6.807 & 5.795 & 54.709 \\
\hline 25 & 3.9 & 6.778 & 8.280 & 73.782 \\
\hline 26 & 4.2 & 6.748 & 6.491 & 60.662 \\
\hline 27 & 5.6 & 6.718 & 1.250 & 19.966 \\
\hline 28 & 6.1 & 6.688 & 0.346 & 9.646 \\
\hline Total & 198.44 & & 209.123 & 1293.567 \\
\hline
\end{tabular}

The estimation of error variance is shown as the following (MSE):

$$
\widehat{\sigma_{\epsilon}^{2}}=\frac{\sum_{t=1}^{T}\left(x_{t}-\widehat{x_{t}}\right)^{2}}{T-2}
$$




$$
\widehat{\sigma_{\epsilon}^{2}}=\frac{209.123}{28-2}=8.043
$$

The mean absolute percentage error (MAPE):

$$
\begin{gathered}
\text { MAPE }=\frac{1}{n} \sum_{t=1}^{n}\left|\frac{A_{t}-F_{t}}{A_{t}}\right| \\
\text { MAPE }=\frac{1}{28}(1293.567)=46.199
\end{gathered}
$$

(3) Fit the regression model: $x_{t}=b_{1}+b_{2} \operatorname{Sin} \frac{2 \pi t}{12}+b_{3} \operatorname{Cos} \frac{2 \pi t}{12}+\epsilon_{t}$

We can rewrite the model in this way:

$x_{j}=b_{1}+b_{2} Z_{2 j}+b_{3} Z_{3 j}+\epsilon_{t}$, where $Z_{2 j}=\operatorname{Sin} \frac{2 \pi j}{12} ; Z_{3 j}=\operatorname{Cos} \frac{2 \pi j}{12}, j=1, \ldots, n$

In our case, we have $\mathrm{k}=3$ unknown parameters and $\mathrm{n}=28$ observations

Solving the normal equations, we can get three matrixes as the following:

$$
\begin{array}{r}
\mathbf{G}=\left[\begin{array}{ccc}
28 & \sum_{j=1}^{28} Z_{2 j} & \sum_{j=1}^{28} Z_{3 j} \\
\sum_{j=1}^{28} Z_{2 j} & \sum_{j=1}^{28} Z_{2 j}^{2} & \sum_{j=1}^{28} Z_{2 j} Z_{3 j} \\
\sum_{j=1}^{28} Z_{3 j} & \sum_{j=1}^{28} Z_{2 j} Z_{3 j} & \sum_{j=1}^{28} Z_{3 j}^{2}
\end{array}\right] \\
\widehat{\boldsymbol{b}}=\left[\begin{array}{c}
\widehat{b_{1}} \\
\widehat{b_{2}} \\
\widehat{b_{3}}
\end{array}\right]
\end{array}
$$

Then, we can get

$\widehat{b}=G^{-1} g$

First, calculate all the $Z_{2 j}=\operatorname{Sin} \frac{2 \pi j}{12}$ and $Z_{3 j}=\operatorname{Cos} \frac{2 \pi j}{12}$ which is presented in Table 3.6 
Table 3.6 Components of the Regression Model Matrices

\begin{tabular}{|c|c|c|c|c|c|c|c|c|}
\hline $\mathrm{J}$ & $x_{j}$ & $Z_{2 j}$ & $Z_{2 j}^{2}$ & $Z_{3 j}$ & $Z_{3 j}^{2}$ & $Z_{2 j} Z_{3 j}$ & $Z_{2 j} x_{j}$ & $Z_{3 j} x_{j}$ \\
\hline 1 & 2.5 & 0.500 & 0.250 & 0.866 & 0.750 & 0.433 & 1.249 & 2.165 \\
\hline 2 & 3.9 & 0.866 & 0.750 & 0.500 & 0.250 & 0.433 & 3.376 & 1.952 \\
\hline 3 & 6.8 & 1.000 & 1.000 & 0.001 & 0.000 & 0.001 & 6.800 & 0.005 \\
\hline 4 & 7.2 & 0.867 & 0.751 & -0.499 & 0.249 & -0.432 & 6.239 & -3.593 \\
\hline 5 & 8.8 & 0.501 & 0.251 & -0.865 & 0.749 & -0.434 & 4.410 & -7.615 \\
\hline 6 & 9.7 & 0.002 & 0.000 & -1.000 & 1.000 & -0.002 & 0.015 & -9.700 \\
\hline 7 & 10.2 & -0.498 & 0.248 & -0.867 & 0.752 & 0.432 & -5.084 & -8.843 \\
\hline 8 & 11.1 & -0.865 & 0.748 & -0.502 & 0.252 & 0.434 & -9.601 & -5.570 \\
\hline 9 & 10.8 & -1.000 & 1.000 & -0.002 & 0.000 & 0.002 & -10.800 & -0.026 \\
\hline 10 & 9.9 & -0.867 & 0.752 & 0.498 & 0.248 & -0.432 & -8.587 & 4.927 \\
\hline 11 & 8.2 & -0.503 & 0.253 & 0.865 & 0.747 & -0.434 & -4.121 & 7.089 \\
\hline 12 & 4.1 & -0.003 & 0.000 & 1.000 & 1.000 & -0.003 & -0.013 & 4.100 \\
\hline 13 & 2.1 & 0.497 & 0.247 & 0.868 & 0.753 & 0.431 & 1.044 & 1.822 \\
\hline 14 & 3.7 & 0.864 & 0.747 & 0.503 & 0.253 & 0.435 & 3.197 & 1.862 \\
\hline 15 & 5.2 & 1.000 & 1.000 & 0.004 & 0.000 & 0.004 & 5.200 & 0.021 \\
\hline 16 & 6.8 & 0.868 & 0.754 & -0.496 & 0.246 & -0.431 & 5.903 & -3.375 \\
\hline 17 & 7.14 & 0.504 & 0.254 & -0.864 & 0.746 & -0.435 & 3.598 & -6.167 \\
\hline 18 & 8.6 & 0.005 & 0.000 & -1.000 & 1.000 & -0.005 & 0.041 & -8.600 \\
\hline 19 & 9.9 & -0.496 & 0.246 & -0.869 & 0.754 & 0.430 & -4.907 & -8.599 \\
\hline 20 & 11.2 & -0.863 & 0.745 & -0.505 & 0.255 & 0.436 & -9.670 & -5.651 \\
\hline 21 & 10.4 & -1.000 & 1.000 & -0.006 & 0.000 & 0.006 & -10.400 & -0.058 \\
\hline 22 & 9.3 & -0.869 & 0.755 & 0.495 & 0.245 & -0.430 & -8.081 & 4.603 \\
\hline 23 & 6.7 & -0.505 & 0.255 & 0.863 & 0.745 & -0.436 & -3.385 & 5.782 \\
\hline 24 & 4.4 & -0.006 & 0.000 & 1.000 & 1.000 & -0.006 & -0.028 & 4.400 \\
\hline 25 & 3.9 & 0.494 & 0.244 & 0.869 & 0.756 & 0.430 & 1.928 & 3.390 \\
\hline 26 & 4.2 & 0.863 & 0.744 & 0.506 & 0.256 & 0.436 & 3.623 & 2.125 \\
\hline 27 & 5.6 & 1.000 & 1.000 & 0.007 & 0.000 & 0.007 & 5.600 & 0.040 \\
\hline 28 & 6.1 & 0.870 & 0.756 & -0.494 & 0.244 & -0.429 & 5.305 & -3.011 \\
\hline Total & 198.44 & 3.223 & 14.750 & 0.877 & 13.250 & 0.441 & -17.146 & -26.524 \\
\hline
\end{tabular}

Therefore, $\mathbf{G}=\left[\begin{array}{ccc}28 & 3.223 & 0.877 \\ 3.223 & 14.750 & 0.441 \\ 0.877 & 0.441 & 13.250\end{array}\right] \quad \mathbf{g}=\left[\begin{array}{c}198.44 \\ -17.146 \\ -26.524\end{array}\right]$ 


$$
\boldsymbol{G}^{-\mathbf{1}}=\left[\begin{array}{ccc}
0.036698 & -0.007954 & -0.00216433 \\
-0.007954 & 0.069588 & -0.001789 \\
-0.00216433 & -0.001789 & 0.0756745
\end{array}\right]
$$

So, $\widehat{\boldsymbol{b}}=\boldsymbol{G}^{-\mathbf{1}} \boldsymbol{g}=\left[\begin{array}{l}\widehat{b_{1}} \\ \widehat{b_{2}} \\ \widehat{b_{3}}\end{array}\right]=\left[\begin{array}{c}7.47614 \\ -2.7241 \\ -2.406\end{array}\right]$

Finally, we fit the regression model is:

$$
x_{t}=7.47614-2.7241 \operatorname{Sin} \frac{2 \pi t}{12}-2.406 \operatorname{Cos} \frac{2 \pi t}{12}+\epsilon_{t}
$$


Table 3.7 Actual and forecast data, and SE (Tabuk City)

\begin{tabular}{|c|c|c|c|c|}
\hline$(\mathbf{t})$ & Actual Data $\left(X_{t}\right)$ & $\hat{\mathbf{Y}}$ & SE & APE \\
\hline 1 & 2.5 & 4.031 & 2.343 & 61.230 \\
\hline 2 & 3.9 & 3.914 & 0.000 & 0.349 \\
\hline 3 & 6.8 & 4.750 & 4.202 & 30.145 \\
\hline 4 & 7.2 & 6.316 & 0.781 & 12.273 \\
\hline 5 & 8.8 & 8.193 & 0.368 & 6.898 \\
\hline 6 & 9.7 & 9.878 & 0.032 & 1.833 \\
\hline 7 & 10.2 & 10.920 & 0.518 & 7.056 \\
\hline 8 & 11.1 & 11.040 & 0.004 & 0.542 \\
\hline 9 & 10.8 & 10.206 & 0.353 & 5.500 \\
\hline 10 & 9.9 & 8.641 & 1.584 & 12.713 \\
\hline 11 & 8.2 & 6.765 & 2.059 & 17.501 \\
\hline 12 & 4.1 & 5.079 & 0.958 & 23.874 \\
\hline 13 & 2.1 & 4.034 & 3.742 & 92.116 \\
\hline 14 & 3.7 & 3.911 & 0.045 & 5.712 \\
\hline 15 & 5.2 & 4.742 & 0.209 & 8.798 \\
\hline 16 & 6.8 & 6.305 & 0.245 & 7.274 \\
\hline 17 & 7.14 & 8.182 & 1.085 & 14.589 \\
\hline 18 & 8.6 & 9.869 & 1.611 & 14.757 \\
\hline 19 & 9.9 & 10.916 & 1.032 & 10.262 \\
\hline 20 & 11.2 & 11.042 & 0.025 & 1.410 \\
\hline 21 & 10.4 & 10.214 & 0.035 & 1.792 \\
\hline 22 & 9.3 & 8.652 & 0.419 & 6.964 \\
\hline 23 & 6.7 & 6.776 & 0.006 & 1.139 \\
\hline 24 & 4.4 & 5.088 & 0.473 & 15.626 \\
\hline 25 & 3.9 & 4.038 & 0.019 & 3.543 \\
\hline 26 & 4.2 & 3.909 & 0.085 & 6.926 \\
\hline 27 & 5.6 & 4.735 & 0.748 & 15.449 \\
\hline 28 & 6.1 & 6.294 & 0.038 & 3.187 \\
\hline Total & 198.44 & 198.4411 & 23.01839 & 389.4584 \\
\hline
\end{tabular}




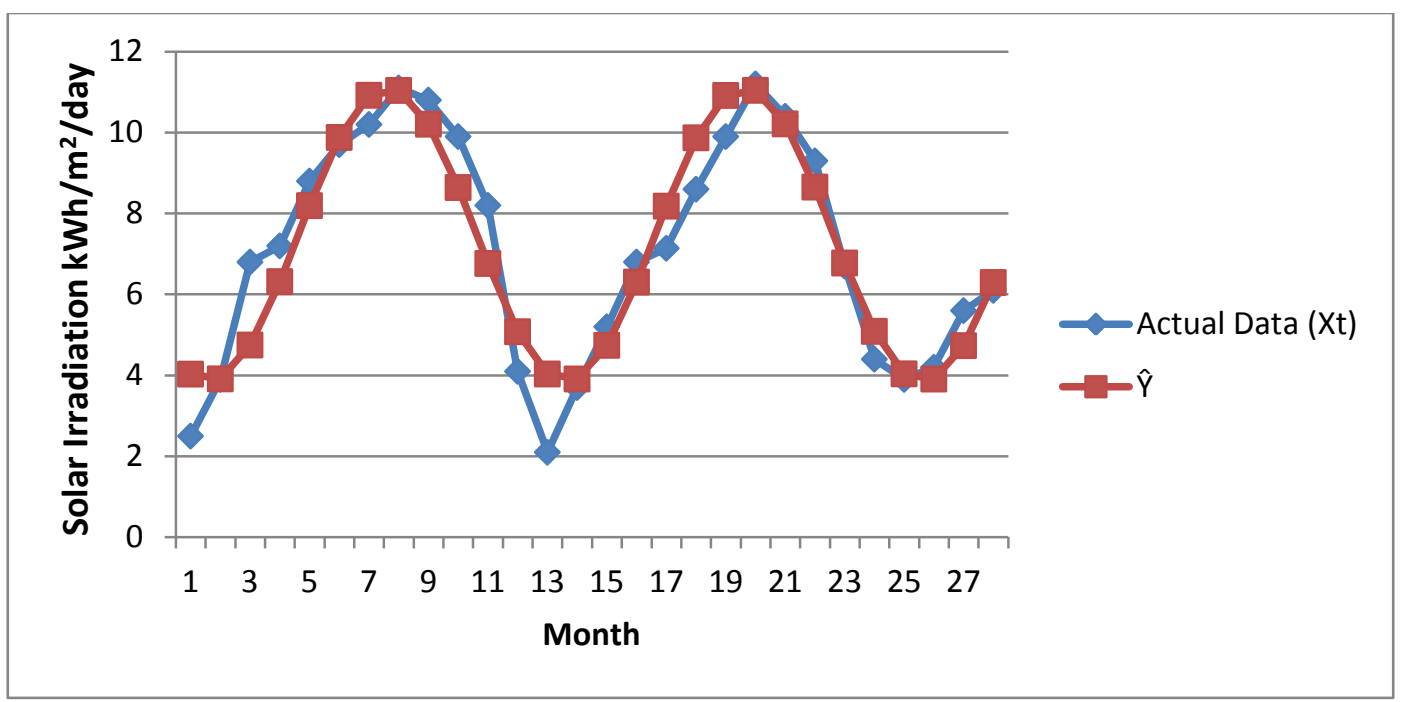

Figure 3.4 Actual and Forecast Data (Multiple Linear with Sin \& Cos Method)

The estimation of error variance is shown as the following (MSE):

$$
\begin{gathered}
\widehat{\sigma_{\epsilon}^{2}}=\frac{\sum_{t=1}^{T}\left(x_{t}-\widehat{x_{t}}\right)^{2}}{T-2} \\
\widehat{\sigma_{\epsilon}^{2}}=\frac{23.018}{28-2}=0.885
\end{gathered}
$$

The mean absolute percentage error (MAPE):

$$
\begin{gathered}
\text { MAPE }=\frac{1}{n} \sum_{t=1}^{n}\left|\frac{A_{t}-F_{t}}{A_{t}}\right| \\
\text { MAPE }=\frac{1}{28}(389.458)=13.91
\end{gathered}
$$

In Table 3.8 will apply three different methods to the data for 32 cities, to find MSE and MAPE for each city. 
Table 3.8 SE and APE of Three Different Methods

\begin{tabular}{|c|c|c|c|c|c|c|}
\hline \multirow[b]{2}{*}{ City } & \multicolumn{2}{|c|}{ Decomposition } & \multicolumn{2}{|c|}{ Multiple Linear Regression } & \multicolumn{2}{|c|}{ Seasonal Regression } \\
\hline & $\mathrm{SE}$ & APE & SE & APE & $\mathrm{SE}$ & $\mathrm{APE}$ \\
\hline Afif & 231.170 & 1328.271 & 206.553 & 1374.258 & 47.210 & 659.704 \\
\hline Al Baha & 346.442 & 1304.309 & 227.464 & 1341.503 & 55.285 & 778.398 \\
\hline Al Dawadmi & 289.653 & 1546.470 & 217.419 & 1476.302 & 47.792 & 664.420 \\
\hline Al Hanakiyah & 279.290 & 1323.318 & 212.204 & 1280.208 & 48.374 & 682.457 \\
\hline Al Qunfudah & 178.491 & 1466.474 & 214.509 & 1481.158 & 43.268 & 542.633 \\
\hline Al Uyaynah & 353.724 & 1531.183 & 216.443 & 1450.473 & 45.093 & 558.268 \\
\hline Al Wajh & 293.831 & 1452.290 & 222.527 & 1490.466 & 50.536 & 748.749 \\
\hline Arar & 546.443 & 1317.171 & 207.200 & 1471.161 & 28.226 & 436.003 \\
\hline Duba & 376.499 & 1558.207 & 211.339 & 1257.393 & 26.382 & 421.528 \\
\hline Hafar Al Batin & 282.230 & 1315.456 & 210.182 & 1310.280 & 39.264 & 509.644 \\
\hline Jazan & 176.282 & 1369.211 & 205.417 & 1361.273 & 37.637 & 487.209 \\
\hline Riyadh & 240.151 & 1412.337 & 214.197 & 1432.290 & 38.584 & 492.721 \\
\hline Jeddah & 404.513 & 1243.253 & 208.440 & 1404.355 & 43.733 & 549.814 \\
\hline Thuwal & 276.144 & 1520.147 & 215.533 & 1311.538 & 42.921 & 525.006 \\
\hline Dammam & 415.476 & 1427.360 & 209.211 & 1378.233 & 48.471 & 688.740 \\
\hline Al Ahsa & 218.226 & 1297.202 & 213.636 & 1500.459 & 47.850 & 661.295 \\
\hline Majmah & 356.310 & 1347.328 & 239.364 & 1568.470 & 58.116 & 794.426 \\
\hline Najran & 217.462 & 1343.212 & 206.841 & 1336.952 & 37.644 & 489.502 \\
\hline Al Kharj & 312.411 & 1401.421 & 203.278 & 1471.309 & 35.274 & 458.226 \\
\hline Qassim & 209.563 & 1460.484 & 204.152 & 1409.148 & 31.381 & 447.007 \\
\hline Rania & 431.570 & 1382.439 & 206.202 & 1380.345 & 34.043 & 452.648 \\
\hline Yanbu & 391.169 & 1506.218 & 212.428 & 1426.215 & 41.477 & 518.183 \\
\hline Al Khafji & 242.448 & 1566.137 & 216.931 & 1437.252 & 45.804 & 559.698 \\
\hline Farrasan & 351.266 & 1362.207 & 210.426 & 1358.257 & 39.236 & 506.144 \\
\hline Hagl & 327.142 & 1399.219 & 208.209 & 1318.493 & 26.072 & 417.054 \\
\hline Umluj & 254.317 & 1456.214 & 209.423 & 1322.340 & 29.366 & 442.712 \\
\hline Al Jubail & 279.561 & 1329.501 & 215.557 & 1430.194 & 43.091 & 539.328 \\
\hline Shagra & 294.426 & 1357.505 & 218.382 & 1481.233 & 44.556 & 548.090 \\
\hline Tabuk & 238.470 & 1495.281 & 209.123 & 1293.567 & 23.018 & 389.458 \\
\hline Taif & 183.376 & 1359.201 & 211.664 & 1464.614 & 48.091 & 676.006 \\
\hline Timaa & 178.300 & 1407.219 & 213.558 & 1383.173 & 36.773 & 469.336 \\
\hline Wadi Addawasir & 309.152 & 1309.554 & 2.10 .778 & 1496.325 & 39.290 & 512.053 \\
\hline
\end{tabular}


Analyzing the error among the forecasted data by the three selected methods is shown in the table 3.9. MAPE and MSE method could be used to obtain the forecast error. As it is mentioned before, methods that are appropriate for models without trends are better than others. The best method is Multiple Linear Regression with Sin and Cos. Hence, they are chosen to forecast solar irradiation in the future.

Table 3.9 Summarized MSE and MAPE of Three Different Methods (Tabuk City)

\begin{tabular}{|l|c|c|}
\hline Forecasting Method & MSE & MAPE\% \\
\hline Decomposition & 9.172 & 53.403 \\
\hline Multiple Linear Regression & 8.043 & 46.199 \\
\hline Multiple Linear Regression with Sin and Cos & $\mathbf{0 . 8 8 5}$ & $\mathbf{1 3 . 9 1 0}$ \\
\hline
\end{tabular}

Table 3.10 is presented the best MES and the preferred model of solar irradiation for 32 Cities. 
Table 3.10 Summarized MSE and Preferred Model

\begin{tabular}{|c|c|c|}
\hline City & MSE & Preferred Model \\
\hline Afif & 47.210 & $x_{t}=7.15-1.93 \operatorname{Sin} \frac{2 \pi t}{12}-1.77 \operatorname{Cos} \frac{2 \pi t}{12}+\epsilon_{t}$ \\
\hline Al Baha & 55.285 & $x_{t}=7.872-2.294 \operatorname{Sin} \frac{2 \pi t}{12}-2.602 \operatorname{Cos} \frac{2 \pi t}{12}+\epsilon_{t}$ \\
\hline Al Dawadmi & 47.792 & $x_{t}=6.839-2.453 \operatorname{Sin} \frac{2 \pi t}{12}-2.109 \operatorname{Cos} \frac{2 \pi t}{12}+\epsilon_{t}$ \\
\hline Al Hanakiyah & 48.374 & $x_{t}=6.933-2.329 \operatorname{Sin} \frac{2 \pi t}{12}-2.609 \operatorname{Cos} \frac{2 \pi t}{12}+\epsilon_{t}$ \\
\hline Al Qunfudah & 43.268 & $x_{t}=7.44-2.188 \operatorname{Sin} \frac{2 \pi t}{12}-1.953 \operatorname{Cos} \frac{2 \pi t}{12}+\epsilon_{t}$ \\
\hline Al Uyaynah & 45.093 & $x_{t}=7.356-2.745 \operatorname{Sin} \frac{2 \pi t}{12}-2.122 \operatorname{Cos} \frac{2 \pi t}{12}+\epsilon_{t}$ \\
\hline Al Wajh & $\mathbf{5 0 . 5 3 6}$ & $x_{t}=7.773-2.233 \operatorname{Sin} \frac{2 \pi t}{12}-2.920 \operatorname{Cos} \frac{2 \pi t}{12}+\epsilon_{t}$ \\
\hline Arar & 28.226 & $x_{t}=7.207-2.533 \operatorname{Sin} \frac{2 \pi t}{12}-1.844 \operatorname{Cos} \frac{2 \pi t}{12}+\epsilon_{t}$ \\
\hline Duba & 26.382 & $x_{t}=7.611-1.917 \operatorname{Sin} \frac{2 \pi t}{12}-2.806 \operatorname{Cos} \frac{2 \pi t}{12}+\epsilon_{t}$ \\
\hline Hafar Al Batin & 39.264 & $x_{t}=7.866-2.295 \operatorname{Sin} \frac{2 \pi t}{12}-2.003 \operatorname{Cos} \frac{2 \pi t}{12}+\epsilon_{t}$ \\
\hline Jazan & 37.637 & $x_{t}=6.927-1.658 \operatorname{Sin} \frac{2 \pi t}{12}-1.937 \operatorname{Cos} \frac{2 \pi t}{12}+\epsilon_{t}$ \\
\hline Riyadh & 38.584 & $x_{t}=6.657-2.907 \operatorname{Sin} \frac{2 \pi t}{12}-2.635 \operatorname{Cos} \frac{2 \pi t}{12}+\epsilon_{t}$ \\
\hline Jeddah & 43.733 & $x_{t}=5.988-1.848 \operatorname{Sin} \frac{2 \pi t}{12}-1.609 \operatorname{Cos} \frac{2 \pi t}{12}+\epsilon_{t}$ \\
\hline Thuwal & 42.921 & $x_{t}=5.798-1.653 \operatorname{Sin} \frac{2 \pi t}{12}-1.740 \operatorname{Cos} \frac{2 \pi t}{12}+\epsilon_{t}$ \\
\hline Dammam & 48.471 & $x_{t}=7.625-2.193 \operatorname{Sin} \frac{2 \pi t}{12}-2.596 \operatorname{Cos} \frac{2 \pi t}{12}+\epsilon_{t}$ \\
\hline Al Ahsa & 47.850 & $x_{t}=5.681-1.397 \operatorname{Sin} \frac{2 \pi t}{12}-1.732 \operatorname{Cos} \frac{2 \pi t}{12}+\epsilon_{t}$ \\
\hline Majmah & 58.116 & $x_{t}=6.781-2.482 \operatorname{Sin} \frac{2 \pi t}{12}-2.276 \operatorname{Cos} \frac{2 \pi t}{12}+\epsilon_{t}$ \\
\hline
\end{tabular}




\begin{tabular}{|c|c|c|}
\hline Najran & 37.644 & $x_{t}=6.506-2.093 \operatorname{Sin} \frac{2 \pi t}{12}-2.262 \operatorname{Cos} \frac{2 \pi t}{12}+\epsilon_{t}$ \\
\hline Al Kharj & 35.274 & $x_{t}=7.561-2.7321 \operatorname{Sin} \frac{2 \pi t}{12}-2.483 \operatorname{Cos} \frac{2 \pi t}{12}+\epsilon_{t}$ \\
\hline Qassim & 31.381 & $x_{t}=5.368-1.526 \operatorname{Sin} \frac{2 \pi t}{12}-1.164 \operatorname{Cos} \frac{2 \pi t}{12}+\epsilon_{t}$ \\
\hline Rania & 34.043 & $x_{t}=7.075-2.4101 \operatorname{Sin} \frac{2 \pi t}{12}-2.152 \operatorname{Cos} \frac{2 \pi t}{12}+\epsilon_{t}$ \\
\hline Yanbu & 41.477 & $x_{t}=6.651-2.091 \operatorname{Sin} \frac{2 \pi t}{12}-2.167 \operatorname{Cos} \frac{2 \pi t}{12}+\epsilon_{t}$ \\
\hline Al Khafji & 45.804 & $x_{t}=6.374-2.324 \operatorname{Sin} \frac{2 \pi t}{12}-1.946 \operatorname{Cos} \frac{2 \pi t}{12}+\epsilon_{t}$ \\
\hline Farrasan & 39.236 & $x_{t}=5.831-1.329 \operatorname{Sin} \frac{2 \pi t}{12}-1.402 \operatorname{Cos} \frac{2 \pi t}{12}+\epsilon_{t}$ \\
\hline Hagl & 26.072 & $x_{t}=5.840-1.732 \operatorname{Sin} \frac{2 \pi t}{12}-1.466 \operatorname{Cos} \frac{2 \pi t}{12}+\epsilon_{t}$ \\
\hline Umluj & 29.366 & $x_{t}=6.722-2.572 \operatorname{Sin} \frac{2 \pi t}{12}-2.171 \operatorname{Cos} \frac{2 \pi t}{12}+\epsilon_{t}$ \\
\hline Al Jubail & 43.091 & $x_{t}=7.320-2.143 \operatorname{Sin} \frac{2 \pi t}{12}-2.251 \operatorname{Cos} \frac{2 \pi t}{12}+\epsilon_{t}$ \\
\hline Shagra & 44.556 & $x_{t}=5.779-1.683 \operatorname{Sin} \frac{2 \pi t}{12}-1.458 \operatorname{Cos} \frac{2 \pi t}{12}+\epsilon_{t}$ \\
\hline Tabuk & 23.0184 & $x_{t}=7.47614-2.7241 \operatorname{Sin} \frac{2 \pi t}{12}-2.406 \operatorname{Cos} \frac{2 \pi t}{12}+\epsilon_{t}$ \\
\hline Taif & 48.091 & $x_{t}=6.637-2.276 \operatorname{Sin} \frac{2 \pi t}{12}-2.126 \operatorname{Cos} \frac{2 \pi t}{12}+\epsilon_{t}$ \\
\hline Timaa & 36.773 & $x_{t}=7.267-2.398 \operatorname{Sin} \frac{2 \pi t}{12}-2.146 \operatorname{Cos} \frac{2 \pi t}{12}+\epsilon_{t}$ \\
\hline Wadi Addawasir & 39.290 & $x_{t}=5.577-1.832 \operatorname{Sin} \frac{2 \pi t}{12}-1.172 \operatorname{Cos} \frac{2 \pi t}{12}+\epsilon_{t}$ \\
\hline
\end{tabular}




\subsection{Solar Panels}

Looking at the Saudi solar energy production profile, it is apparent that they have made some efforts towards making solar energy known to citizens through various programs. According to King Abdullah University of Science and Technology Industry Collaboration Program (2009), it is evident that solar power projects have been in existence for the past four decades. One of the most successful projects was the Solar Village project in the 1980s, which pursued the establishment of a solar-powered village. While successful, this effort was made on small scales and was soon abandoned due to a lack of interest from neighboring regions.

\subsubsection{Average Solar Radiation in Saudi Arabia}

The amount of available solar irradiation varies across Saudi Arabia. According to Pazheri (2014), this region of the country provides the highest potential in the world when it comes to solar energy production. Pazheri's 2014 study generated the map shown in Figure 3.5, indicating solar irradiation in different parts of Saudi Arabia.

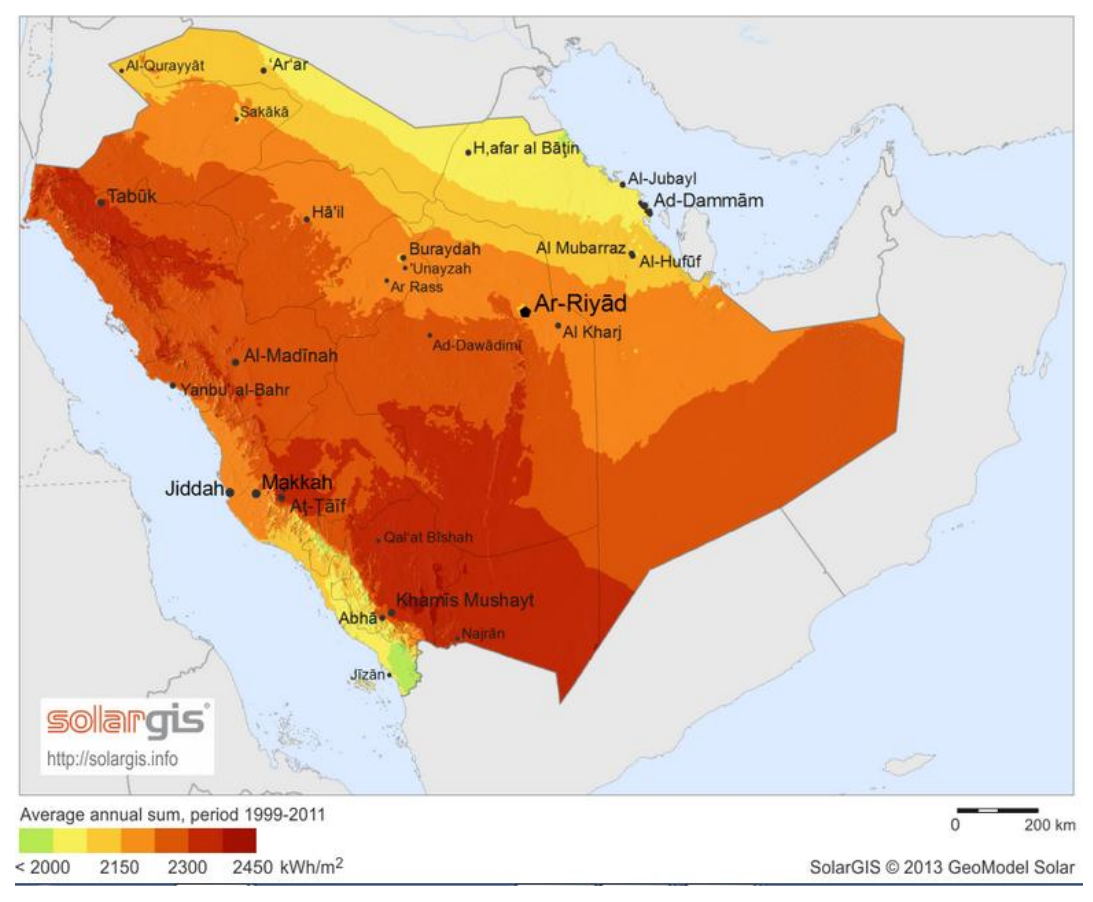

Figure 3.5 Map showing solar irradiation in different parts of Saudi Arabia (Pazheri, 2014) 


\begin{tabular}{|c|c|c|c|}
\hline \multirow[t]{2}{*}{ City } & \multicolumn{3}{|c|}{$\mathrm{kWh} / \mathrm{m}^{2} / \mathrm{day}$} \\
\hline & Average & Maximum & Minimum \\
\hline Afif & 6.24 & 10.1 & 0.04 \\
\hline Al Aflaaj & 5.98 & 9.56 & 0.26 \\
\hline Al Baha & 7.54 & 10.21 & 1.01 \\
\hline Al Dawadmi & 6.12 & 10.39 & $\mathbf{0}$ \\
\hline Al Hanakiyah & 6.36 & 10.99 & $\mathbf{0}$ \\
\hline Al Jouf & 5.17 & 7.99 & 0.22 \\
\hline Al Qunfudah & 4.53 & 8.19 & 0.02 \\
\hline Al Uyaynah & 5.76 & 10.34 & 0.01 \\
\hline Al Wajh & 6.71 & 10.3 & 0.07 \\
\hline Arar & 4.92 & 9.19 & 0.08 \\
\hline Duba & 7.06 & 10.66 & 0.03 \\
\hline Hafar Al Batin & 5.56 & 10.38 & $\mathbf{0}$ \\
\hline Jazan & 4.51 & 6.82 & 0.45 \\
\hline Riyadh & 5.97 & 10.27 & $\mathbf{0}$ \\
\hline Jeddah & 5.15 & 9.33 & 0.1 \\
\hline Thuwal & 5.46 & 9.6 & 0.01 \\
\hline Dammam & 5.44 & 10.08 & $\mathbf{0}$ \\
\hline Al Ahsa & 5.49 & 9.72 & $\mathbf{0}$ \\
\hline Majmah & 5.86 & 10.37 & $\mathbf{0}$ \\
\hline Najran & 6.59 & 10.37 & 0.01 \\
\hline Al Kharj & 5.55 & 9.2 & 0.02 \\
\hline Qassim & 6.1 & 10.27 & $\mathbf{0}$ \\
\hline Rania & 6.68 & 9.65 & 0.26 \\
\hline Yanbu & 5.65 & 8.52 & 0.5 \\
\hline Al Khafji & 4.81 & 8.4 & 0.19 \\
\hline Farrasan & 4.46 & 7.11 & 0.29 \\
\hline Hagl & 6.9 & 11.15 & $\mathbf{0}$ \\
\hline Umluj & 6.33 & 10.17 & $\mathbf{0}$ \\
\hline Al Jubail & 5.39 & 9.93 & $\mathbf{0}$ \\
\hline Shagra & 5.95 & 10.07 & 0.01 \\
\hline Tabuk & 7.09 & 11.27 & 0 \\
\hline Taif & 6.47 & 11.1 & 0.19 \\
\hline Timaa & 7.07 & 10.38 & $\mathbf{0}$ \\
\hline $\begin{array}{l}\text { Wadi } \\
\text { Addawasir }\end{array}$ & 6.18 & 9.68 & 0.06 \\
\hline
\end{tabular}




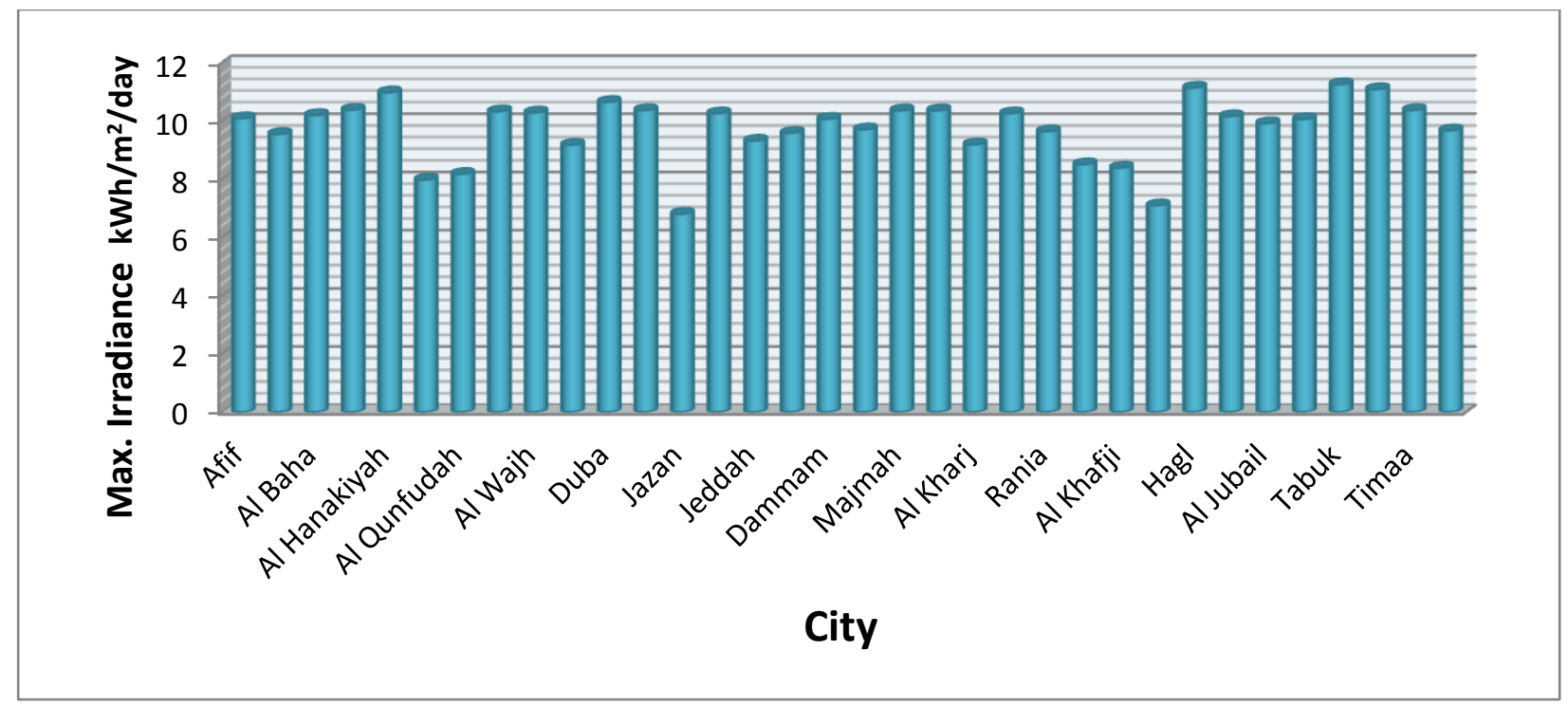

Figure 3.6 Direct Normal Irradiance for Some Cities (K.A.CARE

From the map, it is clear that the regions of Tabuk, Hagl, and Taif receive the highest irradiation levels; hence, they are best suited for the installation of solar energy.

\subsubsection{Cost of Solar Panels}

Determining the cost of solar panels is market-dependent, since costs reflect consumption of solar as a preferred choice of energy supply. In this regard, Shahan (2014) asserts that determining the cost of solar power can sometimes be a difficult task because of various energy industry factors that influence the cost on a regional basis. Shahan (2014) provides a realistic estimate of the cost of solar panel installations per watt of electricity generated. Figure 3.7 demonstrates the trend of decreasing price for crystalline Si from 1977 to 2013. 


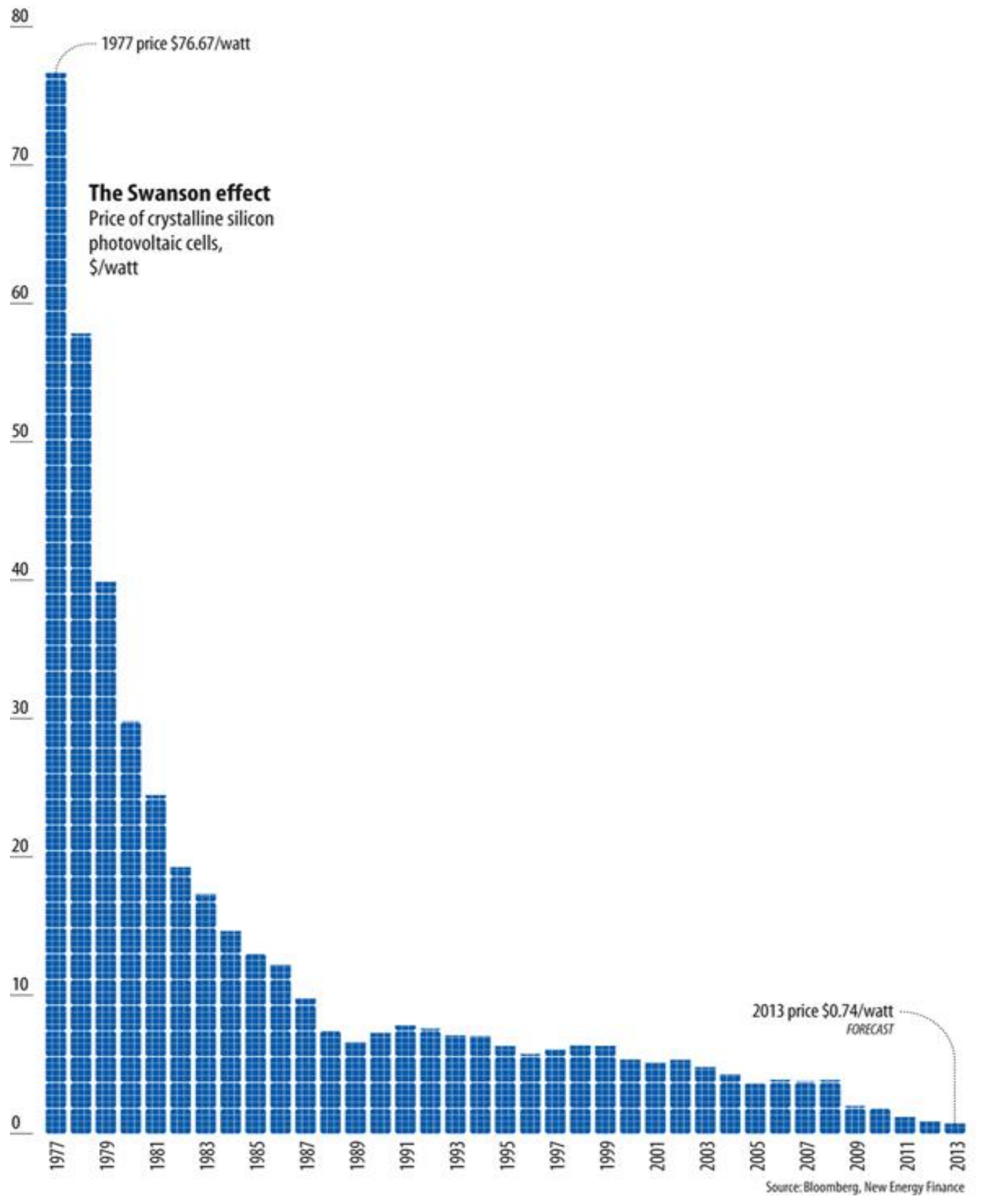

Figure 3.7 Solar Panels Costs (1977-2013) (Shahan, 2014).

Crystalline Si solar panel cost per watt of electricity generated between 1977 and 2013 (Shahan, 2014). 
Using this estimate, it is possible to determine the cost of solar panels required based on the projected watt capacity targeted by a specific solar project. From the graph, it is evident that in 2013 the average cost was US\$0.74 per watt of solar electricity generated.

According to The International Renewable Energy Agency,2015 (IRENA) database, the cost of installation solar power systems has gone down dramatically since 2008, leading to increasing affordability and exponential growth across different countries. The data presented in Figure 3.8 below shows the average cost of solar power system installation between 2006 and 2014 in different developed nations.

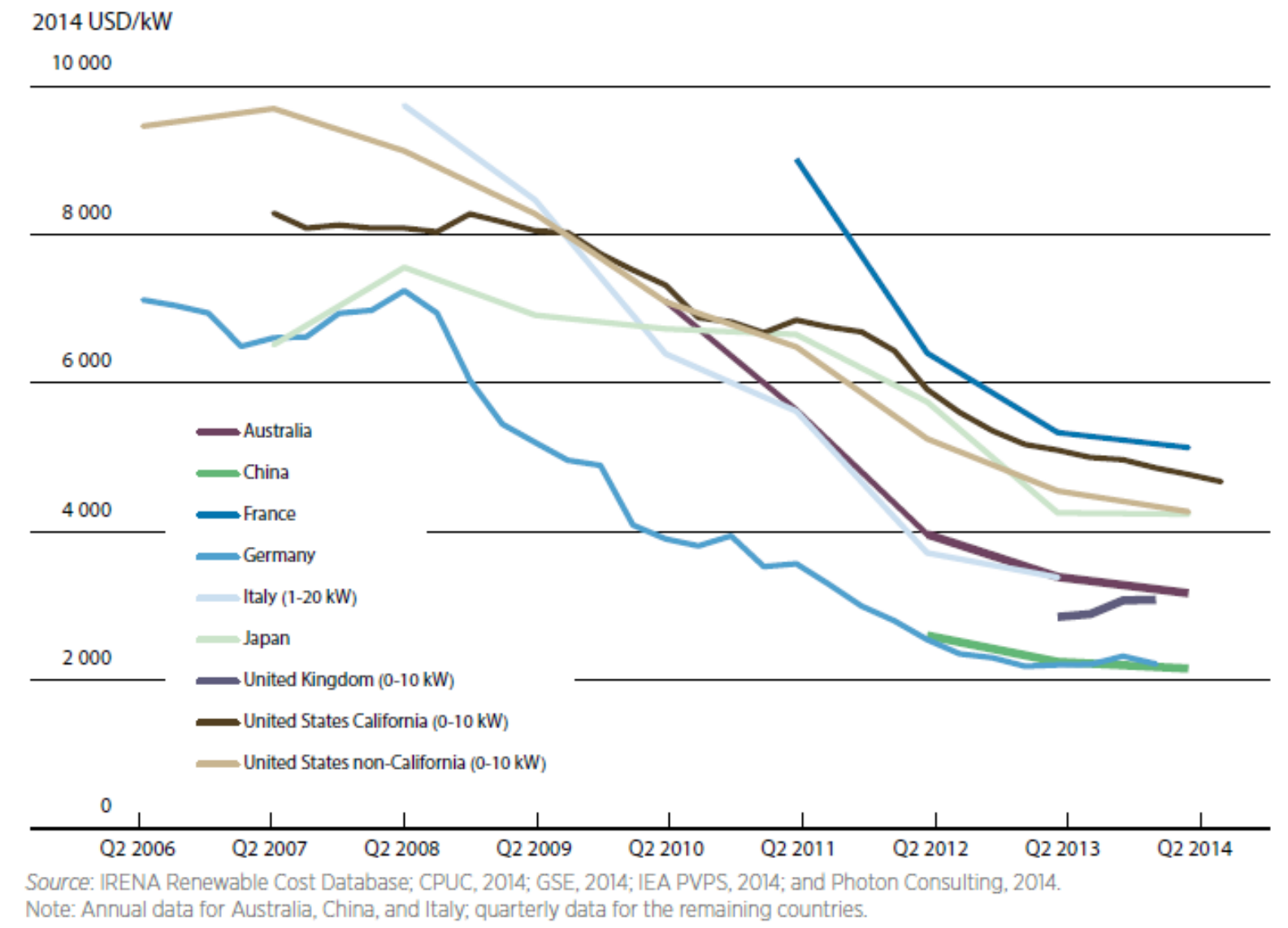

Figure 3.8 Renewable Costs (2006-2014) (International Renewable Energy Agency, 2015) 


\subsubsection{Number of Solar Panels for a Solar Panel Farm}

For a solar panel farm, solar panels are usually arranged in the form of parabolic trough collectors. This is the system that has been installed in some solar panel farms in the Middle East region. Table 3.12 provides a breakdown of the associated civil and structural, solar field and showing share in percentage for different components during solar energy production (International Renewable Energy Agency, 2015).

Table 3.12 Showing share in percentage for different components during solar energy production

\begin{tabular}{|l|c|}
\hline & Share in percent (\%) \\
\hline Civil and Structural & 5 \\
\hline Solar field preparation and solar field work & 1 \\
\hline Solar collector pylon foundations & 2 \\
\hline Power block and balance of plant structures & 2 \\
\hline Solar Field & 64 \\
\hline Health collector elements (HCE) & 10 \\
\hline Reflectors & 14 \\
\hline Metal support structures & 20 \\
\hline Drivers, electronic and controls & 2 \\
\hline Heat transfer fluid (HTF) piping between collectors & 1 \\
\hline HTF header piping & 2 \\
\hline HTF fluid initial filling & 3 \\
\hline Transport, erection, and commissioning & 11 \\
\hline Heat transfer fluid system, including solar heat exchangers & 9 \\
\hline HTF heat exchangers and tanks & 5 \\
\hline HTF pumps & 2 \\
\hline Transport, erection, and commissioning & 2 \\
\hline Power Block & 23 \\
\hline Steam turbine generators & 7 \\
\hline Cooling system including condenser & 7 \\
\hline Fuel gas system including backup & 1 \\
\hline Balance of plant & 0 \\
\hline Waste water treatment & 1 \\
\hline Fire protection & 4 \\
\hline Electrical and installation & 2 \\
\hline Transport, erection and commissioning and other & 2 \\
\hline TOTAL & 100 \\
\hline
\end{tabular}


The information provided shows that in the case of commercialized solar energy production where a large solar panel farm is to be established, the total costs will directly be influenced by individual costs incurred focusing on the different components during actual installation. This is useful because it provides a meaningful explanation on why it is difficult to come up with specific cost ranges since this will put demand on the country where it will be installed.

\subsubsection{Electricity Produced per Solar Panel}

According to Geoscience Australia et al. (2013), the amount of electricity produced per solar panel depends on the peak solar irradiation time. During low irradiation times, the amount of electricity generated is not the same as during high irradiation times. Consequently, Liorens (2012) remarks that a typical solar panel produces an average of $200 \mathrm{~W}$ per day, but this depend on the efficiency and the size of solar panel being used. Liorens adds that 25 panels can produce a $5 \mathrm{kWh}$ array. However, according to Solar Choice Staff (2010), Energy Australia places the output at 3.84-4 kWh, while the Office of the Renewable Energy Regulator provides a figure of $3.79 \mathrm{kWh}$ for Sydney. This disagreement implies that it may not be possible to precisely predict

the output that can be generated from a solar cell array. Figure 3.9 below provides an estimate of solar energy generated using solar panels in different parts of the world. 


\begin{tabular}{|c|c|c|c|c|}
\hline & unit & $\begin{array}{l}\text { Australia } \\
2007-08\end{array}$ & $\begin{array}{l}\text { OECD } \\
2008\end{array}$ & $\begin{array}{l}\text { World } \\
2007\end{array}$ \\
\hline Primary energy consumption" & PJ & 6.9 & 189.4 & 401.8 \\
\hline Share of total & $\%$ & 0.12 & 0.09 & 0.08 \\
\hline Average annual growth, from 2000 & $\%$ & 7.2 & 4.3 & 9.6 \\
\hline \multicolumn{5}{|l|}{ Electricity generation } \\
\hline Electricity output & TWh & 0.1 & 8.2 & 4.8 \\
\hline Share of total & $\%$ & 0.04 & 0.08 & 0.02 \\
\hline Average annual growth, from 2000 & $\%$ & 26.1 & 36.3 & 30.8 \\
\hline Electricity capacity & GW & 0.1 & 8.3 & 14.7 \\
\hline
\end{tabular}

a Energy production and primary energy consumption are identical

Source: IEA 2009b; ABARE 2009a; Watt 2009; EPIA 2009

Figure 3.9 Energy Production (Geoscience Australia et al, 2013)

\subsection{Wind Turbines}

\subsubsection{Average Speed and Strength of Wind in Saudi Arabia}

In his research study, Khonkar (2009) conducted a complete survey of the wind behavior of the geographic region covering the Persian Gulf. The survey included data from three major regions of Saudi Arabia, namely Dahran, Riyadh, and Jeddah, between 1978 and 2007. This is shown below in Figure 3.10. 
Mean Monthly Wind Speed From 1978-2007

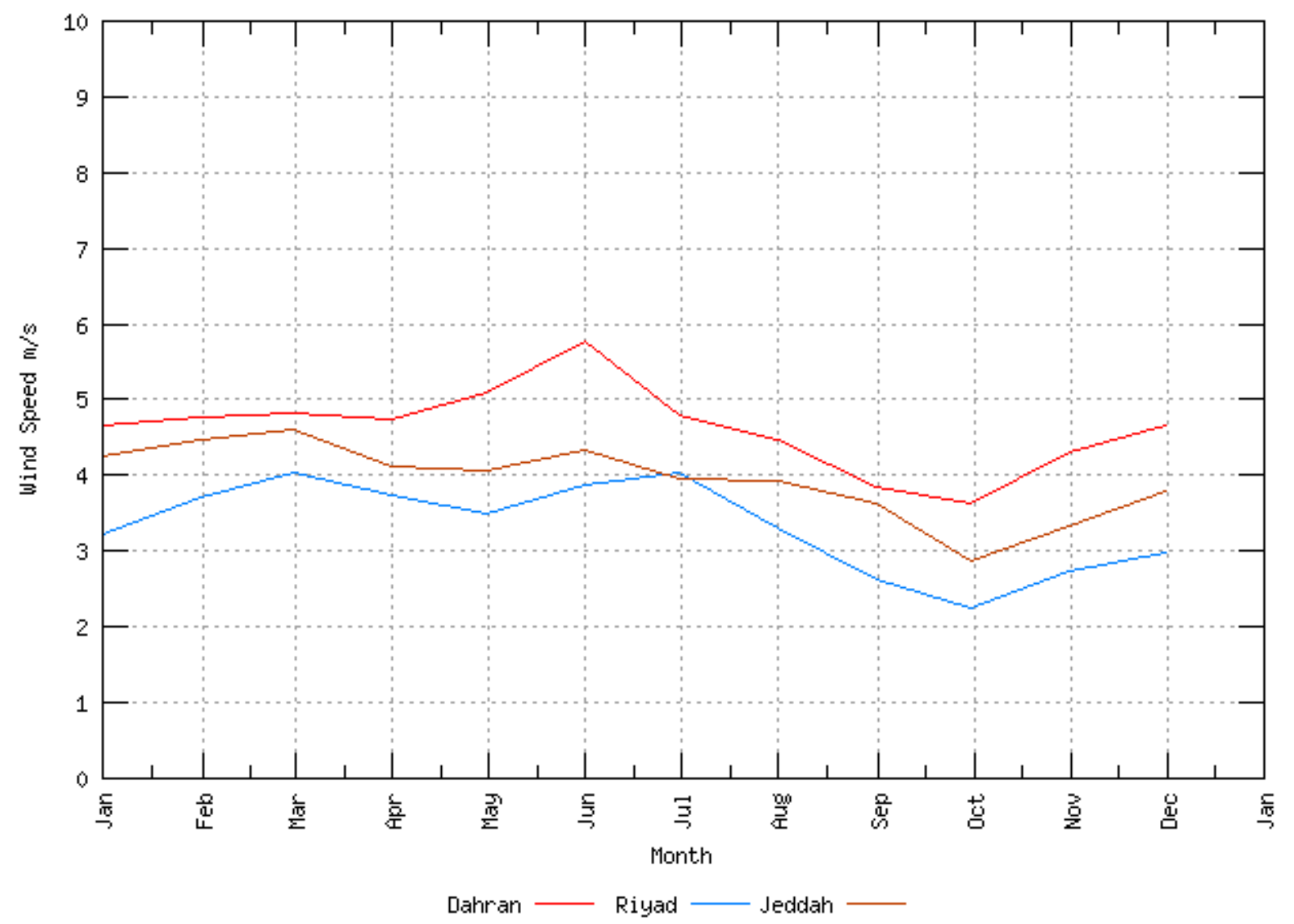

Figure 3.10 Average Speed and Strength of Wind (Dahran, Riyadh, and Jeddah) 
Table 3.13 Average Wind Speed (Some Parts of KSA) (K.A.CARE 2015)

\begin{tabular}{|l|c|}
\hline \multicolumn{1}{|c|}{ City } & Avg. Wind Speed \\
\cline { 2 - 2 } & At 3m $(\mathbf{m} / \mathbf{s})$ \\
\hline Afif & $\mathbf{3 . 7 4 4}$ \\
\hline Al Baha & $\mathbf{2 . 4}$ \\
\hline Al Dawadmi & $\mathbf{2 . 9 2 1}$ \\
\hline Al Hanakiyah & $\mathbf{3 . 2 3 3}$ \\
\hline Al Qunfudah & $\mathbf{2 . 7 6 1}$ \\
\hline Al Uyaynah & $\mathbf{3 . 1 5 2}$ \\
\hline Al Wajh & $\mathbf{2 . 7 8 9}$ \\
\hline Arar & $\mathbf{3 . 1 6 7}$ \\
\hline Duba & $\mathbf{2 . 4 2 1}$ \\
\hline Hafar Al Batin & $\mathbf{4 . 5 9 4}$ \\
\hline Jazan & $\mathbf{3 . 1 2 5}$ \\
\hline Riyadh & $\mathbf{2 . 2 5}$ \\
\hline Jeddah & $\mathbf{3 . 4 5 7}$ \\
\hline Thuwal & $\mathbf{2 . 4 3 8}$ \\
\hline Dammam & $\mathbf{1 . 9 7 6}$ \\
\hline Al Ahsa & 2.03 \\
\hline Majmah & $\mathbf{3 . 6 2 3}$ \\
\hline Najran & $\mathbf{2 . 0 8 6}$ \\
\hline Al Kharj & $\mathbf{2 . 3 4 7}$ \\
\hline Qassim & $\mathbf{2 . 5 4 7}$ \\
\hline Rania & 2.9 \\
\hline Yanbu & 3 \\
\hline Al Khafji & $\mathbf{3 . 5 3 3}$ \\
\hline Farrasan & $\mathbf{3 . 5 1 6 7}$ \\
\hline Hagl & $\mathbf{6 . 2 8 9}$ \\
\hline Umluj & $\mathbf{3 . 2 1 1}$ \\
\hline Al Jubail & $\mathbf{3 . 7 2 2}$ \\
\hline Shagra & $\mathbf{1 . 9 6 8}$ \\
\hline Tabuk & $\mathbf{2 . 4 1 3}$ \\
\hline Taif & $\mathbf{2 . 5 3 1}$ \\
\hline Timaa & $\mathbf{2 . 3 2 6}$ \\
\hline Wadi Addawasir & $\mathbf{2 . 6 1 6}$ \\
\hline & \\
\hline
\end{tabular}




\section{Avg Wind Speed}

\begin{tabular}{|c|c|c|c|c|}
\hline Afif & Al Baha & Al Dawadmi & Al Hanakiyah & Al Qunfudah \\
\hline Al Uyaynah & Al Wajh & Arar & Duba & - Hafar Al Batin \\
\hline - Jazan & Riyadh & Jeddah & - Thuwal & Dammam \\
\hline Al Ahsa & Majmah & Najran & Al Kharj & Qassim \\
\hline Rania & Yanbu & Al Khafji & Farrasan & $\square \mathrm{Hagl}$ \\
\hline Umluj & Al Jubail & Shagra & Tabuk & Taif \\
\hline Timaa & Wadi Adc & & & \\
\hline
\end{tabular}

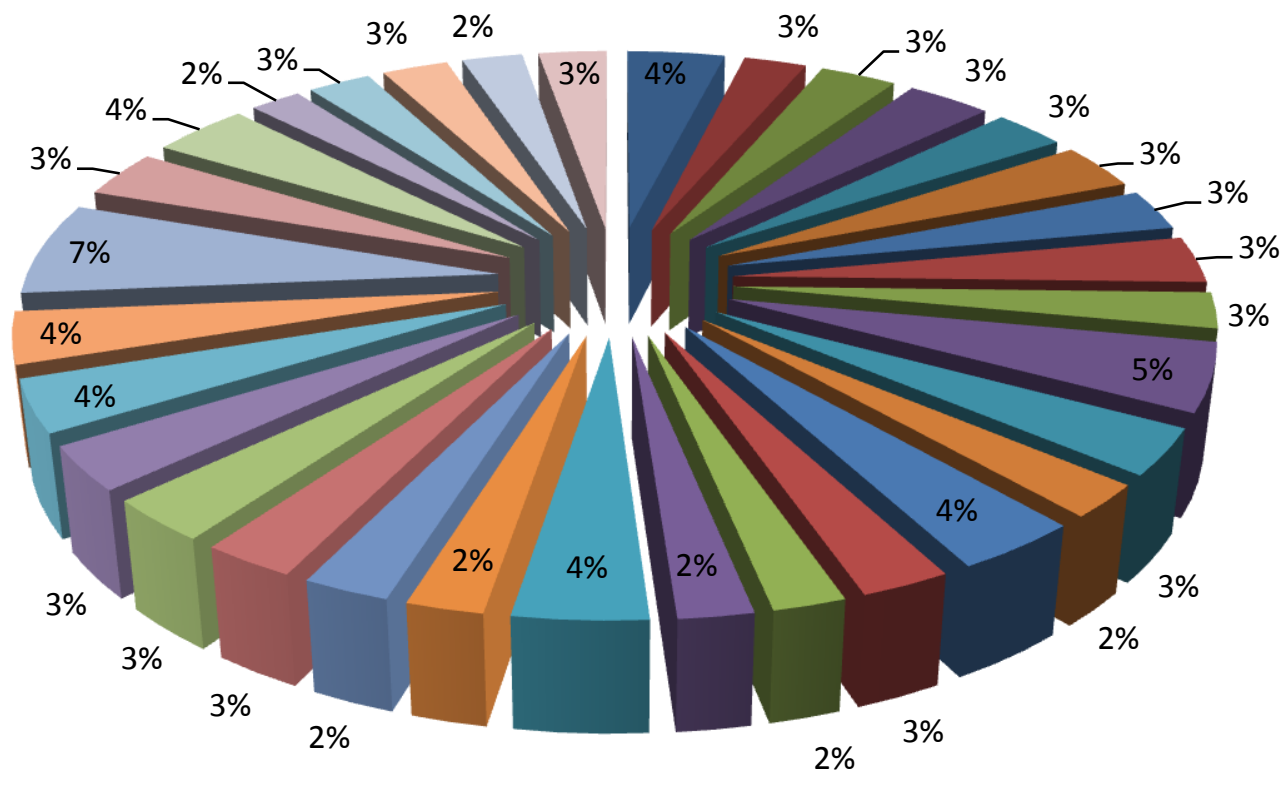

Figure 3.11 Average Wind Speed (Some Parts of KSA)

Figure 3.11 shows the percent of the average wind speed in some parts of Saudi Arabia.

\subsubsection{Cost of Wind Turbines and Setup}

The estimated cost of wind turbines and setup has generally been based on the offshore establishment costs in different parts of the world. For the Middle East region, this can be based on the rest of the world parameters, or potentially China given its proximity to the Middle East region, and in particular Saudi Arabia. 


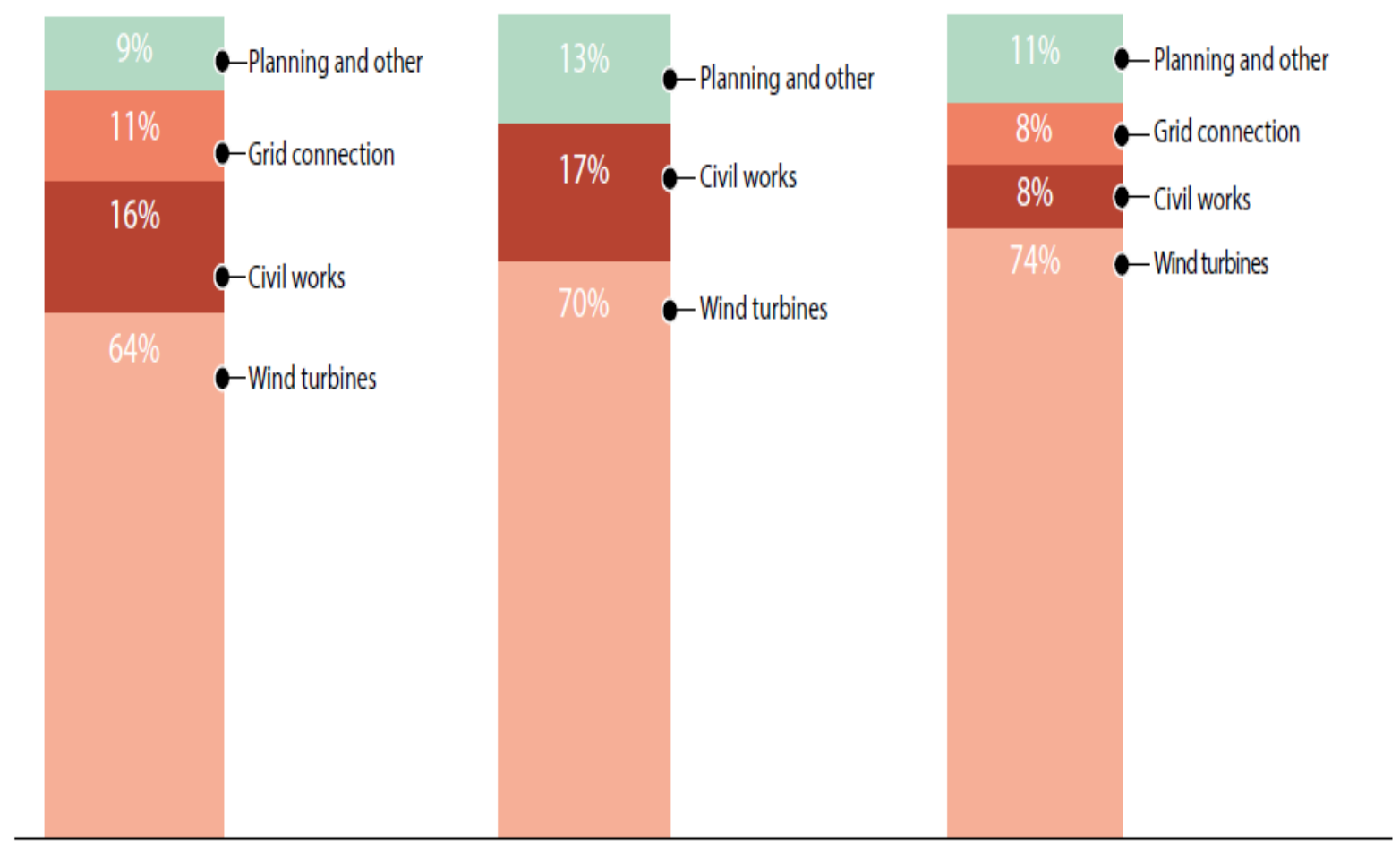

Figure 3.12 New capacity additions in 2013 and cumulative installed capacity at the end of 2013 by country (International Renewable Energy Agency, 2015)

Additionally, it will be important to consider the scale of a wind farm since there are wind farms that have been previously installed to generate power exceeding $5 \mathrm{MW}$, and those that can generate as high as $20 \mathrm{MW}$. This introduces some variation in terms of the costs involved. Figure 
3.13 shows the costs associated with small-scale $(<5$ MW $)$ wind farms.

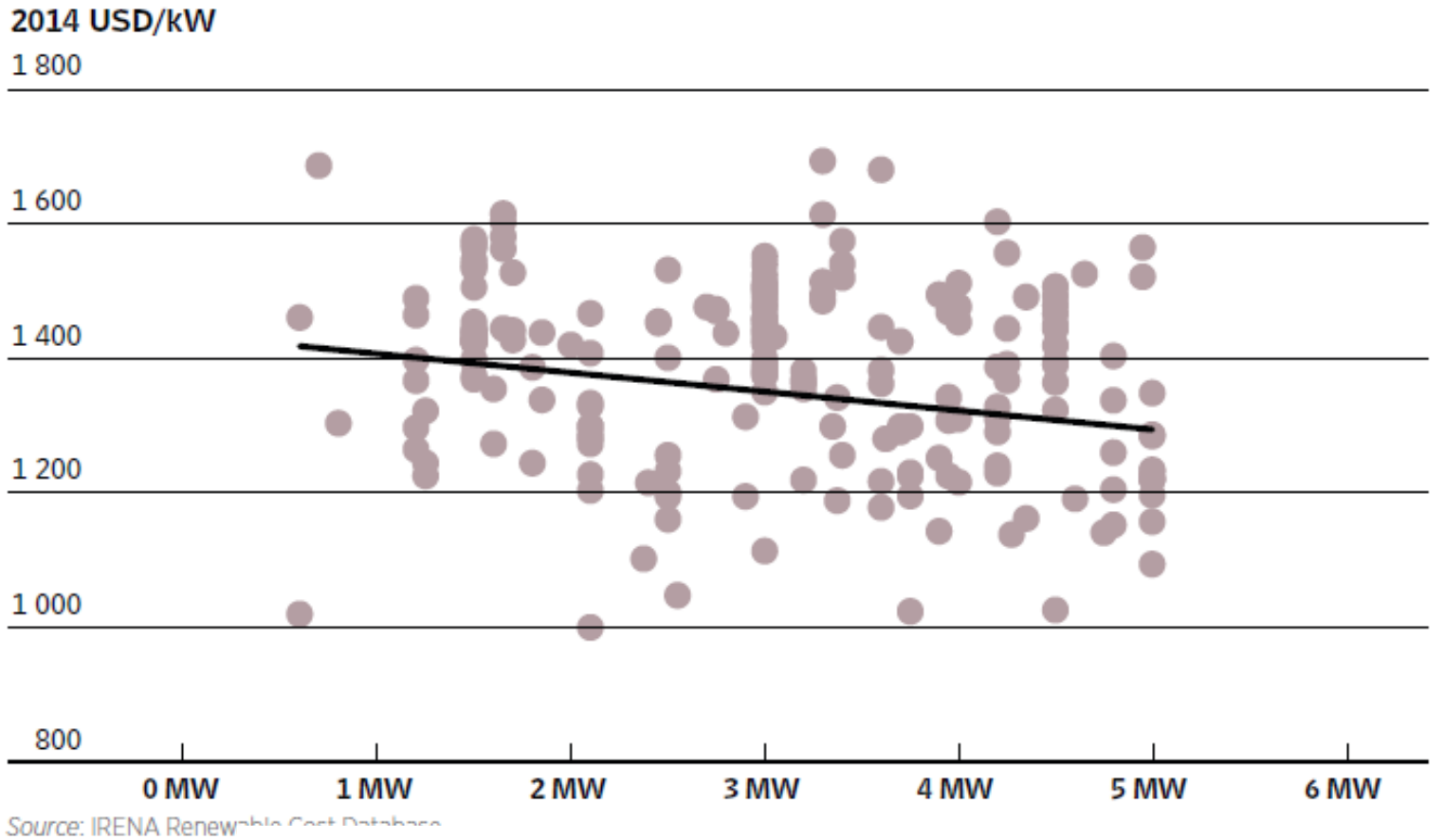

Figure 3.13 Power produced in MW (International Renewable Energy Agency, 2015)

\subsubsection{Solar Panel Required for Farm of Wind Turbines}

According to Annuk et al. (2011), the installation of an integrated wind-solar green energy production system has been found to increase the efficiency with which is the required energy output is achieved. Consequently, based on the model applied in this study, a single solar panel can be installed per small capacity wind turbine. This can change when the system installed is robust and requires relatively more installations to be made. This means that achieving a sustainable solar production level that can be transmitted to different areas, using a blended approach will likely yield a better outcome for profitability. This will also take into account the seasonality aspect experienced in different renewable energy settings. Seasonality 
here refers to varying degrees of solar irradiation and wind energy, necessitating a blended approach.

\subsubsection{Electricity Produced by a Wind Turbine}

In order to determine the electricity produced by a typical wind turbine, a number of factors must be considered. These include the capacity of the wind turbine and the average wind speed generated per hour in the area of reference. According to the National Wind Watch Inc. (2015), a typical 1.5 MW model wind turbine produced by General Electric can produce 2-3 MW of electricity when the wind speed is from 27-56 mph. This data is supported by Global Wind Day, which puts the figure at 2.5-3 MW for a typical wind turbine in such conditions.

\subsection{Transmission Lines}

\subsubsection{Cost of Transmission Lines}

The estimates provided for this section will be retrieved from Wartsila, leading manufacturing and energy Installations Company in Finland, specifically looking at estimates provided for the year 2011. The cost of building a transmission line will largely depend on the model adopted for transmission. In the case of a tunnel transmission system, there will be fixed and variable costs associated with tunnel and shaft construction, tunnel boring machine costs, and overheads. According to Juho (2011), the cost of a transmission line will depend on whether it is an overhead or underground system. For the overhead system, there are single, double, and multiple circuits, all of which affect the cost of transmission.

Alonso and Greenwell (2013) assert that the cost of an underground system is significantly higher than the cost of an overhead system. This is mainly associated with the 
trenching costs that make up the difference in the underground system. Table 3.14 compares the cost of these two transmission systems for different voltage lines.

Table 3.14 Comparison between overhead and underground transmission costs (Alonso \& Greenwell, 2013)

\begin{tabular}{|l|c|c|}
\hline Type & Overhead transmission & Underground transmission \\
\hline $\begin{array}{c}69 \mathrm{kV} \text { single circuit } \\
\text { transmission line }\end{array}$ & $\$ 285,000$ per mile & $\$ 1.5$ million per mile \\
\hline $138 \mathrm{kV}$ & $\$ 390,000$ per mile & $\$ 2$ million per mile \\
\hline
\end{tabular}

Juho (2011) provides other substantive cost estimates for an overhead system, which would be the ideal choice in a solar energy mechanism. According to these estimates, the costs for an overhead system will vary depending on the height of the tower. Juho adds that there are other costs associated with the civil construction process, such as earth excavation, earth filing, boxing work, concrete, iron fitting, land clearing costs (depending on density of vegetation), engineering costs, and commissioning costs. Juho's illustration of the component costs for a typical transmission line can be seen in Figure 3.14. 


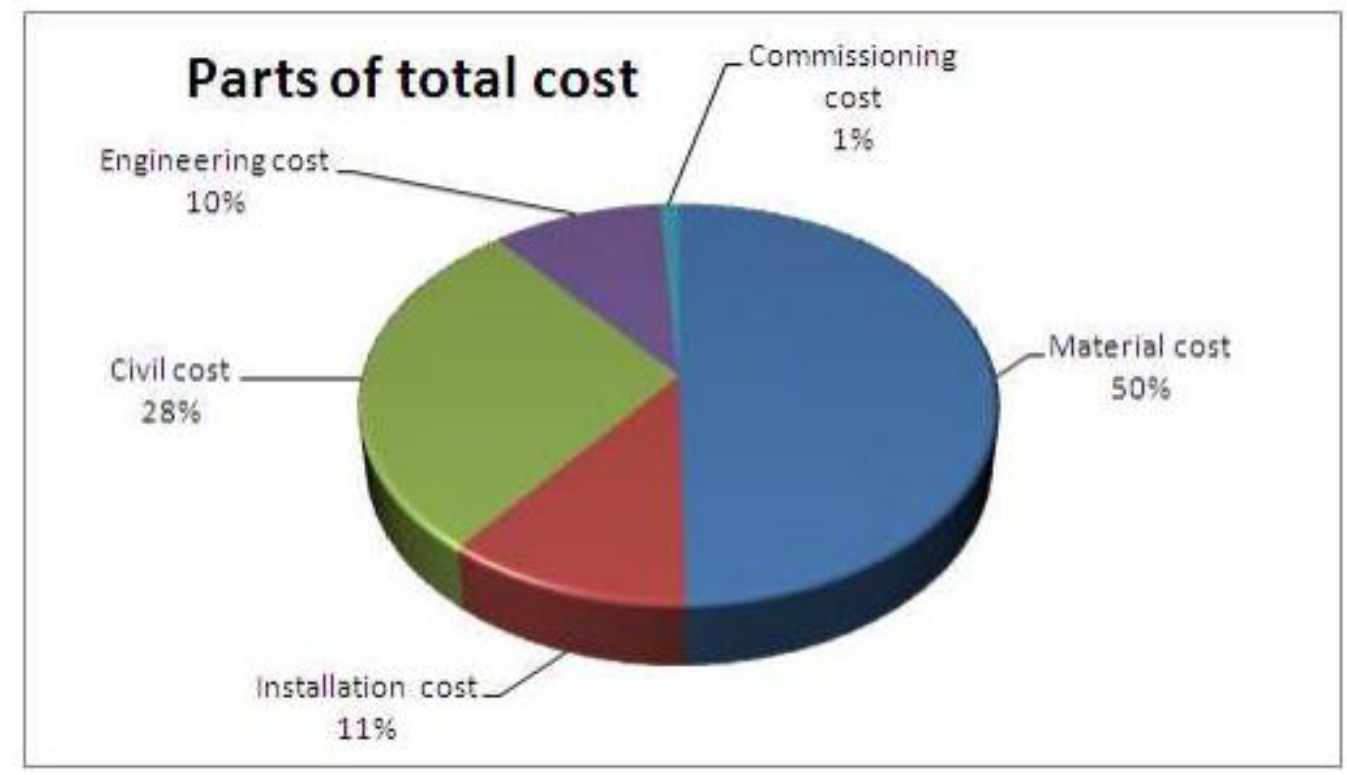

Figure 3.14 Transmission cost estimate components for an 8 km

transmission (Juho, 2011)

Figure 3.15 below shows the prices for different voltage models at a constant line length of 10 $\mathrm{km}$. 


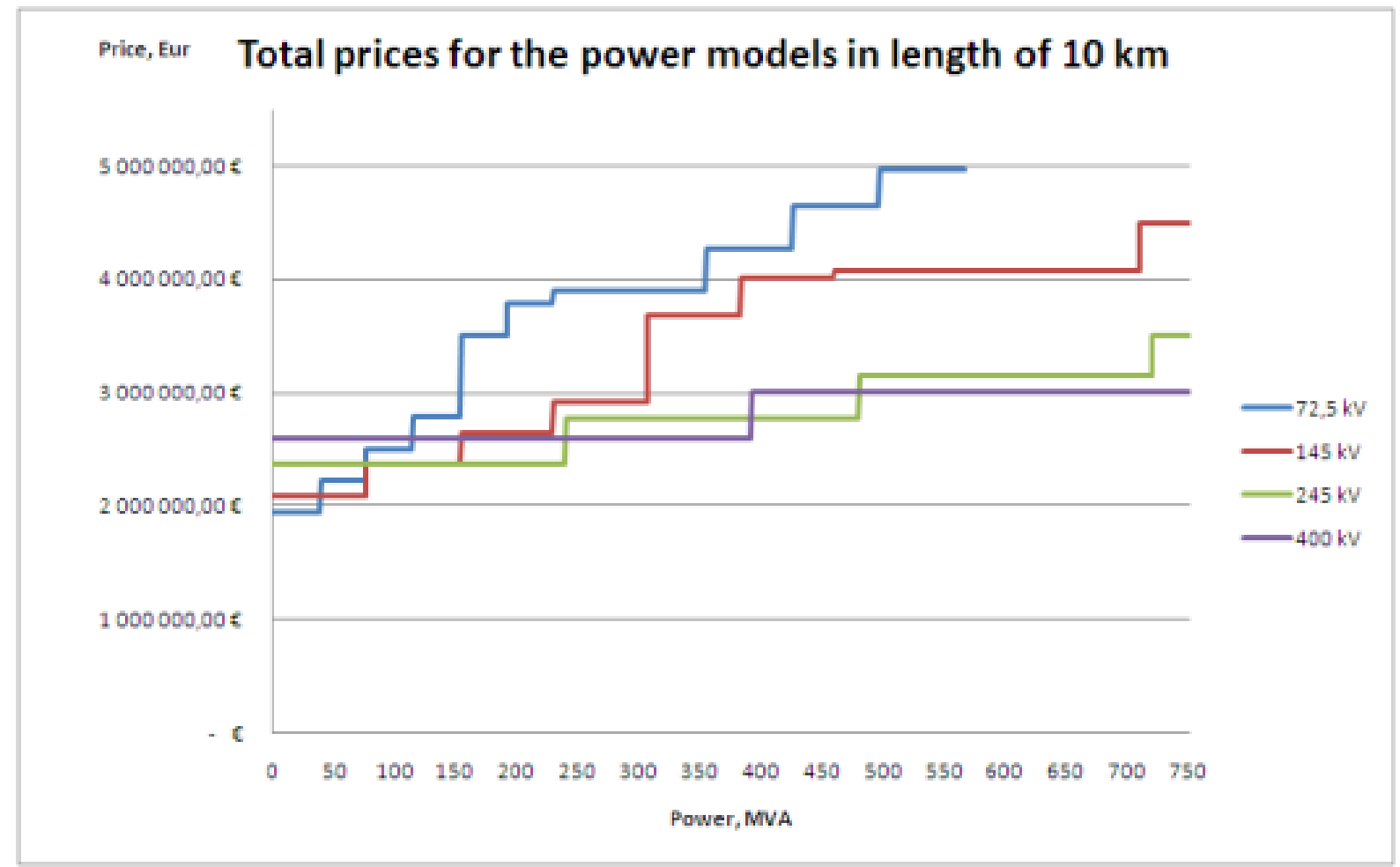

Figure 3.15 Price for the Power Models (Juho, 2011) 
Figure 3.16 is an illustration of the cost per $\mathrm{km}$ and total costs for a $72.5 \mathrm{kV}$ and $0-38 \mathrm{MVA}$.

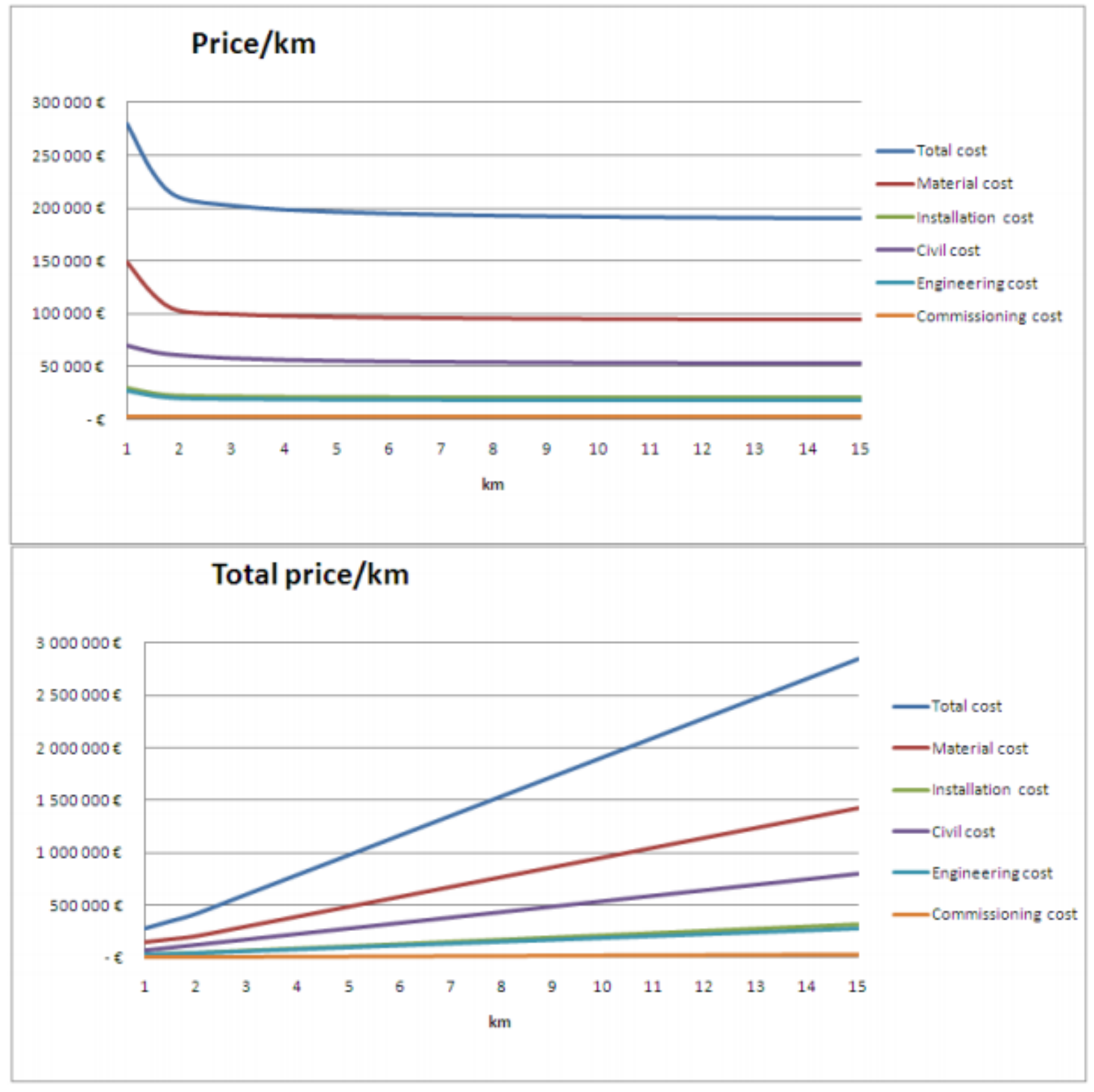

Figure 3.16 Cost per Kilometer and Total Costs (Juho, 2011) 


\subsubsection{Transfer of Electricity through Transmission Lines to Consumers}

The transfer of electricity through the transmission lines to consumers should be done by pursuing a model that lowers the civil, material, engineering, and commissioning costs associated with the transmission line. This should take into consideration the load, which will be determined by the number of consumers to be connected. It should also consider the uses for which the generated electricity will be used (e.g., residential or industrial), as each may have different needs of the system. 


\section{CHAPTER 4}

\section{MODELING}

\subsection{SOLAR POWER SYSTEMS}

Solar power is an example of a renewable source of energy that has been in used for quite some time. The invention of photovoltaic solar panels enabled the large-scale production of electric power using solar energy. With the increasingly politicized discussion surrounding the use of fossil fuel around the world, solar power has gained significant attention as an alternative clean and efficient source of energy that can reduce the impact of global warming and climate change.

Despite the fact that solar power systems require no fuel, there has not been widespread residential adoption, largely due to the high initial investment capital required to set up the system. Additionally, solar power systems depend on the availability of sunlight, which may not abundant in certain parts of the world, hence limiting the usefulness of solar power. For people wishing to invest in solar power, however, it is important to understand exactly what it costs to have a solar power system installed in their homes. Various models have been suggested to predict the cost of solar system installation. The most commonly used model is the Levelised Cost of Electricity (LCOE) generation model, which can be used to calculate the cost of installation of all renewable sources of energy (IRENA, 2012).

\subsubsection{Modeling of Photovoltaic Generator}

The model makes use of the available information on solar radiation, ambient temperatures and manufacturer data for the photovoltaic modules. Using this information and 
model input, the power output of the photovoltaic generator $\mathrm{P}_{\mathrm{PV}}$, can be calculated using the following equation:

$$
P_{P V}=\eta_{g} N A_{m} G_{t}
$$

Here $\eta_{\mathrm{g}}$ represents the instantaneous PV generator efficiency, $A_{m}$ is the area of a single module $\mathrm{inm}^{2}, \mathrm{G}_{\mathrm{t}}$ is the global irradiance incident on the titled plane in $\mathrm{W} / \mathrm{m}^{2}$ and $\mathrm{N}$ is the number of modules. The model assumes that there is zero loss of energy in the system.

The instantaneous efficiency of the generator can be calculated using the equation below:

$$
\eta_{g}=\eta_{r} \eta_{p t}\left[1-\beta_{t}\left(T_{c}-T_{r}\right)\right]
$$

Where $\eta_{\mathrm{r}}$ is the reference efficiency of the PV generator, $\eta_{p t}$ is the efficiency of the power tracking equipment (which is equal to 1 if a perfect maximum power point tracker is used), $\mathrm{T}_{\mathrm{c}}$ is the temperature of the PV cell in Celsius, $T_{r}$ is the PV cell reference temperature and $\beta_{t}$ is the temperature coefficient of efficiency, ranging from 0.004 to 0.006 per ${ }^{\circ} \mathrm{C}$ for silicon cells. Based on the energy balance proposed by Duffie et al. (1991), the PV cell temperature can be expressed as follows:

$$
T_{c}=T_{a}+G_{t}\left(\frac{\tau \alpha}{U_{L}}\right)
$$

where, $T_{a}$ is the ambient temperature in Celsius, $\mathrm{U}_{\mathrm{L}}$ is the overall heat loss coefficient in $\mathrm{W}$ per $\mathrm{m}^{2}$ per ${ }^{\circ} \mathrm{C}, \tau$ represents the transmittance coefficient of the PV cells and $\alpha$ represents the absorption coefficient of PV cells. The overall heat loss coefficient $\left(\tau \alpha / \mathrm{U}_{\mathrm{L}}\right)$ can be estimated from the nominal operating cell temperature (NOCT) as follows (Duffie et al., 1991): 


$$
\left(\frac{\tau \alpha}{\mathrm{U}_{\mathrm{L}}}\right)=\frac{\mathrm{NOCT}-20}{800}
$$

The instantaneous efficiency of the PV generator can therefore be expressed as follows:

$$
\eta_{\mathrm{g}}=\eta_{\mathrm{r}} \eta_{\mathrm{pt}}\left\{1-\beta_{\mathrm{t}}\left(\mathrm{T}_{\mathrm{a}}-\mathrm{T}_{\mathrm{r}}\right)-\beta_{\mathrm{t}} \mathrm{G}_{\mathrm{t}}\left(\frac{\mathrm{NOCT}-20}{800}\right)\left(1-\eta_{\mathrm{r}} \eta_{\mathrm{pt}}\right)\right\} .
$$

The parameters $\eta_{\mathrm{pt}}, \beta_{\mathrm{t}}$, NOCT and $\mathrm{A}_{\mathrm{m}}$ depend on the type of module, and are given by the manufacturer.

\subsubsection{Estimation of the Number of Panels Needed in a Solar Power System}

When installing a solar power system for residential or industrial use, it is important to know exactly how many solar panels are needed. This can give an idea about the total cost likely to be incurred in assembling the system. The following formula can be used in estimating the number solar panels required for a solar system installation:

Number of solar panels $=$ solar radiation power $\times$ surface area of panels

$$
\text { in } \mathrm{m}^{2} \times \text { efficiency } \times \text { average days per month }
$$

An average of $4.5 \mathrm{kWh} / \mathrm{m}^{2} /$ day of solar radiation is commonly used for the United States. However, the values for every state are available in a map provided by the National Renewable Energy Laboratory (NREL) Resource Assessment Program. Most solar panels work at efficiencies of 7-17\%. To fully cover a monthly power usage of $1000 \mathrm{~kW}$, divide 1000 by the figure obtained from equation 6.

\section{$\underline{\text { Example }}$}

For a radiation power of $5 \mathrm{kWh} / \mathrm{m}^{2} /$ day, and a panel with a surface area of $2 \mathrm{~m}^{2}$, the number of panels needed is calculated as follows, assuming an efficiency of $7 \%$ :

$$
5 \times 2 \times 0.07 \times 30.42 \times(365 / 12)=21.294
$$


No. of panels $=1000 / 21.294=46.96$, which must be rounded up to 47 .

Thus we see that 47 panels of this size are needed to completely cover electricity needs.

\subsubsection{Estimation of the Cost of Solar Power}

Despite the efficiency offered by modern solar power systems, many people throughout the world do not know what it costs to install a solar power system in their homes. Residential solar systems typically range in size from $3-8 \mathrm{~kW}$, which translates into a cost of between $\$ 15,000$ and $\$ 40,000$. In recent years the cost per watt, which includes the price of the parts of the system, labor fees, permitting fees, overhead costs, and profit, has been reduced significantly. The current cost per watt stands at around \$6-8 per watt in most parts of the US (IRENA, 2012). Solar power systems benefit significantly from economies of scale, meaning that larger systems translate into a lower cost per watt. In order to find the total cost of a typical solar power system, one must consider all components such as the installation cost and operation and maintenance costs (Nielsen et al., 2010).

\section{a) The Cost of the Solar Panels}

The solar panels usually account for $\sim 30 \%$ of the total cost of a solar power system. A typical residential solar panel with a combined capacity of $3-8 \mathrm{~kW}$ costs between $\$ 4,000$ and $\$ 16,000$. It is important for solar power system users to know that the best solar panels are not necessarily the most expensive ones. The most reliable and most convenient way to rate the cost of solar panels is by considering their cost per watt, the commonly accepted figure of merit. This is a reliable metric because it indicates the cost incurred in the acquisition of the solar panels as it relates to the power output. Due to widespread campaigns encouraging the use of renewable sources of energy, the costs of solar panels have continually gone down in recent years. 
Currently, the typical industrial selling price of solar panels is well below $\$ 0.70 / \mathrm{W}$. For homeowners who buy small quantities at retail prices, this figure translates into approximately $\$ 1.50 / \mathrm{W}$ (Nielsen et al., 2010).

\section{b) Balance of System}

"Balance of system" refers to all the components of solar system with the exception of the panels themselves. The balance of system includes components such as inverters, of which there may be one or several, the mounts, the wiring system and other electrical components of the system. The balance of system represents $\sim 20 \%$ of the total cost of the system. For homeowners, the expected cost of assembling the balance of system ranges from $\$ 3,000$ to $\$ 10,000$ (Nielsen et al., 2010).

\subsection{WIND TURBINE SYSTEMS}

Wind and hydropower have been used by humans since antiquity, and for a long time have served as the oldest large-scale source of power. The invention of the steam engine led to the decline in reliance on turbine wind power as a source of energy for industrial use; however, the large-scale manufacture of wind turbines by Danish companies in the late 1970s motivated the re-emergence of wind power as a useful source of energy for large-scale use (AWEA, 2011). Earlier wind turbines were not as large as the ones used today and had limited capacity of $\sim 10-50$ kW (AWEA, 2011). The work of these Danish scientists ultimately led to the emergence of a more robust wind power industry that is now used around the world (EWEA, 2011a). Modern wind turbines are far superior to the original versions, with typical capacities of $\sim 1.16 \mathrm{MW}$. These mega-capacity turbines can be connected to the grid, hence increasing the power supply in national-scale grid systems. Some modern turbines can have capacities as high as 2-3 MW, while even larger turbines of up to $5 \mathrm{MW}$ have been on the market for close to five years. This 
evolution in wind turbine capacity shows that wind power is increasingly becoming an important source of renewable and clean energy for use, both for industrial and for domestic purposes (EWEA, 2011a).

Wind turbines grouped together are referred to as a "wind farm." A typical wind farm is made up of the turbines themselves, roads to enable accessibility to the site, buildings at the wind farm as well as the grid connection point. Wind power systems can be categorized based on whether they have a horizontal or vertical axis, or whether they are situated in offshore or onshore regions. A wind turbine's power generation capability is determined by a number of factors. These include the capacity of the turbine, the velocity of wind, the height of the turbines from the ground and the rotor diameters (EWEA, 2011a).

Modern large-scale wind turbines are designed such that they have three blades that rotate around the turbine's horizontal axis. Horizontal-axis turbines are often identified using their unique technical specifications like the rotor placement, the number of blades, the output regulation system for the generator, the hub connection to the rotor and the gear box design, rotation speed of the rotor to maintain a constant wind frequency and the wind turbine capacity. Vertical wind turbines, on the other hand, have less aerodynamic efficiency (EWEA, 2011a). .

Apart from the large-scale turbine designs, there has simultaneously been an increase in demand for small-scale wind turbines. Small wind turbines are so named because they have a low generator capacity of less than $100 \mathrm{~kW}$ (AWEA, 2011). These turbines have their use limited to powering remote or off-grid facilities like homes, farms, refuges and other smaller systems that require a power supply. Intermediate-sized turbines can sustain a system that powers facilities with slightly higher power consumption. The difference between the small and intermediate systems, besides their power capacities, is that the latter can be used in both off-the- 
grid and grid-connected applications. Either can be used in conjunction with diesel generators and batteries for remote use in places lacking a grid connection. Despite the fact that small turbines remain a niche application, its growth in the wind energy sector has been quite remarkable.

\subsubsection{Modeling the Output Characteristics of Wind Turbine Systems}

The overall formula for the output characteristic of wind generator can be expressed as:

$$
\mathrm{P}_{\mathrm{WG}}(\mathrm{V})=\left(\begin{array}{ll}
0 & V \leq V_{c i} \quad \text { or } \quad V \geq V_{c o} \\
\mathrm{a}_{1} \mathrm{~V}^{3}+\mathrm{b}_{1} \mathrm{~V}^{2}+\mathrm{c}_{1} V+d_{1} & V_{c i}<V<V_{1} \\
\mathrm{a}_{2} \mathrm{~V}^{3}+\mathrm{b}_{2} \mathrm{~V}^{2}+\mathrm{c}_{2} V+d_{2} & V_{1}<V<V_{2} \\
\cdots \cdots \cdots \cdots \cdots \cdots \cdots \cdots \cdots \cdots \cdots \cdots \cdots \cdots \cdots \cdots \cdots \cdots \cdots \cdots \cdots \cdots \cdots & \\
\mathrm{a}_{\mathrm{n}} \mathrm{V}^{3}+\mathrm{b}_{\mathrm{n}} \mathrm{V}^{2}+\mathrm{c}_{\mathrm{n}} V+d_{n} & V_{n-1}<V<V_{r} \\
P_{r} & V_{r} \leq V<V_{c o}
\end{array}\right.
$$

where $\mathrm{P}_{\mathrm{WG}}(\mathrm{V})$ is the output power of the wind generator at wind speed $\mathrm{V}, \mathrm{P}_{\mathrm{r}}$ is the rated power, $\mathrm{V}$ is the wind speed at the hub height $\mathrm{V}_{\mathrm{ci}}$, and $\mathrm{V}_{\mathrm{r}}$ and $\mathrm{V}_{\mathrm{co}}$ are the cut-in, rated and cut-out wind speeds, respectively (Ilinka et al., 2003). $\mathrm{n}$ represents the number of cubic spline interpolation functions corresponding to $\mathrm{n}+1$ value couples (speed, power) of data provided by the manufacturers and a, b, c and d are the polynomial coefficients of the cubic spline interpolation functions, which depend on the wind turbine generator type.

As the installation height of the wind turbine has a large effect on the energy available from the system, the adjustment of the wind profile as a function of height can be taken into account by using a height adjustment equation. In this study, the power law is applied for the vertical wind speed profile, as shown in equation 8 below (Ilinka et al., 2003). 


$$
\mathrm{V}=\mathrm{V}_{0}\left(\frac{\mathrm{H}}{\mathrm{H}_{0}}\right)^{\alpha_{1}}
$$

Where, $\mathrm{V}$ is the wind speed at hub height $\mathrm{H}, \mathrm{V}_{0}$ is the wind speed measured at the reference height $H_{0}$ and $\alpha_{1}$ is the power law exponent which varies with the elevation, the time of day, the season, the nature of the terrain, the wind speed and temperature. Many authors give a typical value of $\alpha_{1}=1 / 7$ as corresponding to low roughness surfaces and well-exposed sites, so this value is used in this study (Ilinka et al., 2003; Johnson, 1985).

\subsubsection{Cost Estimation of Wind Power}

Wind power also requires an enormous amount of initial capital investment, as is typical of all renewable sources of energy. Despite the initial cost, however, wind power has one of the lowest costs of operation since there is no fuel requirement, which makes it among the most efficient sources of energy available for human use. In wind power economics, the following are some of the key parameters considered in the estimation of the cost of wind power estimation: operation and maintenance costs (may be fixed or variable, depending on the nature of power use), capacity factor (this includes wind velocity and availability of turbines), economic lifetime and the initial capital investment (Junginger et al., 2004).

The installation cost of a wind power system is largely due to the initial capital investment required by the wind turbines, which can account for as much as $84 \%$ of the total cost of installation (AWEA, 2011). Most people are deterred from installing wind power by the huge capital investment required to install the system, despite the fact that the running cost and maintenance costs are incredibly low. The capital cost of wind power installation can be further broken down into the following sub-components. 


\section{a) Wind Turbine Cost}

The cost of wind turbines contributes to the largest proportion of the cost of installation of a wind turbine system. The price of wind turbines experienced a recent surge, but it has since stabilized. The average cost of a single turbine was $\$ 700$ per kilowatt between the year 2000 and 2002. By 2009, however, the price had risen to $\$ 1500$ and $\$ 1800$ in the US and Europe, respectively (AWEA, 2011). Today, the price of turbines is experiencing a downward trend due to competition among wind turbine manufacturers around the world. The low cost of copper, steel and cement, which are all required in the manufacture of wind turbines, has also contributed to this downward trend in the price of turbines ( $\mathrm{Li}$ et al., 2010).

By analyzing different markets, it has been shown that there is a huge disparity in wind turbine prices across the world. The prices largely depend on the cost structure of the local market and the availability of the raw materials required for the manufacture of the turbines. The Chinese market offers the lowest price package for wind turbines by far ( $\mathrm{Li}$ et al., 2010). This is probably because of the cheap labor dynamics of the Chinese market system (EWEA, 2011a). Chinese wind turbines retailed at a cost of approximately $\$ 644 / \mathrm{kW}$ according to the 2010 statistical release. Japan and Austria, on the other hand, produce the most expensive wind turbines (Junginger et al., 2004), at an estimated $\$ 2,000 / \mathrm{kW}$ and $\$ 2,100 / \mathrm{kW}$ respectively (AWEA, 2011).

\section{b) Grid connection costs}

Wind power stations can be linked to national grids through the transmission network or distribution networks. When the transmission network is used, step-up transformers are required in order to convert to a higher voltage that can be easily transported by the grid system. Alternatively, the distribution of wind power through a distribution network does not require any 
stepping-up or stepping down, and hence there is no need for transformer installation (Blanco, 2009).

The cost of grid connection also largely depends on the distance between the wind farm and the point at which the grid connection is done (2009). In scenarios where the grid connection points are far away from the wind farm, additional large costs would be incurred in converting the produced High Voltage Alternating Current (HVAC) into High Voltage Direct Current (HVDC) to facilitate easy transportation with minimal losses. However, if the gridconnection point is immediately adjacent to the wind farm there is no need to convert HVAC to HVDC. It is important to note that HVAC transmission reduces power loss and avoids the inevitable loss associated with changing from AC to DC and then back to AC (2009).

Grid connection costs also vary by country, and even by jurisdiction within the same country. Different areas have different provisions or guidelines on who is responsible for the cost of grid connection. In some countries, the onus lies on the transmission system operator to bear the cost of connecting wind farms to the national grid (Junginger et al., 2004). Other countries require that wind farm owners take full responsibility for properly integrating their power into the existing grid system. On average, the grid connection costs account for $11-30 \%$ of the total cost of the system. For onshore wind farms this cost accounts for $15-30 \%$ of the total capital cost. In offshore wind systems, on the other hand, this cost accounts for only $11-14 \%$ of the total cost (AWEA, 2011).

\section{c) Civil Works and Construction Costs}

These costs cover the expenses incurred in the transportation and installation of wind turbine foundations. Wind farms need to have access roads and other infrastructure, and the costs of these constructions contribute to the overall cost of installation of the system (Blanco, 
2009). The cost of civil works and construction costs depends largely on the availability of cheap labor, as well as the availability of the raw materials needed for the job.

\section{d) Operation and Maintenance Costs}

Operational costs can be fixed or variable, depending on the way in which the system is being used. Like other renewable sources of energy, operation and maintenance costs account for the smallest proportion of the total cost. This is because wind power systems, just like solar systems, do not require any fuel to run. Proper maintenance, however, is crucial to ensuring the system remains operational for a long period of time with minimal mechanical damage. The general trend is that operation and maintenance cost have been on the decline since the early 1990s. In the US, operation and maintenance costs have fallen by over $50 \%$, from $\$ 22 / \mathrm{W}$ in the early 1990s to $\$ 10 / \mathrm{W}$ in 2011 (AWEA, 2011).

\subsubsection{The Cost Model and Equations for Solar and Wind Turbine Systems}

The preferred cost model for renewable sources of energy, according to the International Renewable Energy Agency (IRENA), is the LCOE model. This model is based on a discounted cash flow (DCF) analysis to a common basis, taking into account the effect of time on the value of money (Blanco, 2009). The fact that most renewable sources of energy require a huge initial capital investment followed by almost zero operational cost means that the weighted average cost of capital (WACC), or the discounted rate used to evaluate the project, has a critical impact on the LCOE (IRENA, 2012).

The Levelised Cost of Electricity is defined mathematically as:

$$
L C E=\frac{T P V . C R F}{E_{\text {load }}},
$$


Where $\mathrm{E}_{\text {load }}$ the yearly output in $\mathrm{kWh}, \mathrm{TPV}$ and CRF is are the Total Present Value of the actual cost of all system components and the Capital Recovery Factor, respectively, which can be expressed as follows (Athanasia et al., 2000):

$$
C R F=\frac{i(1+i)^{n}}{(1+i)^{n}-1}
$$

And

$$
\mathrm{TPV}=\mathrm{C}_{\mathrm{pv}}+\mathrm{C}_{\text {wind }}
$$

Where, $\mathrm{i}$ is the annual discount rate, $\mathrm{n}$ is the system life in years, $\mathrm{C}_{\mathrm{pv}}$ is the sum of the present value of capital and maintenance costs of the PV generator in system life and $\mathrm{C}_{\text {wind }}$ is the sum of the present value of capital and maintenance costs of the wind turbines over the system's lifetime. The configuration with the lowest LCE is taken as the optimal one from the set of configurations which guarantee the required LPSP.

There are many potential trade-offs that have to be taken into consideration when developing an LCOE modeling approach to the cost of renewable energy. First, the model is a simplistic approach because it needs to be applicable to a wider range of technologies in different countries and regions (IRENA, 2012). The analysis method is, however, transparent and easily understood. In addition, more detailed LCOE analysis results in a significantly higher overhead in terms of the many assumptions that have to be made. This means that the equations are, probably, more accurate (IRENA, 2012)

The overall formula used for the calculation of the LCOE in $\$ / \mathrm{kWh}$ for renewable energy technology is:

$$
L C O E=\frac{\sum_{t=1}^{n} \frac{I_{t}+M_{t}}{(1+r)^{t}}}{\sum_{t=1}^{n} \frac{E_{t}}{(1+r)^{t}}}
$$


(IRENA, 2012)

where LCE is the average lifetime levelised cost of electricity generation, $\mathrm{I}_{\mathrm{t}}$ is the investment expenditure in year $t, \mathrm{M}_{\mathrm{t}}$ is the operation and maintenance expenditures in year $\mathrm{t}, \mathrm{F}_{\mathrm{t}}$ is the amount in fuel expenditures in year $t, E_{t}$ is the electricity generation in year $t, r$ is the discount rate and $n$ is the economic life of the system in years.

\section{4 Applying the Cost Model to the City of Tabuk}

As a demonstration of how the cost model works, I will use the data for the city of Tabuk and show the steps for cost modeling in detail. For Tabuk City, a solar farm consisting of 12,729 solar panels and a wind farm consisting of 5,309 turbines will be used.

Table 4.1 below provides the nameplate generation capacity of solar panels, as well a wind turbine which is described as the maximum rated output of any electric power production equipment, given in units of GW for Tabuk City. The second item given is the capacity factor of both, which is the ratio of a power plant's actual power output to its potential output if it was possibly operating consistently at full nameplate capacity over the same duration. The table also provides their annual generation rates and their individual parts or shares of electricity generated annually. It also shows the capacity factor and annual electricity generation statistics. Total electricity generation capacity is $45.1 \mathrm{MW}$, of which $25.8 \mathrm{MW}$ is produced using solar panels and $19.3 \mathrm{GW}$ is produced using wind turbines. A total of $16 \%$ capacity factor is from solar panels and 30\% capacity factor is from wind turbines. $36.161 \mathrm{TWh}$ are produced annually using solar panels, which is $42 \%$ of total annual production share, while $50.720 \mathrm{TWh}$ is produced using wind turbines, which accounts for $58 \%$ of total annual production share. This shows that the majority contribution to electricity production is from wind turbines. 
Table 4.1 Capacity, capacity factor and generation

\begin{tabular}{|l|c|c|c|c|}
\hline Capacity, capacity factor and generation & Units & Solar Panels & Wind Turbines & Total \\
\hline Nameplate Generation Capacity & MW & 25.8 & 19.3 & 45.1 \\
\hline Capacity Factor & & $16 \%$ & $30 \%$ & \\
\hline Annual Generation & GWh & $\mathbf{3 6 , 1 6 1}$ & $\mathbf{5 0 , 7 2 0}$ & $\mathbf{8 6 , 8 8 2}$ \\
\hline Share & & $\mathbf{4 2 \%}$ & $\mathbf{5 8 \%}$ & $\mathbf{1 0 0 \%}$ \\
\hline
\end{tabular}

Table 4.2 shows the capital cost table, which provides the capital cost rate, capital cost, capital cost for transmission and distribution additions and the total capital cost for both solar panels and wind turbines. The cost of capital describes the opportunity cost of making a particular investment. It is the rate of return that should have been earned by putting the same amount of money into a different investment with an equal rate of risk. In the same context, the capital cost of transmission and distribution refers to the opportunity cost of making the transmission and distribution of the solar panels or wind turbines.

Table 4.2, also shows the cost comparison of solar panels and wind turbines for electricity production. The capital cost rate for solar panels is $\$ 4,650 / \mathrm{kW}$, while for wind turbines it is $\$ 2,744 / \mathrm{kW}$. Capital cost for solar panels is estimated to be $\$ 120 \mathrm{M}$, while for wind turbines it is estimated to be $\$ 53 \mathrm{M}$. Including transmission and distribution costs, a total of $\$ 116 \mathrm{M}$ is spent. Summing up the total capital cost for both solar panels and wind turbines gives a price of $\$ 289 \mathrm{M}$. The table shows that wind turbines are consuming less capital cost than solar panels. 
Table 4.2 Capital Cost

\begin{tabular}{|l|c|c|c|c|}
\hline Capital Cost & Units & Solar Panels & Wind Turbines & Total \\
\hline Capital Cost Rate & $\mathbf{\$ / k W}$ & $\mathbf{\$ 4 , 6 5 0}$ & $\mathbf{\$ 2 , 7 4 4}$ & \\
\hline Capital Cost & $\mathbf{\$ M i l l i o n}$ & $\mathbf{\$ 1 2 0}$ & $\$ 53$ & $\mathbf{\$ 1 7 3}$ \\
\hline $\begin{array}{l}\text { Capital Cost for Transmission \& } \\
\text { Distribution Additions }\end{array}$ & $\mathbf{\$ M i l l i o n}$ & & & $\mathbf{\$ 1 1 6}$ \\
\hline Total Capital Cost & $\mathbf{M i l l i o n}$ & & & $\mathbf{\$ 2 8 9}$ \\
\hline
\end{tabular}

In Table 4.3 the LCE is described as the measurement of a power source which attempts to compare different techniques of electricity generation on a fair basis. It gives the cost of operating and building a generating plant for the period of an assumed financial life and duty cycle. The table provides the LCE for both the system and for technology in $\$ / M W h$. It also shows the sum of the total cost of electricity for the transmission and distribution for both solar panels and wind turbines and provides the total levelised cost of both technologies in \$/MWh. Table 4.3 shows the LCE for both solar panels and for wind turbines. For the technology LCE, $\$ 394 / \mathrm{MWh}$ is spent for solar panels while $\$ 130 / \mathrm{MWh}$ is spent for wind turbines. $\$ 164 / \mathrm{MWh}$ is spent on the system LCE for solar panels, while only $\$ 76 / \mathrm{MWh}$ is spent for wind turbines. For solar panels and wind turbines the LCE for transmission \& distribution adds a total of \$74/MWh. Summing up the LCE of both the wind turbines and solar panels, a total of $\$ 314 / \mathrm{MWh}$ is spent between them. 
Table 4.3 Levelised Cost of Electricity (LCE)

\begin{tabular}{|l|l|l|l|l|}
\hline Levelised Cost of Electricity (LCE) & Units & Solar Panels & Wind Turbines & Total \\
\hline Technology & $\mathbf{\$ M W h}$ & $\mathbf{\$ 3 9 4}$ & $\mathbf{\$ 1 3 0}$ & \\
\hline System & $\mathbf{\$ M W h}$ & $\mathbf{\$ 1 6 4}$ & $\mathbf{\$ 7 6}$ & $\mathbf{\$ 2 4 0}$ \\
\hline Transmission \& Distribution Additions & $\mathbf{\$ M W h}$ & & & $\mathbf{\$ 7 4}$ \\
\hline Total & $\mathbf{\$ M W h}$ & & & $\mathbf{\$ 3 1 4}$ \\
\hline
\end{tabular}

Table 4.4 contains the total gross plant cost in $\$ / \mathrm{kW}$, total sent out plant cost in $\$ / \mathrm{kW}$, plant size in MW, capacity factor, auxiliary load, thermal efficiency, fuel cost in $\$ / G J, \mathrm{CO}_{2}$ transport and storage, fixed O\&M in $\$ / \mathrm{kW}-\mathrm{yr}$, variable O\&M in $\$ / \mathrm{MWh}$, plant life in years, discount rate and capital recovery factor. Total gross plant cost is the amount paid for any owned asset. Plant size describes the physical dimensions of a plant. Auxiliary load is the device used to provide power for performing different functions. Fixed O\&M is the cost used for the operation and maintenance of the plant. Plant life describes the duration for which the plant can survive and function properly. The capital recovery factor is the ratio of a constant annuity to the current value of acquiring that annuity for a specific duration of time. Table 4.4 below shows that the total (gross and sent out) plant cost of solar panels is $\$ 4,650$, nearly double the $\$ 2,744$ total (gross and sent out) plant cost of wind turbines. The sizes of the solar panels are $1 \times 5$ and $10 \times 5$, while the size of the wind turbines is 500 . The capacity factor of wind turbines is $30 \%$, which is nearly double the $16 \%$ capacity factor of the solar panels. The auxiliary load of both of them is zero, which shows that neither uses any external device to provide power. The thermal efficiency, fuel cost and $\mathrm{CO}_{2}$ transport and storage for both types of power plants is N/A. At $\$ 55$, the fixed O\&M of solar panels is greater than that of wind turbines at $\$ 37$, which means more money is needed to operate and maintain the solar panels than the wind turbines. The solar 
panels can survive longer than the wind turbines, as their life is $~ 20$ years while that of wind turbines is $\sim 20$ years. The discount rate is $10.1 \%$ for both. The capital recovery factor of the wind turbines is 0.1110 , which is greater than that of the solar panels at 0.1070 .

Table 4.4 LCE Inputs

\begin{tabular}{|c|c|c|c|}
\hline LCE Inputs & Units & Solar Panels & Wind Turbines \\
\hline Total Plant Cost (gross) & $\$ / \mathbf{k W}$ & $\$ 4,650$ & $\$ 2,744$ \\
\hline Total Plant Cost (sent out) & $\$ / \mathbf{k W}$ & $\$ 4,650$ & $\$ 2,744$ \\
\hline Plant Size (MW) & MW & $1 \times 5,10 \times 5$ & 500 \\
\hline Capacity Factor & $\%$ & $16 \%$ & $30 \%$ \\
\hline Auxiliary Load & $\%$ & $0 \%$ & 0\% \\
\hline Thermal Efficiency (HHV) & $\%$ & N/A & N/A \\
\hline Fuel Cost & \$/GJ & N/A & N/A \\
\hline CO2 Transport and Storage & & N/A & N/A \\
\hline Fixed O\&M & $\$ / \mathbf{k W}-\mathbf{y r}$ & $\$ 55$ & $\$ 37$ \\
\hline Variable O\&M & \$/MWh & $\$ 0$ & \$0 \\
\hline Plant Life & Years & 20 & 20 \\
\hline Discount Rate & $\%$ & $10.1 \%$ & $10.1 \%$ \\
\hline Capital Recovery Factor (CRF) & & 0.1070 & $\mathbf{0 . 1 1 1 0}$ \\
\hline
\end{tabular}

Table 4.5 shows the LCE calculator for solar panels and wind turbines. It includes capital charges, fixed O\&M costs, variable O\&M costs and fuel costs. Summing these all up, we can see that the solar panels take $\$ 394 / \mathrm{MWh}$ while wind turbines take $\$ 130 / \mathrm{MWh}$. The LCE cost for wind turbines is approximately three times less than that of solar panels. 
Table 4.5 LCE Calculator

\begin{tabular}{|l|c|c|c|}
\hline LCE Calculator & & & \\
\hline Capital Charges & $\$ / M W h$ & $\$ 355$ & $\$ 116$ \\
\hline Fixed O\&M Cost & $\$ / M W h$ & $\$ 39$ & $\$ 14$ \\
\hline Variable O\&M Cost & $\$ / M W h$ & $\$ 0$ & $\$ 0$ \\
\hline CO2 Transport and Storage & $\$ / M W h$ & & \\
\hline Fuel Cost & $\$ / M W h$ & & \\
\hline LCE & $\$ / M W h$ & $\$ 394$ & $\$ 130$ \\
\hline
\end{tabular}

Table 4.6 shows the capital cost for distributing electricity from Tabuk to other cities. The capacity varies from place to place depending upon the distance from Tabuk. The unit cost of all locations remains the same, but the capital cost varies widely. The highest capital cost is for Riyadh as it has the largest consumption at $16.5 \mathrm{GW}$. In total, a capital cost of $\$ 107,135,850,000$ would be incurred by delivering electricity from Tabuk to the other considered cities.

Countries are crisscrossed with high-voltage transmission lines, which transport electrical power from generators at power plants to substations and ultimately consumers. The voltage in these lines can be hundreds of thousands of volts and the transmission over long distances creates power losses which is $\$ 1.5$ per $\mathrm{GW} \times \mathrm{km}$ in Table 4.6. 
Table 4.6 Capital Cost for Distributing

\begin{tabular}{|c|c|c|c|c|c|c|}
\hline From & To & $\begin{array}{c}\text { Capacity } \\
\text { (GW) }\end{array}$ & $\begin{array}{c}\text { Distance } \\
(\mathbf{k m})\end{array}$ & $\mathbf{G W} \times \mathbf{k m}$ & $\begin{array}{l}\text { Unit Cost } \\
(\$ / \mathbf{G W} \times \mathbf{k m})\end{array}$ & $\begin{array}{c}\text { Capital Cost } \\
\text { (\$millions) }\end{array}$ \\
\hline Tabuk & Jazan & 2.6 & 1,587 & 4,126 & 1.50 & $\$ 6,189$ \\
\hline Tabuk & Riyadh & 16.5 & 1,194 & 19,701 & 1.50 & $\$ 29,552$ \\
\hline Tabuk & Jeddah & 9.3 & 1,036 & 9,635 & 1.50 & $\$ 14,452$ \\
\hline Tabuk & Thuwal & 2.6 & 960 & 2,496 & 1.50 & $\$ 3,744$ \\
\hline Tabuk & Dammam & 4.7 & 1,420 & 6,674 & 1.50 & $\$ 10,011$ \\
\hline Tabuk & Najran & 2.5 & 1,029 & 2,573 & 1.50 & $\$ 3,859$ \\
\hline Tabuk & Hagl & 3.9 & 680 & 2,652 & 1.50 & $\$ 3,978$ \\
\hline Tabuk & Al Jubail & 6.3 & 1,305 & 8,222 & 1.50 & $\$ 12,332$ \\
\hline Tabuk & Taif & 5.8 & 1,005 & 5,829 & 1.50 & $\$ 8,744$ \\
\hline Tabuk & Timaa & 2.1 & 217 & 456 & 1.50 & $\$ 684$ \\
\hline Tabuk & Wadi Addawasir & 4.8 & 909 & 4,363 & 1.50 & $\$ 6,545$ \\
\hline Tabuk & Al Baha & 4.2 & 790 & 3,318 & 1.50 & $\$ 4,977$ \\
\hline Tabuk & Yanbu & 4.6 & 300 & 1,380 & 1.50 & $\$ 2,070$ \\
\hline
\end{tabular}

\section{Transmission and Distributions from Tabuk to Riyadh City}

Now, applying the cost model to the city of Tabuk and see how is the cost and possibility if transmit it to Riyadh City. Table 4.7 includes the capital cost, capacity, capital cost unit rate, book life, energy transmitted, load factor, LCE (capital component only), LCE (O\&M component), LCE transmission additions, LCE transmission and distributions and the capital cost of transmission and distribution for transmission from Tabuk to Riyadh. The transmission cost 
of electricity is $\$ 29.552 \mathrm{M}$, while the distribution cost is $\$ 8.816 \mathrm{M}$. The capital cost per unit rate for transmission is $\$ 3,174 / \mathrm{kW}$, while for distribution it is $\$ 261 / \mathrm{kW}$.

Table 4.7 LCE of 'Copper-Plate' Additions

\begin{tabular}{|c|c|c|c|}
\hline LCE of 'Copper-Plate' additions & & Transmission & Distribution \\
\hline Capital Cost & \$millions & $\$ 29,552$ & $\$ 8,816$ \\
\hline Capacity (demand) & MW & $\mathbf{3 3 , 7 5 8}$ & $\mathbf{3 3 , 7 5 8}$ \\
\hline Capital Cost Unit Rate & $\$ / \mathbf{k W}$ & $\$ 3174$ & $\$ 261$ \\
\hline Book Life & Years & 20 & 20 \\
\hline Energy Transmitted & MWh & $198,256,000$ & $198,256,000$ \\
\hline Load Factor & & $67 \%$ & $67 \%$ \\
\hline LCE (Capital Component only) & \$/MWh & $\$ 0$ & $\$ 0$ \\
\hline LCE (O\&M Component) & \$/MWh & $\$ 3$ & $\$ 3$ \\
\hline LCE, Transmission Additions & \$/MWh & $\$ 3$ & $\$ 3$ \\
\hline
\end{tabular}

Table 4.8 shows that the distribution cost for other LCE heads is less than the transmission cost. The total capital cost for transmission and distribution of electricity is $\$ 38$ bn, while $\$ 6 \mathrm{bn} / \mathrm{MWh}$ is LCE transmission \& distribution cost.

Table 4.8 Capital Cost - Transmission \& Distribution

\begin{tabular}{|l|c|c|}
\hline Capital Cost - Transmission \& Distribution & \$Millions & $\$ 38$ \\
\hline LCOE Transmission \& Distribution & \$M/MWh & $\$ 6$ \\
\hline
\end{tabular}

Table 4.9 shows the asset life in years, discount rate, capital recovery factor, capital cost unit rate, load factor, fixed O\&M and variable O\&M for both plant types. The table also shows 
the LCE inputs for transmission and distribution costs. Transmission and distribution asset life is 20 years, having a $10.1 \%$ discount rate. Both types of plants have the same capital recovery factor of 0.1183 , while transmission has a higher capital cost unit rate than distribution. Fixed O\&M charges for distribution are higher than transmission.

Table 4.9 LCOE Inputs

\begin{tabular}{|l|c|c|c|}
\hline LCOE Inputs & Units & Transmission & Distribution \\
\hline Asset Life & Years & 20 & 20 \\
\hline Discount Rate & $\%$ & $10.1 \%$ & $10.1 \%$ \\
\hline Capital Recovery Factor & & $\mathbf{0 . 1 1 8 3}$ & $\mathbf{0 . 1 1 8 3}$ \\
\hline Capital Cost Unit Rate & $\$ / \mathbf{k W}$ & $\$ 0$ & $\$ 0$ \\
\hline Load Factor & $\%$ & $67 \%$ & $67 \%$ \\
\hline Fixed O\&M & $\$ / \mathbf{k W}-\mathbf{y r}$ & $\$ 18$ & $\$ 15$ \\
\hline Variable O\&M & $\$ / \mathbf{M W h}$ & $\$ 0$ & $\$ 0$ \\
\hline
\end{tabular}

Table 4.10 includes capital charges, fixed and variable O\&M, LCE, number of businesses, O\&M per business per year, O\&M, generation, cost of electricity, capex, opex electricity transmitted, asset value, line length, cost copper-plate, copper-plate additions and O\&M for transmission and distribution additions. The table also shows the LCE calculator for transmission and distribution. It includes capital charges and fixed and variable O\&M costs.

Summing all these up, transmission and distribution both take $\$ 3 / \mathrm{MWh}$, so the LCE cost for distribution is less than it is for transmission. 


\begin{tabular}{|l|c|c|c|}
\hline LCE Calculator & Units & Transmission & Distribution \\
\hline Capital Charges & $\$ / M W h$ & $\$ 0$ & $\$ 0$ \\
\hline Fixed O\&M & $\$ / M W h$ & $\$ 3$ & $\$ 3$ \\
\hline Variable O\&M & $\$ / M W h$ & $\$ 0$ & $\$ 0$ \\
\hline LCE & $\$ / M W h$ & $\$ 3$ & $\$ 3$ \\
\hline
\end{tabular}

Table 4.11 shows the number businesses and other O\&M parameters for transmission and distribution. Both transmission and distribution have the same number of businesses at 13, while distribution has more O\&M per business per year. O\&M costs for distribution are $\$ 2.600 \mathrm{M}$, while for transmission they are $\$ 1.300 \mathrm{M}$. The cost of electricity for distribution is much higher than for transmission.

Table 4.11 Number Businesses and Other O\&M Parameters for Transmission and Distribution

\begin{tabular}{|l|c|c|c|}
\hline & Units & Transmission & Distribution \\
\hline No. of Businesses & & 13 & 13 \\
\hline O\&M per Business per Year & $\$$ millions & $\$ 100$ & $\$ 200$ \\
\hline O\&M & $\$$ millions & $\$ 1.3$ & $\$ 2.6$ \\
\hline Generation, & TWh & 204.4 & 204.4 \\
\hline Cost of Electricity & $\$ /$ MWh & $\$ 6.40$ & $\$ 12.70$ \\
\hline
\end{tabular}

Table 4.12 provides the cost for transmission and distribution for capex and opex. It is immediately evident that distribution requires more capital than transmission. The total cost for distribution is $\$ 44.40 / \mathrm{MWh}$, while for transmission it is $\$ 14.60 / \mathrm{MWh}$ since the line length needed for transmission is less than the line length needed for distribution. 
Table 4.12 Transmission and Distribution for Capex and Opex

\begin{tabular}{|l|c|c|c|}
\hline & Units & Transmission & Distribution \\
\hline Capex & $\$$ millions & $\$ 1.6$ & $\$ 6.5$ \\
\hline Opex & $\$$ millions & $\$ 1.3$ & $\$ 2.3$ \\
\hline Electricity Transmitted & TWh & 198.256 & 198.256 \\
\hline Capex & $\$ / M W h$ & $\$ 8.10$ & $\$ 32.80$ \\
\hline Opex & $\$ / M W h$ & $\$ 6.60$ & $\$ 11.60$ \\
\hline Total & $\$ / M W h$ & $\$ 14.60$ & $\$ 44.40$ \\
\hline Asset value & $\$$ millions & $\$ 13.1$ & $\$ 44.1$ \\
\hline Line Length & Km & $\mathbf{2 , 5 0 0}$ & $\mathbf{2 , 7 0 0}$ \\
\hline Cost "Copper-Plate" & & $48 \%$ & $20 \%$ \\
\hline
\end{tabular}

Table 4.13 shows the cost and line length for transmission and distribution. It shows that the total line length needed for transmission is less than that needed for distribution. Moreover, the O\&M for transmission and distribution additions cost for transmission is $\$ 3.13 / \mathrm{MWh}$, while for distribution it is $\$ 2.32 / \mathrm{MWh}$.

Table 4.13 Line Length for Transmission and Distribution

\begin{tabular}{|l|c|c|c|}
\hline Line Length & Km & $\mathbf{2 , 5 0 0}$ & $\mathbf{2 , 7 0 0}$ \\
\hline Copper-Plate Additions & $\mathbf{K m}$ & $\mathbf{1 , 1 9 4}$ & \\
\hline O\&M for Transmission \& Distribution Additions & $\$ / \mathrm{MWh}$ & $\mathbf{\$ 3 . 1 3}$ & $\mathbf{\$ 2 . 3 2}$ \\
\hline
\end{tabular}




\section{CHAPTER 5}

\section{SOFTWARE DEVELOPMENT}

\subsection{Introduction}

In order to perform economic and sensitivity analyses based on the results of this research, a software package was written in Visual Basic was developed. The software assists in:

1. Finding the LOCE cost and the output solar power, and output wind turbines for each city.

2. Saving the input data and the results in database which can be accessed and updated easily.

3. Presenting the inputs and results in a standardized report form which can be saved to a file or printed.

\subsection{Design of System Using Visual Basic}

Visual Basic is the programming language used for graphical user interface and system design. In visual basic, the application windows are called forms. These forms contain controls that also interact with Windows, other forms, controls, and even other applications. Two other features of visual basic: database manager and crystal reports were used to handle and save the input and output data (Salim, M, 1997).

\subsection{Programming Structure}

The building blocks that make up Visual Basic projects are called modules. There are three modules: power output of solar energy, power output of wind turbines, and the distribution 
and transfer energy cost between cities. Figure 5.1 shows the flow chart for the programming structure.

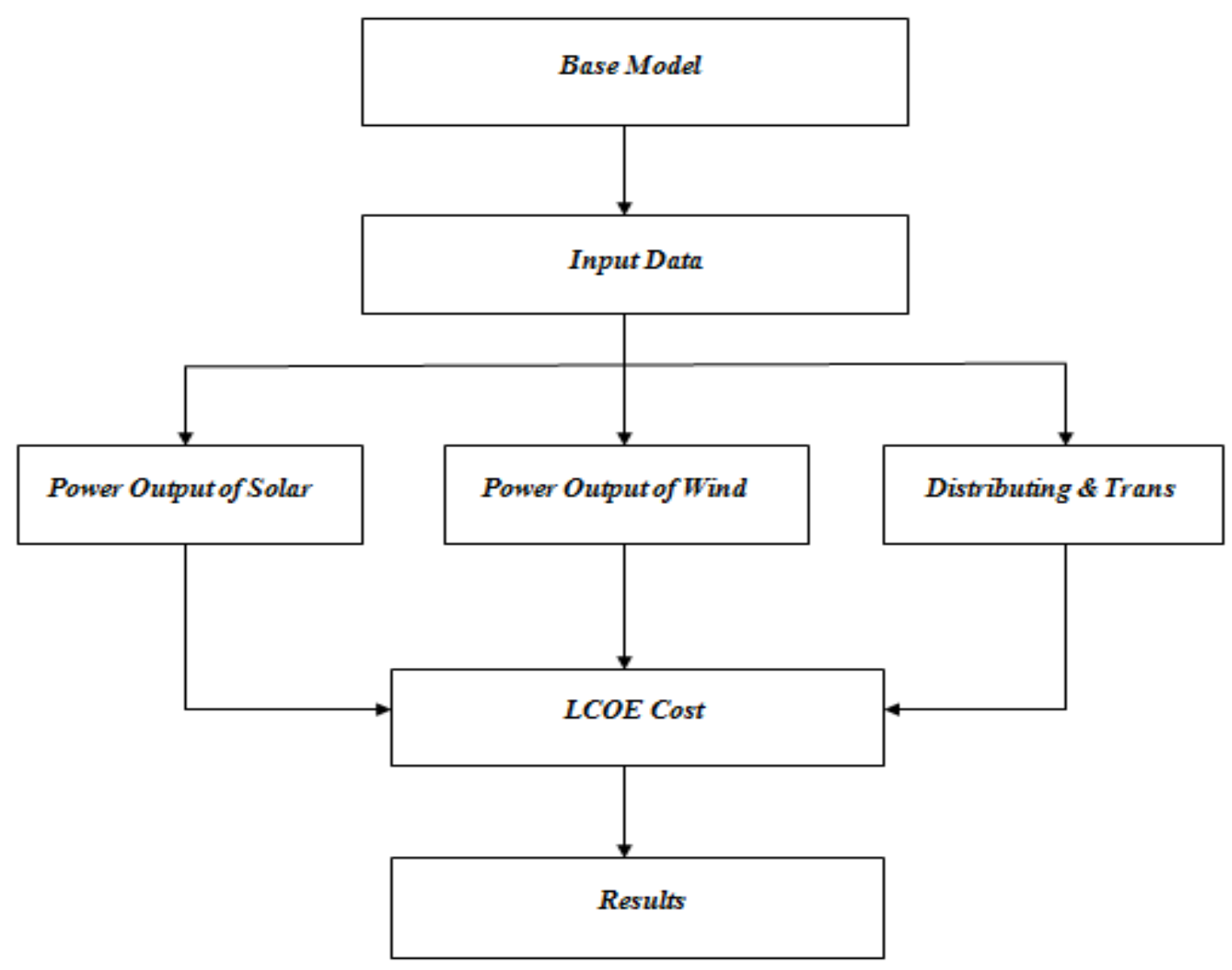

Figure 5.1 Flowchart for Programming

\subsection{Input Data into Excel}

Excel was used to calculate the values and make standardized tables. Formulas were used in these tables to produce the necessary outputs. If users want to make any changes then it will automatically update the table wherever the value is used.

Given the nature of this research, Excel proved to be an optimal choice for improving the efficiency of the many calculations that had to be done. Its main benefits are: 
- It saves time

- It ensures that no mistakes are made in the calculations

- It is flexible to changes

- It can easily convert the values to a graphical representation

\subsubsection{Data Input}

With the help of this table it is possible to calculate the output power of a photovoltaic generator. As described earlier, the values must be input manually. The formulas used by the Excel sheet will locate the appropriate values according to the formula. After solving the entered formula, this table will provide us with the required results.

Inputs consist of two parts. The first is the formula part, and the other is the entries part. Once all the entries have been entered and formulas have been applied, the results will be calculated automatically. The details of the formulas used in each table, and the entries used in each table, are given below in Figure 5.2.

\begin{tabular}{|c|c|c|c|c|c|c|c|c|c|c|c|c|c|c|}
\hline 4 & A & B & $C$ & D & $E$ & $\mathrm{~F}$ & G & $\mathrm{H}$ & 1 & J & K & L & M & $\mathrm{N}$ \\
\hline 1 & City & $\mathrm{Am}$ & $\mathrm{N}$ & Gt & $\mathrm{nr}$ & npt & Bt & $\mathrm{Ta}$ & $\mathrm{Tr}$ & Gt & $\mathrm{ta} / \mathrm{UL}$ & NOCT & & \\
\hline 2 & Afif & 26000 & 100 & 6.24 & 0.15 & 1 & 0.0041 & 43 & 25 & 6.24 & 0.03375 & 47 & & \\
\hline 3 & Al Baha & 9921 & 100 & 7.54 & 0.117 & 1 & 0.0038 & 39 & 28 & 7.54 & 0.03375 & 47 & & \\
\hline 4 & Al Dawadmi & 28000 & 100 & 6.12 & 0.11 & 1 & 0.003 & 42 & 25 & 6.12 & 0.03375 & 47 & & \\
\hline 5 & Al Hanakiyah & 19000 & 100 & 6.36 & 0.13 & 1 & 0.0041 & 41 & 25 & 6.36 & 0.03375 & 47 & & \\
\hline 6 & Al Qunfudah & 11000 & 100 & 4.53 & 0.1 & 1 & 0.005 & 34 & 28 & 4.53 & 0.03375 & 47 & & \\
\hline 7 & Al Uyaynah & 16000 & 100 & 5.76 & 0.1 & 1 & 0.004 & 42 & 26 & 5.76 & 0.03375 & 47 & & \\
\hline 8 & Al Wajh & 9000 & 100 & 6.71 & 0.125 & 1 & 0.0041 & 41 & 25 & 6.71 & 0.03375 & 47 & & \\
\hline 9 & Arar & 174355 & 100 & 4.92 & 0.13 & 1 & 0.004 & 38 & 23 & 4.92 & 0.03375 & 47 & & \\
\hline 10 & Duba & 10000 & 100 & 7.06 & 0.11 & 1 & 0.0026 & 37 & 24 & 7.06 & 0.03375 & 47 & & \\
\hline 11 & Hafar Al Batin & 57000 & 100 & 5.56 & 0.05 & 1 & 0.004 & 44 & 25 & 5.56 & 0.03375 & 47 & & \\
\hline 12 & Jazan & 11671 & 100 & 4.51 & 0.168 & 1 & 0.004 & 41 & 24 & 4.51 & 0.03375 & 47 & & \\
\hline 13 & Riyadh & 412000 & 100 & 5.97 & 0.134 & 1 & 0.0011 & 46 & 26 & 5.97 & 0.03375 & 47 & & \\
\hline 14 & Jeddah & 305000 & 100 & 5.15 & 0.12 & 1 & 0.00375 & 42 & 25 & 5.15 & 0.03375 & 47 & & \\
\hline 15 & Thuwal & 8000 & 100 & 5.46 & 0.096 & 1 & 0.0045 & 42 & 25 & 5.46 & 0.03375 & 47 & & \\
\hline 16 & Dammam & 710000 & 100 & 5.44 & 0.09 & 1 & 0.0045 & 43 & 24 & 5.44 & 0.03375 & 47 & & \\
\hline 17 & Al Ahsa & 375000 & 100 & 5.49 & 0.12 & 1 & 0.004 & 44 & 26 & 5.49 & 0.03375 & 47 & & \\
\hline 18 & Majmah & 28000 & 100 & 5.86 & 0.12 & 1 & 0.0045 & 45 & 25 & 5.86 & 0.03375 & 47 & & \\
\hline 19 & Najran & 25000 & 100 & 6.59 & 0.127 & 1 & 0.0045 & 36 & 25 & 6.59 & 0.03375 & 47 & & \\
\hline 20 & Al Kharj & 36000 & 100 & 5.55 & 0.113 & 1 & 0.0041 & 41 & 25 & 5.55 & 0.03375 & 47 & & \\
\hline 21 & Qassim & 65000 & 100 & 6.1 & 0.082 & 1 & 0.006 & 43 & 28 & 6.1 & 0.03375 & 47 & & \\
\hline 22 & Rania & 22000 & 100 & 6.68 & 0.116 & 1 & 0.0057 & 40 & 25 & 6.68 & 0.03375 & 47 & & \\
\hline & Yanbu & 17000 & 100 & 5.65 & 0.1 & 1 & 0.0054 & 42 & 27 & 5.65 & 0.03375 & 47 & & \\
\hline
\end{tabular}


By then adding some formulas as an input for the wind turbine power and entering the appropriate values, the Excel sheet converted this input to produce the appropriate new output. These values can be seen in Figure 5.3.

\begin{tabular}{|c|c|c|c|c|c|c|c|c|c|c|c|c|c|c|c|c|c|c|c|}
\hline 4 & A & B & C & D & E & $F$ & G & $\mathrm{H}$ & 1 & J & K & L & M & $\mathrm{N}$ & 0 & $P$ & $Q$ & $R$ & $S$ \\
\hline 1 & City & a1 & $\mathrm{a} 2$ & b1 & b2 & $c 1$ & $c 2$ & d1 & $d 2$ & v & V1 & V2 & Vci & Vco & $\mathrm{Vr}$ & Pr & $\mathrm{V} 0=?$ & $(\mathrm{H} / \mathrm{HO})$ & \\
\hline 2 & Afif & 1 & 1 & 1 & 1 & 1 & 1 & 1 & 1 & 3.744 & 3 & 5 & 2.5 & 25 & 11 & 2000 & & 0.14286 & \\
\hline 3 & A1 Baha & 1 & 1 & 1 & 1 & 1 & 1 & 1 & 1 & 2.4 & 4 & 6 & 2.5 & 25 & 9 & 2000 & & 0.14286 & \\
\hline 4 & Al Dawadmi & 1 & 1 & 1 & 1 & 1 & 1 & 1 & 1 & 2.921 & 2 & 5 & 2.5 & 25 & 11 & 2000 & & 0.14286 & \\
\hline 5 & A1 Hanakiyah & 1 & 1 & 1 & 1 & 1 & 1 & 1 & 1 & 3.233 & 3 & 7 & 2.5 & 25 & 11 & 2000 & & 0.14286 & \\
\hline 6 & A1 Qunfudah & 1 & 1 & 1 & 1 & 1 & 1 & 1 & 1 & 2.761 & 2 & 4 & 2.5 & 25 & 10 & 2000 & & 0.14286 & \\
\hline 7 & Al Uyaynah & 1 & 1 & 1 & 1 & 1 & 1 & 1 & 1 & 3.152 & 2 & 7 & 2.5 & 25 & 11 & 2000 & & 0.14286 & \\
\hline 8 & Al Wajh & 1 & 1 & 1 & 1 & 1 & 1 & 1 & 1 & 2.789 & 3 & 5 & 2.5 & 25 & 10 & 2000 & & 0.14286 & \\
\hline 9 & Arar & 1 & 1 & 1 & 1 & 1 & 1 & 1 & 1 & 3.167 & 2 & 7 & 2.5 & 25 & 11 & 2000 & & 0.14286 & \\
\hline 10 & Duba & 1 & 1 & 1 & 1 & 1 & 1 & 1 & 1 & 2.421 & 3 & 6 & 2.5 & 25 & 10 & 2000 & & 0.14286 & \\
\hline 11 & Hafar A1 Batin & 1 & 1 & 1 & 1 & 1 & 1 & 1 & 1 & 4.594 & 2 & 7 & 2.5 & 25 & 13 & 2000 & & 0.14286 & \\
\hline 12 & Jazan & 1 & 1 & 1 & 1 & 1 & 1 & 1 & 1 & 3.125 & 3 & 4 & 2.5 & 25 & 11 & 2000 & & 0.14286 & \\
\hline 13 & Riyadh & 1 & 1 & 1 & 1 & 1 & 1 & 1 & 1 & 2.25 & 2 & 6 & 2.5 & 25 & 10 & 2000 & & 0.14286 & \\
\hline 14 & Jeddah & 1 & 1 & 1 & 1 & 1 & 1 & 1 & 1 & 3.457 & 2 & 5 & 2.5 & 25 & 12 & 2000 & & 0.14286 & \\
\hline 15 & Thuwal & 1 & 1 & 1 & 1 & 1 & 1 & 1 & 1 & 2.438 & 2 & 7 & 2.5 & 25 & 11 & 2000 & & 0.14286 & \\
\hline 16 & Dammam & 1 & 1 & 1 & 1 & 1 & 1 & 1 & 1 & 1.976 & 2 & 6 & 2.5 & 25 & 7 & 2000 & & 0.14286 & \\
\hline 17 & A1 Ahsa & 1 & 1 & 1 & 1 & 1 & 1 & 1 & 1 & 2.03 & 2 & 5 & 2.5 & 25 & 8 & 2000 & & 0.14286 & \\
\hline 18 & Majmah & 1 & 1 & 1 & 1 & 1 & 1 & 1 & 1 & 3.623 & 3 & 6 & 2.5 & 25 & 12 & 2000 & & 0.14286 & \\
\hline 19 & Najran & 1 & 1 & 1 & 1 & 1 & 1 & 1 & 1 & 2.086 & 2 & 7 & 2.5 & 25 & 10 & 2000 & & 0.14286 & \\
\hline 20 & Al Kharj & 1 & 1 & 1 & 1 & 1 & 1 & 1 & 1 & 2.347 & 2 & 6 & 2.5 & 25 & 11 & 2000 & & 0.14286 & \\
\hline 21 & Qassim & 1 & 1 & 1 & 1 & 1 & 1 & 1 & 1 & 2.547 & 2 & 8 & 2.5 & 25 & 11 & 2000 & & 0.14286 & \\
\hline 22 & Rania & 1 & 1 & 1 & 1 & 1 & 1 & 1 & 1 & 2.9 & 2 & 6 & 2.5 & 25 & 12 & 2000 & & 0.14286 & \\
\hline 23 & Yanbu & 1 & 1 & 1 & 1 & 1 & 1 & 1 & 1 & 3 & 2 & 4 & 2.5 & 25 & 12 & 2000 & & 0.14286 & \\
\hline 24 & Al Khafji & 1 & 1 & 1 & 1 & 1 & 1 & 1 & 1 & 3.533 & 3 & 6 & 2.5 & 25 & 13 & 2000 & & 0.14286 & \\
\hline 25 & Farrasan & 1 & 1 & 1 & 1 & 1 & 1 & 1 & 1 & 3.5167 & 3 & 5 & 2.5 & 25 & 12 & 2000 & & 0.14286 & \\
\hline 26 & Hagl & 1 & 1 & 1 & 1 & 1 & 1 & 1 & 1 & 6.289 & 4 & 9 & 2.5 & 25 & 15 & 2000 & & 0.14286 & \\
\hline 27 & Umluj & 1 & 1 & 1 & 1 & 1 & 1 & 1 & 1 & 3.211 & 3 & 6 & 2.5 & 25 & 12 & 2000 & & 0.14286 & \\
\hline 28 & A1 Jubail & 1 & 1 & 1 & 1 & 1 & 1 & 1 & 1 & 3.722 & 3 & 7 & 2.5 & 25 & 12 & 2000 & & 0.14286 & \\
\hline 29 & Shagra & 1 & 1 & 1 & 1 & 1 & 1 & 1 & 1 & 1.968 & 2 & 6 & 2.5 & 25 & 7 & 2000 & & 0.14286 & \\
\hline
\end{tabular}

Figure 5.3 Wind Power Input Data

By using the models, users can find the levelised cost of energy. Also, it can enter some values which are described below and the calculated those by using the models which are given as input. This saved so much time and reduced the chances of mistakes to zero. It is shown in Figure 5.4. 


\begin{tabular}{|c|c|c|c|c|c|c|c|c|c|c|c|c|c|c|}
\hline$\pi$ & A & B & C & D & $\mathrm{E}$ & $\mathrm{F}$ & G & H & $\mathrm{I}$ & J & K & L & $M$ & $\mathrm{~N}$ \\
\hline 1 & City & TPV & CRF & E load=Ppv+Pwg? & $\mathbf{i}$ & $n$ & $\mathrm{Cpv}$ & Cwind & It & Mt & $r$ & Eload=Ppv+Pwg? & $n$ & \\
\hline 2 & Afif & 524 & 0.118262 & & 0.101 & 20 & 394 & 130 & 471 & 53 & 0.101 & & 20 & \\
\hline 3 & Al Baha & 524 & 0.118262 & & 0.101 & 20 & 394 & 130 & 471 & 53 & 0.101 & & 20 & \\
\hline 4 & Al Dawadmi & 524 & 0.118262 & & 0.101 & 20 & 394 & 130 & 471 & 53 & 0.101 & & 20 & \\
\hline 5 & Al Hanakiyah & 524 & 0.118262 & & 0.101 & 20 & 394 & 130 & 471 & 53 & 0.101 & & 20 & \\
\hline 6 & Al Qunfudah & 524 & 0.118262 & & 0.101 & 20 & 394 & 130 & 471 & 53 & 0.101 & & 20 & \\
\hline 7 & Al Uyaynah & 524 & 0.118262 & & 0.101 & 20 & 394 & 130 & 471 & 53 & 0.101 & & 20 & \\
\hline 8 & Al Wajh & 524 & 0.118262 & & 0.101 & 20 & 394 & 130 & 471 & 53 & 0.101 & & 20 & \\
\hline 9 & Arar & 524 & 0.118262 & & 0.101 & 20 & 394 & 130 & 471 & 53 & 0.101 & & 20 & \\
\hline 10 & Duba & 524 & 0.118262 & & 0.101 & 20 & 394 & 130 & 471 & 53 & 0.101 & & 20 & \\
\hline 11 & Hafar Al Batin & 524 & 0.118262 & & 0.101 & 20 & 394 & 130 & 471 & 53 & 0.101 & & 20 & \\
\hline 12 & Jazan & 524 & 0.118262 & & 0.101 & 20 & 394 & 130 & 471 & 53 & 0.101 & & 20 & \\
\hline 13 & Riyadh & 524 & 0.118262 & & 0.101 & 20 & 394 & 130 & 471 & 53 & 0.101 & & 20 & \\
\hline 14 & Jeddah & 524 & 0.118262 & & 0.101 & 20 & 394 & 130 & 471 & 53 & 0.101 & & 20 & \\
\hline 15 & Thuwal & 524 & 0.118262 & & 0.101 & 20 & 394 & 130 & 471 & 53 & 0.101 & & 20 & \\
\hline 16 & Dammam & 524 & 0.118262 & & 0.101 & 20 & 394 & 130 & 471 & 53 & 0.101 & & 20 & \\
\hline 17 & Al Ahsa & 524 & 0.118262 & & 0.101 & 20 & 394 & 130 & 471 & 53 & 0.101 & & 20 & \\
\hline 18 & Majmah & 524 & 0.118262 & & 0.101 & 20 & 394 & 130 & 471 & 53 & 0.101 & & 20 & \\
\hline 19 & Najran & 524 & 0.118262 & & 0.101 & 20 & 394 & 130 & 471 & 53 & 0.101 & & 20 & \\
\hline 20 & Al Kharj & 524 & 0.118262 & & 0.101 & 20 & 394 & 130 & 471 & 53 & 0.101 & & 20 & \\
\hline 21 & Qassim & 524 & 0.118262 & & 0.101 & 20 & 394 & 130 & 471 & 53 & 0.101 & & 20 & \\
\hline 22 & Rania & 524 & 0.118262 & & 0.101 & 20 & 394 & 130 & 471 & 53 & 0.101 & & 20 & \\
\hline & Yanbu & 524 & 0.118262 & & 0.101 & 20 & 394 & 130 & 471 & 53 & 0.101 & & 20 & \\
\hline
\end{tabular}

Figure 5.4 LCOE Input Data

\subsection{Data Entry}

The first step is data entry. This is accomplished through four main forms or screens, which provide further links to databases and forms. The first data entry form of Visual Basic is shown in Figure 5.5.

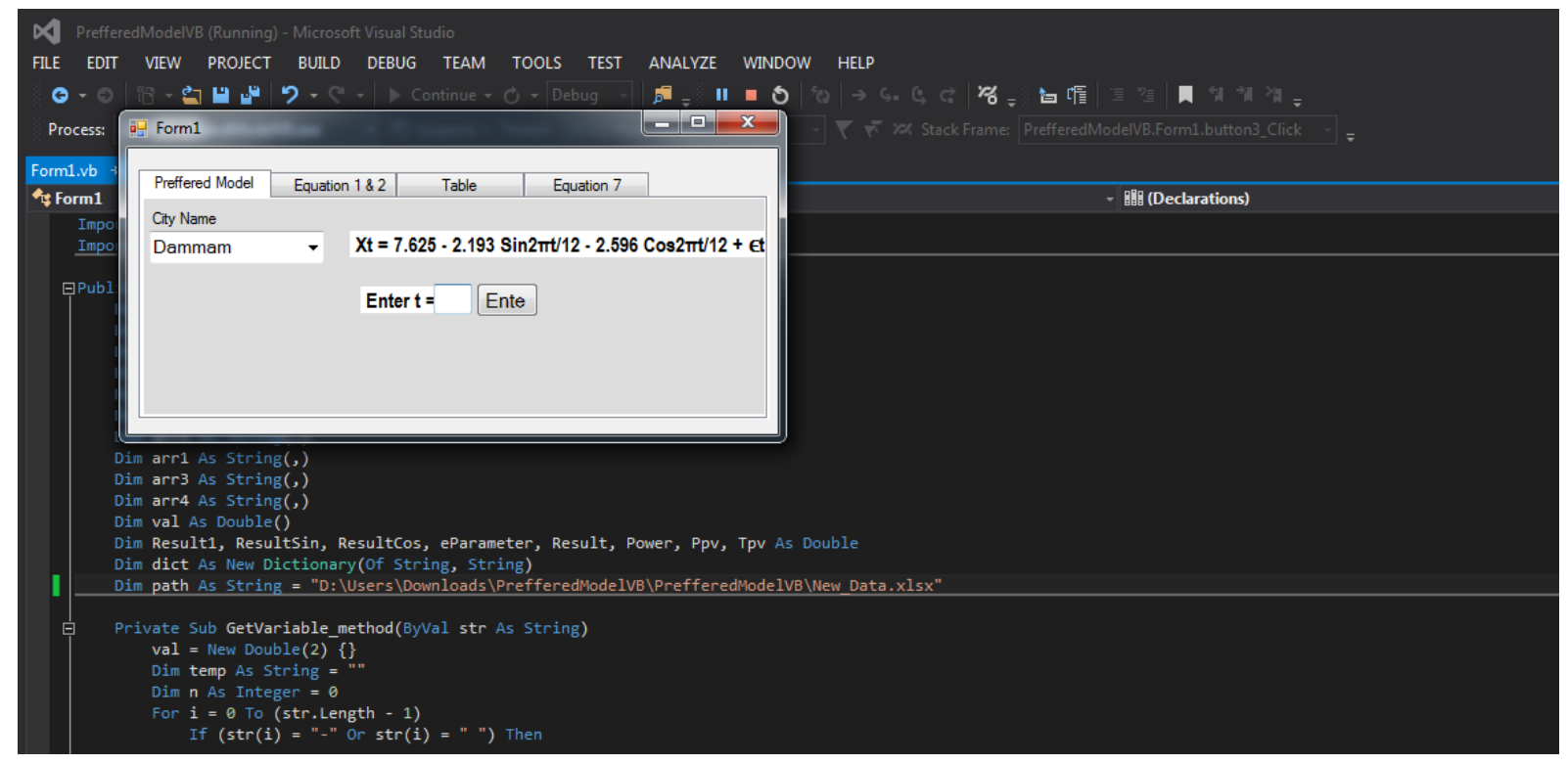

Figure 5.5 Screen for Component Data Entry 
In the first, there are 32 preferred models, each of which is the best forecasting model for each city, that calculate outputs based on the input data from each city. This made a program and some analysis was run on the entered data to produce the outputs of values like the preferred model (Xt). These are the outputs of the data which was previously entered. A dialogue box appears with equations that can be checked, as shown in Figure 5.5.

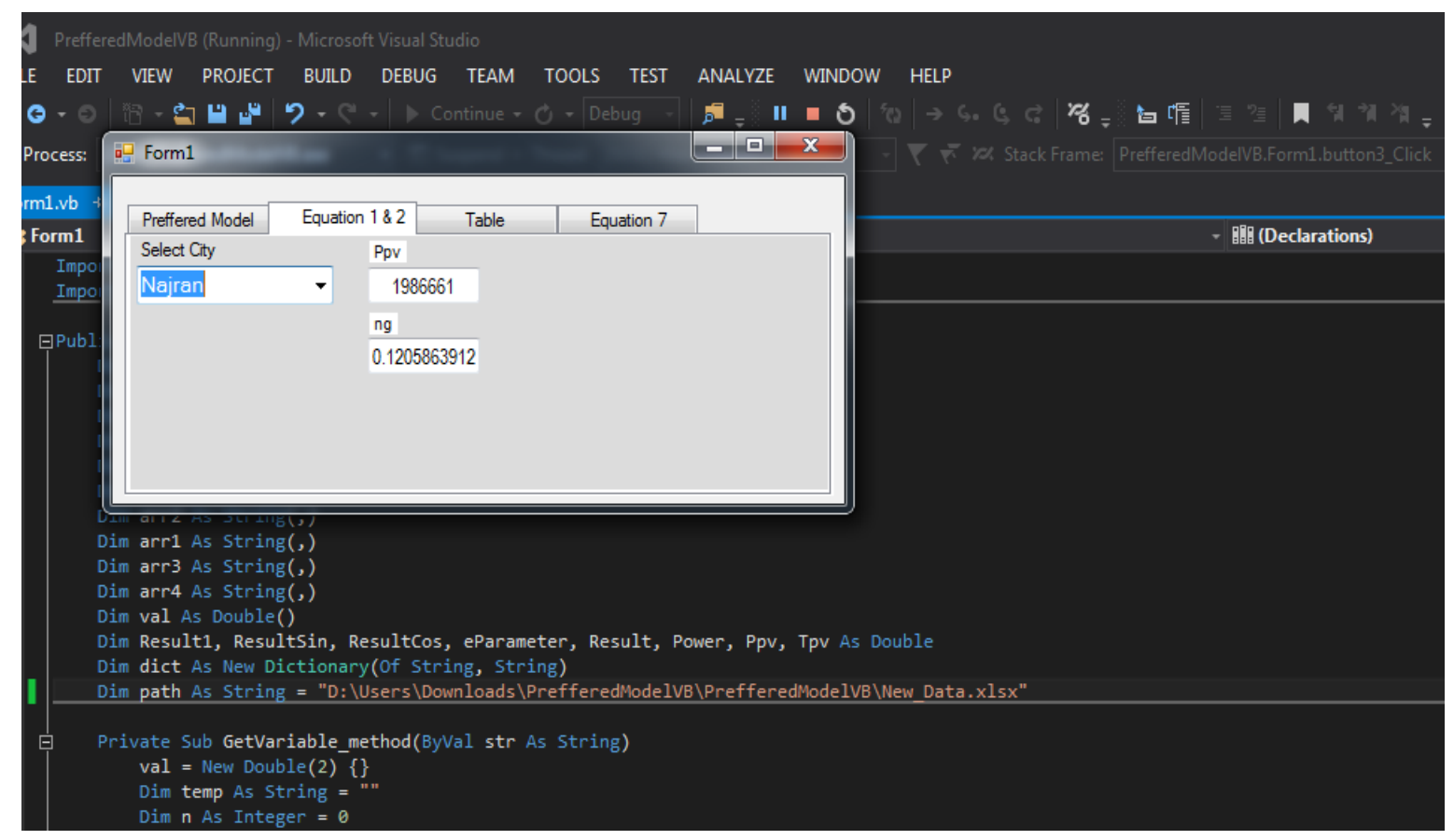

Figure 5.6 Screen for Component Data Entry

The second screen, which is shown in Figure 5.6, shows the calculated output power data for each city. Here the values of Ppv, which is the output power of solar for each city, and ng can be found. $\mathrm{Ppv}$ is calculated as $\mathrm{P}_{\mathrm{PV}}=\eta_{\mathrm{g}} \mathrm{NA}_{\mathrm{m}} \mathrm{G}_{\mathrm{t}}$ and $\mathrm{ng}$ is calculated as $\eta_{\mathrm{g}}=\eta_{\mathrm{r}} \eta_{\mathrm{pt}}\left[1-\beta_{\mathrm{t}}\left(\mathrm{T}_{\mathrm{c}}-\mathrm{T}_{\mathrm{r}}\right)\right]$ 


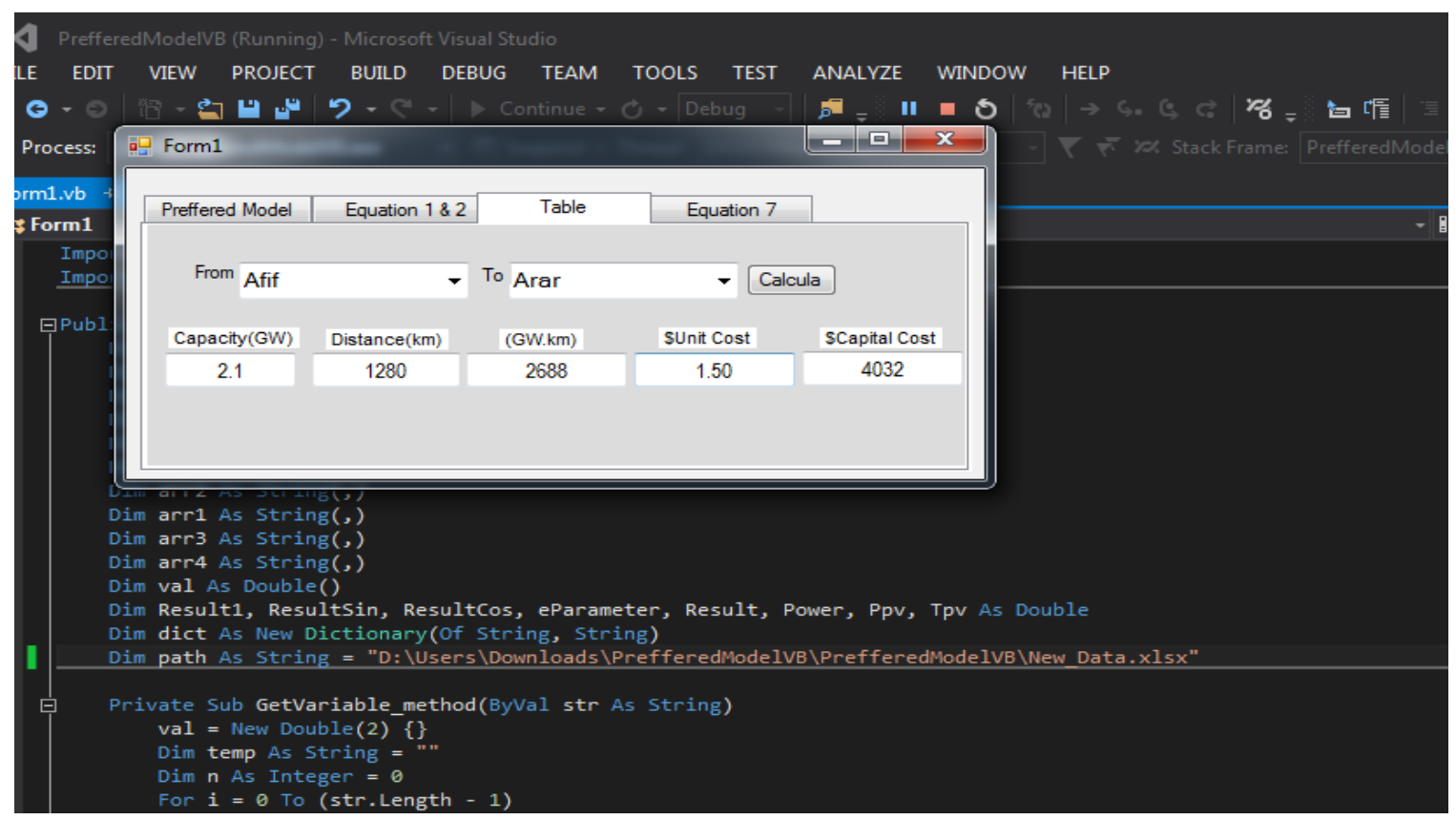

Figure 5.7 Screen for Component Data Entry

On the third screen, there are some outputs that show the cost of the distributions between two cities. Figure 5.6 shows the distance, the calculated GW.km, and the capacity in GW. Then it calculates the unit cost with users, so it could easily find the total cost.

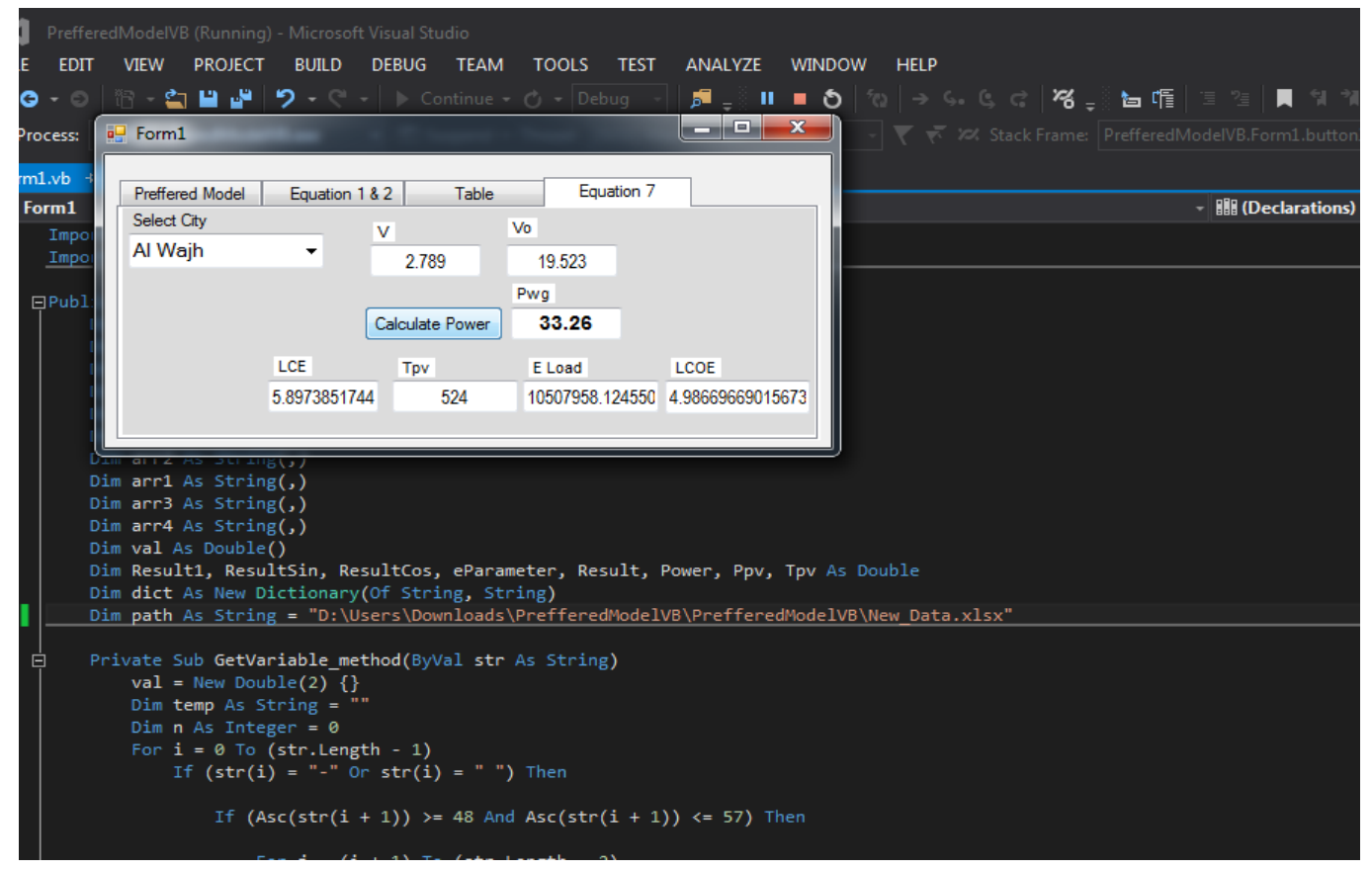

Figure 5.8 Screen for Component Data Entry 
The LOCE can be seen in Figure 5.8, where that screen also shows the calculated details for each city. Users can enter values for all the inputs in an Excel file, and then the values of the output power of wind (Pwg), LCE, Tpv, E Load and LOCE will be calculated for each of the 32 cities. 


\section{CHAPTER 6}

\section{RESULTS AND DISCUSSIONS}

\subsection{Introduction}

The objectives of this research were:

i. Develop forecasting model for the amount of irradiation and wind energy that can be produced in 32 major cities of Saudi Arabia. So, that can be input to the economic analysis model.

ii. Develop an economic analysis model to investigate the potential of solar and wind energy as a cost-effective, suitable alternative to petroleum products.

iii. Develop user-friendly software to perform economic and sensitivity analyses.

\subsection{Forecasting}

Analyzing the error among the forecasted data for 32 cities by the three selected methods is shown in the table 6.1. MAPE and MSE could be used to obtain the forecast error. As explained previously, such methods that are appropriate for models without trends are better than others. These results obtained from three different methods of forecasting, these three metheds were applaying for 32 cities in Saudi Arabia. The primary reason of developing these models is to find the optimal model for each city which has a low value of MSE and MAPE. The best method is Multiple Linear Regression with Sin and Cos which has MSE is 0.826 and MAPE is $11.537 \%$. Both of these values are significantly lower than the values obtained for the other

methods. Thus the optimal method was chosen to forecast the potential of renewable energy in the future. 
Table 6.1 Summarized MSE and MAPE of Three Different Methods

\begin{tabular}{|l|c|c|}
\hline Forecasting Method & MSE & MAPE\% \\
\hline Decomposition & 11.16 & $\mathbf{5 5 . 7 8 1}$ \\
\hline Multiple Linear Regression & 9.335 & 49.422 \\
\hline Seasonal Regression with Sin and Cos & $\mathbf{0 . 8 2 6}$ & 11.537 \\
\hline
\end{tabular}

In order to ascertain the validity of the assumption inherent in the seasonal regression model an analysis of forecast errors was carried out, as shown in Figure 6.1. It can be seen that the residuals follow a normal distribution and have a constant variance. The residual histogram shows that the mean is approximately zero, and from the normality plot we can conclude that they are normally distributed and the normality assumption is met. Also, the fitted value versus residual plot shows that the residuals are uncorrelated and have fairly constant variance and the assumption of equality of variances is met. Hence, it can be concluded that the model provided satisfactory results and the basic assumptions are met.

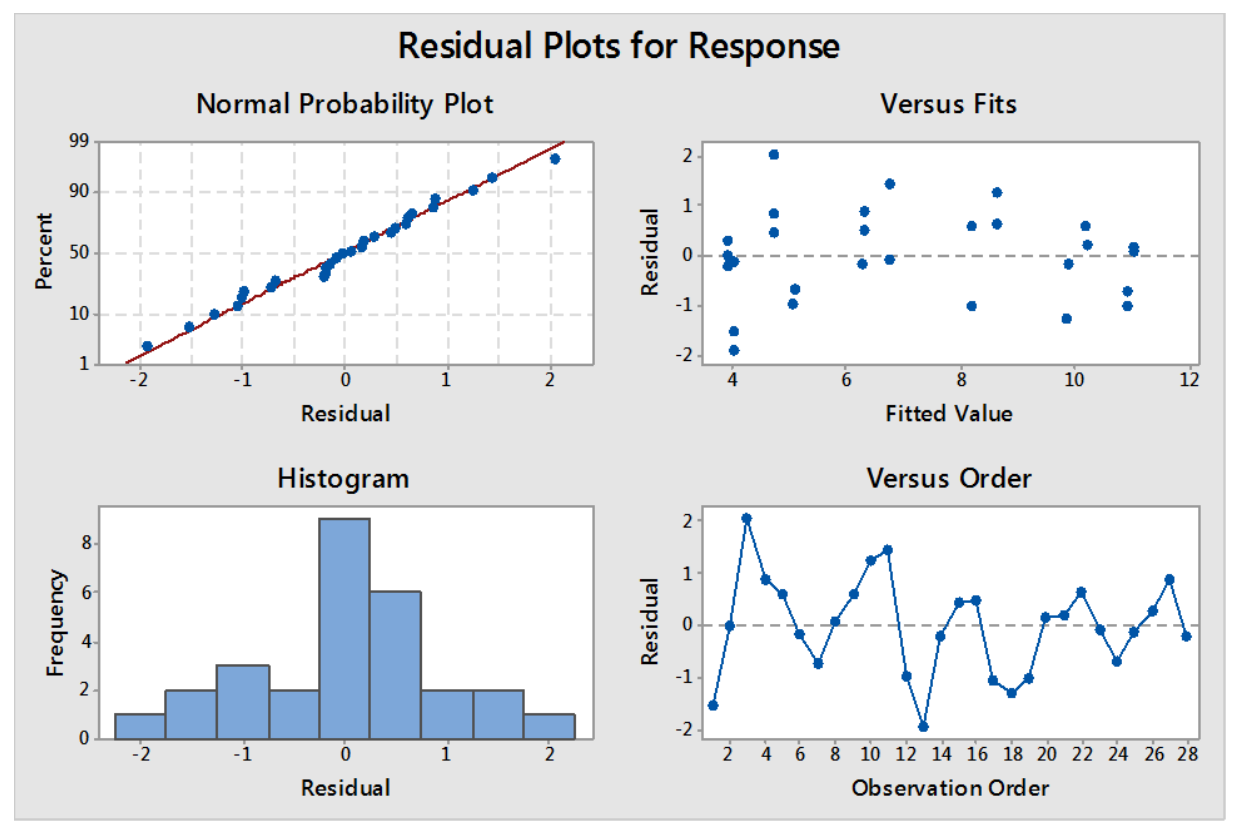

Figure 6.1 Residual Plots 


\subsection{Output of Solar Power}

32 optimum locations for solar stations were selected from within Saudi Arabia. Details of the solar output of such locations are shown in Table 6.2 and compared in Figure 6.2. Model validation was done to guarantee the reliability of the representations of the system it represents. From the data collected for the demand capacity of each city and how much power each city needs requires, the output for all 32 locations is shown. In order to get the necessary demand data, the model must generate a power for that when that city reach all requirements of parameters.

The model was run for different cities to report the output that can be generated from each location. Based on the model and the available data, users still have to be able to perform proper analysis in order to reach accurate conclusions. For example, in these results Riyadh City has the highest amount of solar output at $32.22 \mathrm{GW}$, which represents $19.89 \%$ of the total output of all 32 locations. This is due to the ever increasing demand for energy from the population and businesses in the city, which contains 7 million people. In total, $20 \%$ of the country's total electricity consumption is due to the demand from Riyadh City. According to Alrashed and Asif (2015), a large portion of Saudi Arabia's electricity consumption is from the housing sector. 
Table 6.2 Summarized Solar Output in GW

\begin{tabular}{|l|l|l|l|l|l|}
\hline City & Solar Output (GW) & $\begin{array}{l}\text { Number of } \\
\text { Solar } \\
\text { Panel }\end{array}$ & City & Solar Output (GW) & $\begin{array}{l}\text { Number } \\
\text { of Solar } \\
\text { Panel }\end{array}$ \\
\hline Afif & 2.252 & 4,093 & Hagl & 1.809 & 3,751 \\
\hline Al Ahsa & 22.910 & 17,484 & Jazan & 0.824 & 1,907 \\
\hline Al Baha & 0.838 & 1,966 & Jeddah & 17.637 & 14,953 \\
\hline Al Dawadmi & 1.788 & 3,636 & Majmah & 1.790 & 3,686 \\
\hline Al Hanakiyah & 1.467 & 3,257 & Najran & 1.987 & 3,832 \\
\hline Al Jubail & 0.970 & 2,426 & Qassim & 2.955 & 4,981 \\
\hline Al Khafji & 0.870 & 1,984 & Rania & 1.557 & 3,462 \\
\hline Al Kharj & 2.108 & 3,983 & Riyadh & 32.228 & 39,519 \\
\hline Al Qunfudah & 0.483 & 1,527 & Shagra & 1.038 & 2,522 \\
\hline Al Uyaynah & 0.862 & 1,972 & Tabuk & 10.510 & 12,729 \\
\hline Al Wajh & 0.705 & 1,851 & Taif & 2.487 & 4,546 \\
\hline Arar & 10.476 & 12,696 & Thuwal & 0.387 & 1,338 \\
\hline Dammam & 31.763 & 36,428 & Timaa & 2.745 & 4,743 \\
\hline Duba & 0.750 & 1,897 & Umluj & 1.012 & 2,621 \\
\hline Farrasan & 0.237 & 980 & $\begin{array}{l}\text { Wadi } \\
\text { Addawasir }\end{array}$ & 2.243 & 4,006 \\
\hline $\begin{array}{l}\text { Hafar Al } \\
\text { Batin }\end{array}$ & 1.463 & 3,238 & Yanbu & 0.882 & 1,995 \\
\hline
\end{tabular}




\section{Solar output (GW)}

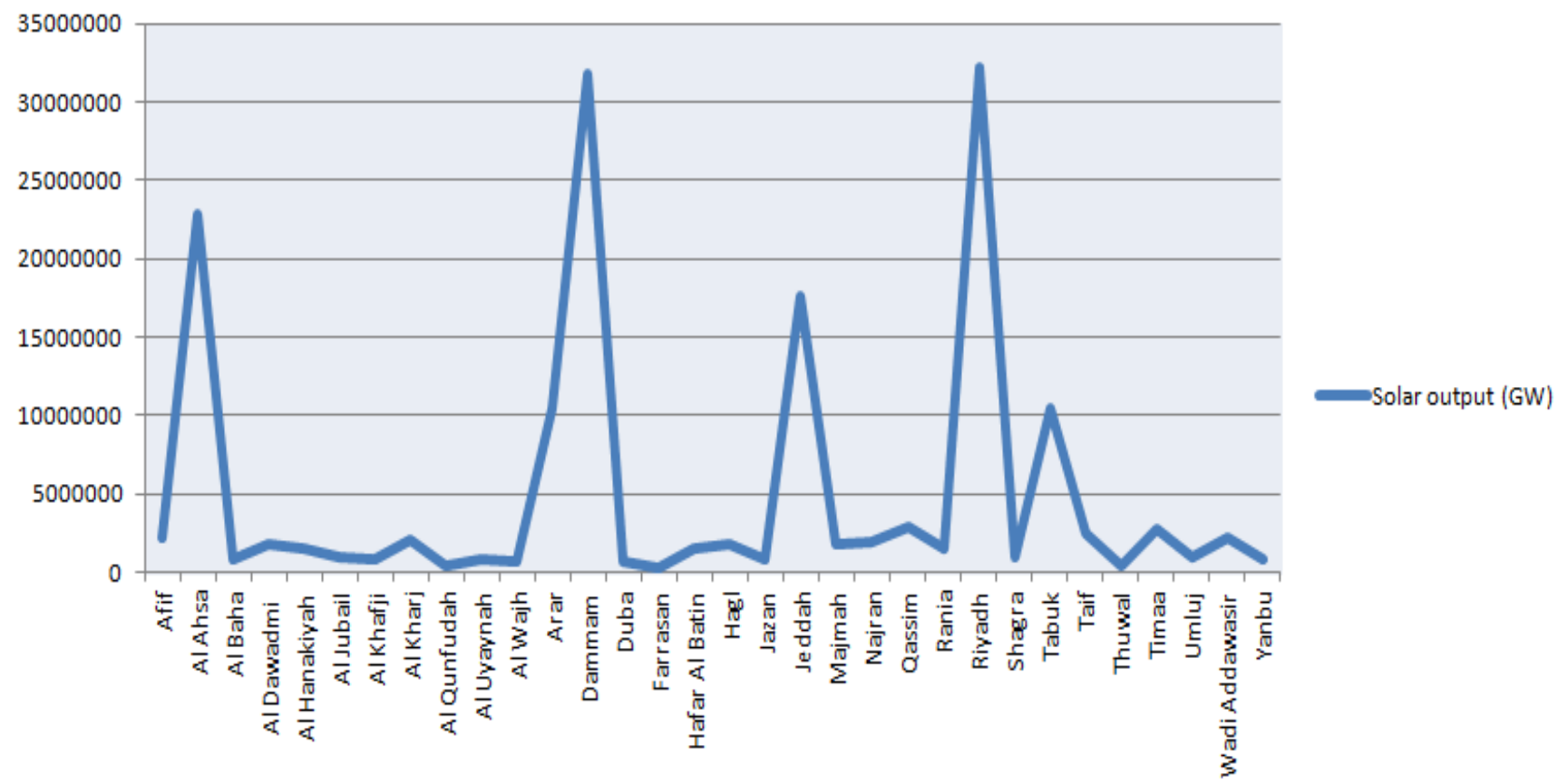

Figure 6.2 Summarized Solar Output in GW

From Figure 6.2, it is clear that the regions of Tabuk, Arar, Taif, Riyadh, Dammam, and Jeddah receive the highest output of solar irradiation levels; hence, they are best suited for the installation of solar energy farm. Therefore, in Table 6.3 shows the percent of the total output of solar for each city. Riyadh and Dammam City have the highest values of percentage which are $19.89 \%$ and $19.603 \%$, respectively. 
Table 6.3 Percentage of Total output \%

\begin{tabular}{|l|c|l|c|}
\hline City & Percentage of Total output $\%$ & City & Percentage of Total output \% \\
\hline Afif & 1.390 & Hagl & 1.117 \\
\hline Al Ahsa & 14.139 & Jazan & 0.508 \\
\hline Al Baha & 0.517 & Jeddah & 10.885 \\
\hline Al Dawadmi & 1.103 & Majmah & 1.105 \\
\hline Al Hanakiyah & 0.905 & Najran & 1.226 \\
\hline Al Jubail & 0.599 & Qassim & 1.824 \\
\hline Al Khafji & 0.537 & Rania & 0.961 \\
\hline Al Kharj & 1.301 & Riyadh & 19.890 \\
\hline Al Qunfudah & 0.298 & Shagra & 0.640 \\
\hline Al Uyaynah & 0.532 & Tabuk & 6.486 \\
\hline Al Wajh & 0.435 & Taif & 1.535 \\
\hline Arar & 6.465 & Thuwal & 0.239 \\
\hline Dammam & 19.603 & Timaa & 1.694 \\
\hline Duba & 0.463 & Umluj & 0.624 \\
\hline Farrasan & 0.146 & Wadi Addawasir & 1.384 \\
\hline Hafar Al Batin & 0.903 & Yanbu & 0.544 \\
\hline
\end{tabular}

\subsection{Output of Wind Power}

Saudi Arabia covers a large geographical area, which affects local wind generator output. Research was done for the same 32 locations to have an output useful for comparison. As mentioned earlier, the output power of a wind generator can be zero if certain conditions are not satisfied. Table 6.4 shows the 11 locations that do not satisfy the necessary conditions and thus give zero output, which represents nearly $33 \%$ of the locations selected for this analysis. The outputs from the locations that do satisfy the conditions can also be found in that table.

With 296 MW, Hagl has the highest potential power output from wind generators, which represents $23 \%$ of the total power from all locations. Compared to the same location for solar power, this figure is $600 \%$ less power than could be generated using solar irradiation. Overall, 
the power produced by wind generators would not be enough to meet the nation's energy demands.

Table 6.4 Summarized Wind Output in MW

\begin{tabular}{|l|c|c|l|c|c|}
\hline City & $\begin{array}{c}\text { Wind Output } \\
\text { (MW) }\end{array}$ & $\begin{array}{c}\text { Number of } \\
\text { Wind Turbine }\end{array}$ & City & Wind Output (MW) & $\begin{array}{c}\text { Number of Wind } \\
\text { Turbine }\end{array}$ \\
\hline Afif & 71.24 & 8,230 & Hagl & 295.58 & 22,683 \\
\hline Al Ahsa & 0.00 & 0 & Jazan & 44.41 & 4,844 \\
\hline Al Baha & 0.00 & 0 & Jeddah & 57.72 & 6,427 \\
\hline Al Dawadmi & 37.38 & 4,753 & Majmah & 65.31 & 7,418 \\
\hline Al Hanakiyah & 48.48 & 5,296 & Najran & 0.00 & 0 \\
\hline Al Jubail & 70.14 & 8,046 & Qassim & 26.56 & 2,836 \\
\hline Al Khafji & 61.11 & 6,982 & Rania & 36.70 & 4,653 \\
\hline Al Kharj & 0.00 & 0 & Riyadh & 0.00 & 0 \\
\hline Al Qunfudah & 32.43 & 3,681 & Shagra & 0.00 & 0 \\
\hline Al Uyaynah & 45.40 & 4,971 & Tabuk & 48.51 & 5,309 \\
\hline Al Wajh & 33.26 & 4,319 & Taif & 26.15 & 2,794 \\
\hline Arar & 45.96 & 4,989 & Thuwal & 0.00 & 0 \\
\hline Dammam & 0.00 & 0 & Timaa & 0.00 & 0 \\
\hline Duba & 0.00 & 0 & Umluj & 47.63 & 5,107 \\
\hline Farrasan & 60.38 & 6,743 & $\begin{array}{l}\text { Wadi } \\
\text { Addawasir }\end{array}$ & 28.36 & 2,951 \\
\hline $\begin{array}{l}\text { Hafar Al } \\
\text { Batin }\end{array}$ & 123.65 & 15,720 & & & 4,801 \\
\hline
\end{tabular}




\section{Wind Output (MW)}

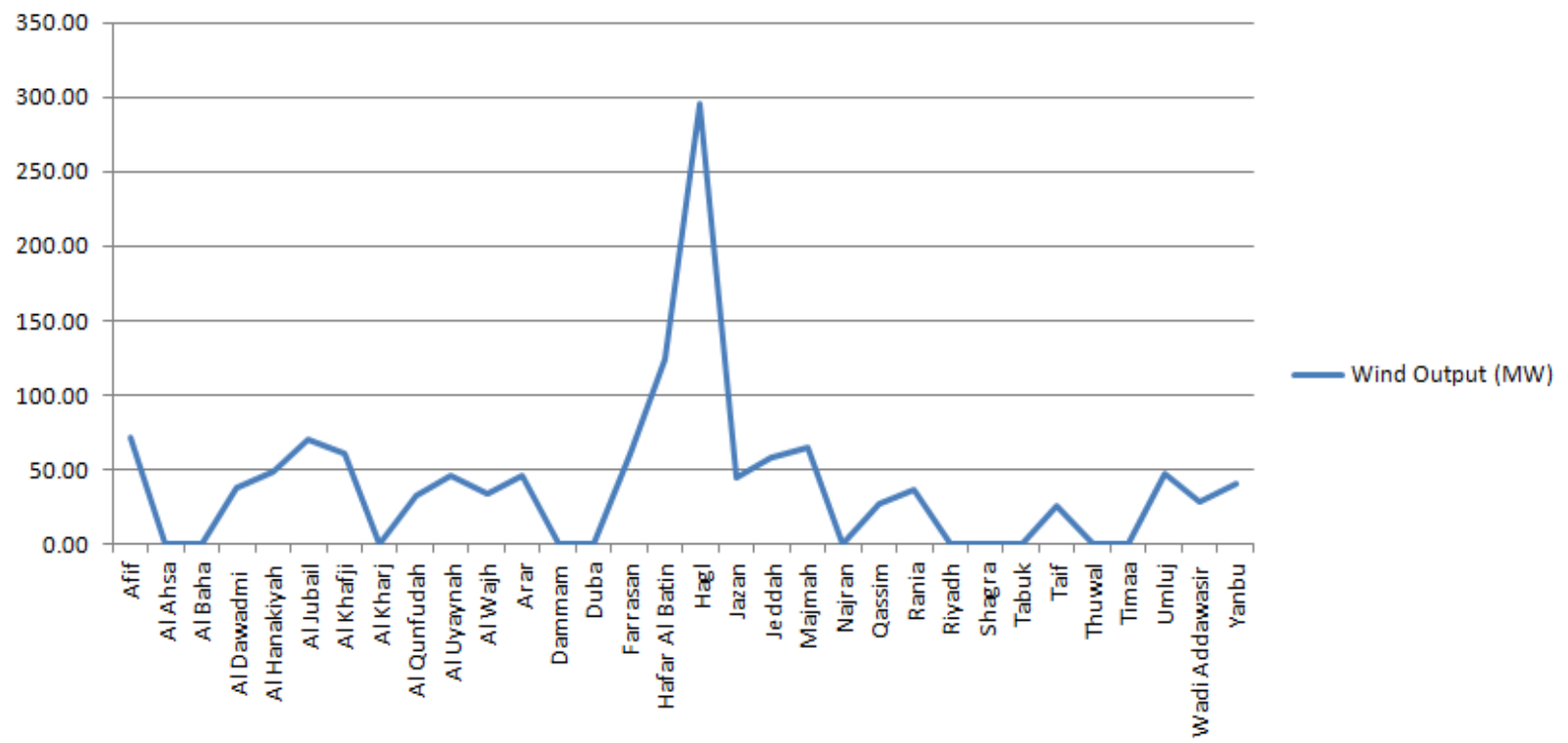

Figure 6.3 Summarized Wind Output in MW

From Figure 6.3, it is clear that the regions of Al Ahsa, Al Baha, Al Kharj, Riyadh, and

Dammam produce zero output from wind levels, and thus are not well-suited for the installation of wind energy farms. Table 6.5 shows the percentage of the total output of wind from each city, with Hagl City having the highest value at $23 \%$. 
Table 6.5 Percentage of Total Output \%

\begin{tabular}{|l|c|l|c|}
\hline City & Percentage of Total output $\%$ & City & Percentage of Total output \% \\
\hline Afif & 5.49 & Hagl & 22.77 \\
\hline Al Ahsa & 0.00 & Jazan & 3.42 \\
\hline Al Baha & 0.00 & Jeddah & 4.45 \\
\hline Al Dawadmi & 2.88 & Majmah & 5.03 \\
\hline Al Hanakiyah & 3.74 & Najran & 0.00 \\
\hline Al Jubail & 5.40 & Qassim & 2.05 \\
\hline Al Khafji & 4.71 & Rania & 2.83 \\
\hline Al Kharj & 0.00 & Riyadh & 0.00 \\
\hline Al Qunfudah & 2.50 & Shagra & 0.00 \\
\hline Al Uyaynah & 3.50 & Tabuk & 0.00 \\
\hline Al Wajh & 2.56 & Taif & 2.01 \\
\hline Arar & 3.54 & Thuwal & 0.00 \\
\hline Dammam & 0.00 & Timaa & 0.00 \\
\hline Duba & 0.00 & Umluj & 3.67 \\
\hline Farrasan & 4.65 & Wadi Addawasir & 2.19 \\
\hline Hafar Al Batin & 9.53 & Yanbu & 3.08 \\
\hline
\end{tabular}

\subsection{LCOE Analysis}

Table 6.6 shows the total cost for both solar and wind power is $\$ 719.67 \mathrm{M} / \mathrm{MWh}$, which represents the cost of generating that power in each city. However, the zero of output of wind for some locations made the cost of them low compared to other cities. The highest cost was from Farrasan, with $\$ 110.6 \mathrm{M} / \mathrm{MWh}$, which represents $15 \%$ of the total cost. The locations with the lowest costs are Dammam and Riyadh City, which have \$0.825 M/MWh, and \$0.813 M/MWh, respectively. 
Table 6.6 Summarized LCOE for Each City

\begin{tabular}{|l|c|l|c|}
\hline City & LCOE $(\$ \mathrm{M} / \mathrm{MWh})$ & City & LCOE $\$$ M/MWh) \\
\hline Afif & 11.633 & Hagl & 14.479 \\
\hline Al Ahsa & 1.144 & Jazan & 31.806 \\
\hline Al Baha & 31.269 & Jeddah & 1.486 \\
\hline Al Dawadmi & 14.655 & Majmah & 14.635 \\
\hline Al Hanakiyah & 17.863 & Najran & 13.186 \\
\hline Al Jubail & 27.000 & Qassim & 8.866 \\
\hline Al Khafji & 30.115 & Rania & 16.826 \\
\hline Al Kharj & 12.428 & Riyadh & 0.813 \\
\hline Al Qunfudah & 54.240 & Shagra & 25.246 \\
\hline Al Uyaynah & 30.394 & Tabuk & 2.493 \\
\hline Al Wajh & 37.175 & Taif & 10.533 \\
\hline Arar & 2.501 & Thuwal & 67.712 \\
\hline Dammam & 0.825 & Timaa & 9.544 \\
\hline Duba & 34.937 & Umluj & 25.899 \\
\hline Farrasan & 110.673 & Wadi Addawasir & 11.679 \\
\hline Hafar Al Batin & 17.906 & Yanbu & 29.710 \\
\hline
\end{tabular}

Table 6.7 shows annual electricity generation statistics for all 32 cities. According to these statistics, the total electricity generation by fuel is $45.1 \mathrm{GW}$. In total, the cost of producing that amount of power is $\$ 2,300 \mathrm{M} / \mathrm{MWh}$. Thus, the total cost of generating power by fuel represents just $31.3 \%$ of the total cost of generating power from solar and wind sources. Using statistical analysis, it was demonstrated that building new farms of solar panels and wind turbines further reduces generation expenses. This recommendation, if adopted, could result in significant cost savings for Saudi Arabia 
Table 6.7 Summarized Average Levalized Cost of Production (Fuel)

\begin{tabular}{|l|c|c|l|c|c|}
\hline Plant Name & Fuel Type & $\begin{array}{c}\text { Average Levalized } \\
\text { Cost of Production } \\
(\$ \mathbf{M} / \mathrm{MWh})\end{array}$ & Plant Name & $\begin{array}{c}\text { Fuel } \\
\text { Type }\end{array}$ & $\begin{array}{c}\text { Average Levalized } \\
\text { Cost of Production } \\
(\$ \mathrm{M} / \mathrm{MWh})\end{array}$ \\
\hline Afif & Diesel & 62.6 & Hagl & NG & 64.7 \\
\hline Al Ahsa & NG & 58.7 & Jazan & Diesel & 65.6 \\
\hline Al Baha & Diesel & 58.5 & Jeddah & Diesel & 70.1 \\
\hline Al Dawadmi & Diesel & 61.6 & Majmah & Diesel & 69 \\
\hline Al Hanakiyah & NG & 58.6 & Najran & NG & 73.9 \\
\hline Al Jubail & NG & 59.2 & Qassim & NG & 66.8 \\
\hline Al Khafji & Crude & 64.9 & Rania & Diesel & 74.6 \\
\hline Al Kharj & CR/ Diesel & 68.8 & Riyadh & Diesel & 76.7 \\
\hline Al Qunfudah & Diesel & 65 & Shagra & CR & 74.5 \\
\hline Al Uyaynah & Diesel & 67.7 & Tabuk & Diesel & 76.6 \\
\hline Al Wajh & Diesel & 63.1 & Taif & Diesel & 105 \\
\hline Arar & Crude & 64.9 & Thuwal & Diesel & 79.3 \\
\hline Dammam & CR & 67.5 & Timaa & Crude & 88.5 \\
\hline Duba & NG & 70.1 & Umluj & Diesel & 93.1 \\
\hline Farrasan & Diesel & 78 & Wadi Addawasir & Diesel & 85.2 \\
\hline $\begin{array}{l}\text { Hafar Al } \\
\text { Batin }\end{array}$ & Diesel & 66 & Yanbu & Diesel & 101.9 \\
\hline
\end{tabular}




\section{Chapter 7}

\section{CONCLUSION AND FUTURE WORK}

\subsection{Conclusion}

This research was aimed at applying economic and sensitivity analyses to solar and wind energy to compare various energy generation schemes to non-renewable energy in Saudi Arabia.

Economic and sensitivity analyses of data collected at King Abdullah City for Atomic and Renewable Energy showed that, among the forecasted data from the three selected methods, the MAPE and MSE could be used to obtain the forecasting error. Methods that are appropriate for models without trends are better than others in this case. The best method for forecasting was found to be Multiple Linear Regression with Sin and Cos. Hence, this was chosen to forecast solar irradiation and wind speed in the future.

In the course of this research, a model was also applied to find the power output of the solar generator, $\mathrm{P}_{\mathrm{PV}}$, by using this information as input: $\mathrm{A}_{\mathrm{m}}$ is the area of a single module used in the system in $\mathrm{m}^{2}, \mathrm{G}_{\mathrm{t}}$ is the global irradiance incident on the titled plane in $\mathrm{W} / \mathrm{m}^{2}$, and $\mathrm{N}$ is the number of modules in the system. The result of that model was used to find the power generation output showed that Riyadh City has the largest amount of potential output. Based on those results, Riyadh City is the best candidate city for the construction of a solar farm.

The power output of wind turbines was also considered in this research. The model of output from wind in the same 32 cities results showed that Hagl City had the highest power generation output. It follows that the recommendation here is to support the decision to make Hagl City the location for the installation of wind turbine farms. 
Concentrating solar power technology utilizes focused sunlight. Concentrating solar power plants generate electric power by using mirrors to concentrate the sun's energy and convert it into high-temperature heat. That heat is then channelled through a conventional generator. The plants consist of two parts: one that collects solar energy and converts it to heat, and another that converts the heat energy to electricity. Concentrating solar power technology utilizes three alternative technological approaches: trough systems, power tower systems, and dish/engine systems. By concentrating sunlight onto a little area, this innovation has three upper hands:

- Requires less photovoltaic material to capture the same sunlight as non-concentrating PV.

- Makes the use of high efficiency but expensive multi-junction cells economically viable due to smaller space requirements.

- The optical system comprises standard materials, manufactured in proven processes. Thus, it is less dependent on the immature silicon supply chain. Moreover, optics are less expensive than cells.

Solar panel system is capable of storing enough energy to produce power 6 hours after the Sun had set by using thermal storage. Solar panel plants can potentially operate for 65 percent of the year without the need for a back-up fuel source. Also, plant will have a capability with up to 6 hours worth of storage. However, in aggregate it is sensitive; sometimes on cloudy or rainy days, should have a storage capacity to compensate for the inability to produce energy on those days and also be able to generate power with diesel and natural gas as a back-up. 


\subsection{Future Work}

This study focused on forecasting solar irradiation and wind speed monthly over a period of 20 years, the potential output of solar and wind power, and the total cost of generating and transmitting that power in Saudi Arabia. Below are several recommendations for further research:

- Obtain additional data to include a larger number and wider variety of cities, which will increase the accuracy of the input data.

- Include additional analysis to study the potential for maximizing renewable power generation to support the grid supply to other nations.

- Collect additional data, more than the current 28 months, in order to better capture the seasonality of irradiation and wind speed.

- Enhance the multiple linear regression model to include higher order terms to improve its prediction power.

- Enhance the predictive ability by using hourly data of solar irradiation and wind speed to investigate the details of the output data.

- Develop a statistical model to find the optimal location by minimizing the total cost of power distribution.

- Develop prediction intervals on forecasts obtained from the seasonal model so that an upper and a lower limit on the expected costs associated with each option studied may be presented. 


\section{References}

Alrashed, F. \&Asif, M. (2015). Analysis of critical climate related factors for the application of Zero-energy homes in Saudi Arabia. Renewable and sustainable energy reviews, 4l(January 2015), 1395-1403.

Alawaji, H.S. (2001a). Evaluation of solar energy research and its applications in Saudi Arabia 20 years of experience. Renewable and sustainable energy reviews, 5(1), 59-77.

Alawaji, H.S. (2001b). Life after oil: Solar energy research and applications in Saudi Arabia. Refocus, 2(2), 14-19.

Alnatheer, O. (2005). The potential contribution of renewable energy to electricity supply in Saudi Arabia. Energy policy, 33(18), 2298-2312.

Almasoud, H.A. \&Gandayh, M.H. (2015).Future of solar energy in Saudi Arabia. Journal of King Saud University-Engineering sciences, 27(2), 153-157.

Al-Ajlan, A.S. et al. (2006). Developing sustainable energy policies for electrical energy Conservation in Saudi Arabia. Energy policy, 34(13), 1556-1565.

Al-filali, Y.I. et al. (2012). Smart development: Saudi Arabia's quest for a knowledge economy. International studies, 49(182), 47-76.

Ramli, M.M. \&Twaha, S. (2015). Analysis of renewable energy feed-in tariffs in selected Regions of the globe: Lessons for Saudi Arabia. Renewable and sustainable energy reviews, 45(May2015), 649-661.

Hepbasli, A. \&Alsuhaibani, Z. (2011). A key review of the present status and future directions of solar energy studies and applications in Saudi Arabia. Renewable and sustainable energy reviews, 15(9), 5021-5050.

Dincer, F. (2010). The analysis on photovoltaic electricity generation status, potential and 
policies of the leading countries in solar energy. Renewable and sustainable energy reviews, 15(1), 713-720.

Razykov, M.T. et al. (2011). Solar photovoltaic electricity: Current status and future prospects. Solar energy, 85(8), 1580-1608.

Huraib, S.F. et al. (1996). Lessons learned from solar energy projects in Saudi Arabia. Renewable energy, 9(1-4).1144-1147.

Timilsina, R.G. et al. (2011). Solar energy: Markets, economics, and policies. Renewable and sustainable energy reviews, 16(1), 449-465.

Solangi, H.K. et al. (2011). A review on global solar energy policy. Renewable and sustainable energy reviews. Renewable and sustainable energy reviews, 15(4), 2149-2163.

Lund, H. (2007). Renewable energy strategies for sustainable development. Energy, 32(6), 912919.

Omer, M, A. (2008).Energy, environment and sustainable development. Renewable and sustainable energy reviews, 12(9), 2265-2300.

Borenstein, S. (2012).The private and public economies of renewable electricity generation. The journal of economic perspectives. 26(1), 67-92.

Metcalf, E.G. (2010).Investment in energy infrastructure and the tax code. Tax policy and the economy, 24(1), 1-34. DOI: 10.1086/64982

Sharma, K.N. et al. (2012). Solar energy in India: Strategies, policies, perspectives, and future potential. Renewable and sustainable energy reviews, 16(1), 933-941.

Banos, R. et al. (2012). Optimization methods applied to renewable and sustainable energy: A review. Renewable and sustainable energy reviews, 15(4), 1753-1766.

Panwar, L.N. et al. (2011). Role of renewable energy sources in environmental protection: A 
review. Renewable and sustainable energy reviews, 15(3), 1513-1524.

Marques, C.A\&Fuinhas, A.J. (2011). Drivers promoting renewable energy: A dynamic panel approach. Renewable and sustainable energy reviews, 15(3), 1601-1608.

Alonso, F. \& Greenwell, C. (2013). Underground vs. overhead: Power line installation-cost comparison and mitigation. Retrieved from: http://www.elp.com/articles/powergrid_international/print/volume-18/issue2/features/underground-vs-overhead-power-line-installation-cost-comparison-.html

Annuk, A. et al. (2011). Performance of wind-solar integrated grid connected energy system. Agronomy research, 9(1-2), 273-280. Retrieved from http://agronomy.emu.ee/vol091/p9101.pdf

Geoscience Australia et al. (2013). Australian Energy Resource Assessment. Canberra: Commonwealth of Australia.

International Renewable Energy Agency (IRENA). (2015). Renewable power generation costs in 2014. Innovation and Technology Centre. Bonn, Germany.

Juho, Y.H. (2011). The transmission line cost calculation. Vaasan Ammattikoskeakoulu Vasa Yerkeshhogskola University of Applied Sciences. Retrieved from https://www.theseus.fi/bitstream/handle/10024/29401/YliHannuksela_Juho.pdf?sequence=1

Khonkar, H. (2009). Complete survey of wind behavior over the Arabian Gulf: JKAU: Mar Sci. 20(1). 31-47. Retrieved from https://www.kau.edu.sa/Files/320/Researches/54555_24880.pdf 
King Abdullah University of Science and Technology Industry Collaboration Program (KICP). (2009). Saudi Arabia solar energy manufacturing and technology assessment. Retrieved from http://www.kaust.edu.sa/assets/downloads/kicp-solar-energy-study.pdf

Liorens, D. (2012). How much electricity does a solar panel produce? Retrieved from http://www.solarpowerrocks.com/solar-basics/how-much-electricity-does-a-solar-panelproduce/

National Wind Watch Inc. (2015). Presenting the facts about industrial wind power. Retrieved frorm https://www.wind-watch.org/faq-output.php

Pazheri, R.F. (2014). Solar power potential in Saudi Arabia. Journal of engineering research and applications, 4(9), 171-174. Retrieved from http://www.ijera.com/papers/Vol4_issue9/Version\%205/AD4905171174.pdf

Shahan, Z. (2014). Solar Panel Cost Trends 10 Charts. Retrieved from http://cleantechnica.com/2014/09/04/solar-panel-cost-trends-10-charts/

Solar Choice Staff. (2010). How much energy will my solar cells produce? Solar Choice. Retrieved from http://www.solarchoice.net.au/blog/how-much-energy-will-my-solarcells-produce/

Abosedra, S. (2005), "Futures versus Univariate Forecast of Crude Oil Prices", OPEC Review $29,231-241$

Athanasia A. Lazou, Anastassios D. Papatsoris. 2000. The economics of PV stand-alone residential households: A case study for various European and Mediterranean locations; Solar Energy Materials and Solar Cells. 62 411-427. 
American Wind Energy Association (AWEA) (2011), Small Wind Turbine Global Market Study, AWEA, Washington, D.C

Blanco, M.I. (2009), The economics of wind energy, Renewable and Sustainable Energy Reviews, Elsevier, Vol. 13, Issues 6-7, pp. 1372-1382.

EWEA (2011a), The European Onshore Wind Industry Key Trends and Statistics: 1st half 2011, EWEA, Brussels.

International Energy Agency (IEA) (2009), Technology Roadmap: Wind Energy, IEA/OECD, Paris. IEA,

International Renewable Energy Agency (IRENA) (2012), Renewable energy technologies: cost analysis series. Wind Power. Vol. 5, Issues 5/5.

Junginger, M. et al. (2004), Cost Reduction Prospects for Offshore Wind Farms, Wind Engineering, Volume 28, No. 1, 2004, pp 97-118.

Li, J., et al. (2010), 2010 China Wind Power Outlook, Chinese Renewable Energy Industries Association (CREIA), Global Wind Energy Council and Greenpeace.

Nielsen, et al. (2010), Economy of Wind Turbines (Vindmøllers Økonomi), EUDP, Denmark.

Schwartz, E. and J. E. Smith (2000); "Short-term Variations and Long-term Dynamics in Commodity Prices”, Management Science 46, 893-911.

Wiser, R. and M. Bollinger (2011), 2010 Wind Technologies Market Report, US DOE, Office of Energy Efficiency and Renewable Energy, Washington, D.C.

Porter, A., Connolly, T., Heikes, R., \& Park, C. (1981). Misleading indicators: The limitations of multiple linear regression in formulation of policy recommendations. Policy Sci, 13(4), 397-418. http://dx.doi.org/10.1007/bf00146959 
Shekhar, S. (2004). Recursive methods for forecasting short-term traffic flow using seasonal ARIMA time series model.

Yan, X., \& Su, X. (2009). Linear regression analysis. Singapore: World Scientific Pub. Co. 